\title{
CDNA CLONING AND TRANSCRIPTIONAL REGULATION OF THE VITELLOGENIN RECEPTOR FROM THE IMPORTED FIRE ANT, SOLENOPSIS INVICTA BUREN (HYMENOPTERA: FORMICIDAE)
}

\author{
A Dissertation \\ by \\ MEI-ER CHEN \\ Submitted to the Office of Graduate Studies of \\ Texas A\&M University \\ in partial fulfillment of the requirements for the degree of \\ DOCTOR OF PHILOSOPHY
}

December 2003

Major Subject: Entomology 


\title{
cDNA CLONING AND TRANSCRIPTIONAL REGULATION OF THE VITELLOGENIN RECEPTOR FROM THE IMPORTED FIRE ANT, SOLENOPSIS INVICTA BUREN (HYMENOPTERA: FORMICIDAE)
}

\author{
A Dissertation \\ by \\ MEI-ER CHEN \\ Submitted to Texas A\&M University \\ in partial fulfillment of the requirements \\ for the degree of \\ DOCTOR OF PHILOSOPHY
}

Approved as to style and content by

\begin{abstract}
Larry L. Keeley
(Co-Chair of Committee)
\end{abstract}

Patricia V. Pietrantonio

(Co-Chair of Committee)
Max D. Summers

(Member)

Kevin M. Heinz

(Head of Department)

Duncan S. MacKenzie

(Member)

December 2003

Major Subject: Entomology 


\begin{abstract}
cDNA cloning and Transcriptional Regulation of the Vitellogenin Receptor from the Imported Fire Ant, Solenopsis invicta (Hymenoptera: Formicidae).

(December 2003)

Mei-Er Chen, B.S.; M.S., National Chung-Hsing University, Taiwan Co-Chairs of Advisory Committee: Dr. Larry L. Keeley

Dr. Patricia V. Pietrantonio
\end{abstract}

Receptors that transport vitellogenin into oocytes are of vital importance to egglaying species because they promote oocyte development. In this study, we describe the cloning of the first hymenopteran vitellogenin receptor (VgR) cDNA. Using reverse transcription polymerase chain reaction (RT-PCR) and both 5'- and 3'- rapid amplification of cDNA ends (RACE), cDNA fragments encompassing the entire coding region of a putative $\mathrm{VgR}$ from fire ant $(=S i \mathrm{VgR})$ were cloned and sequenced. The complete $\mathrm{SiVgR}$ cDNA has a length of 5764 bp encoding a 1782-residue protein with a predicted molecular mass of $201.3 \mathrm{kDa}$. The deduced amino acid sequence of the $\mathrm{Si} \mathrm{VgR}$ revealed that it encoded a protein belonging to the low-density lipoprotein receptor superfamily. The number and arrangement of modular domains of $\mathrm{SiVgR}$ are the same as those of mosquito and fruit fly $\mathrm{VgRs}$, except there are only four Class $\mathrm{A}$ cysteine-rich repeats in the first ligand binding domain of $\mathrm{SiVgR}$ compared to five in the mosquito and fruit fly. The deduced amino acid sequence of the $S i \mathrm{VgR}$ exhibited $35 \%$ and $31 \%$ identity to those of the mosquito and fruit fly $\mathrm{VgRs}$, respectively. Northern blot analysis demonstrated that the 7.4-kb $\mathrm{SiVgR}$ mRNA was present only in 
Northern blot analysis demonstrated that the 7.4-kb SiVgR mRNA was present only in ovaries of reproductive females - both alates (virgins) and queens (mated) and was more abundant in alates. The developmental profile of transcriptional expression was determined by semiquantitative RT-PCR. It showed that the $S i \mathrm{VgR}$ transcript increased 6-fold from 0 - to 10-days after mating, then remained constant through 30 days. It also showed that the SiVgR transcripts increased with age in alate virgin females. The transcriptional expression of the $S i \mathrm{VgR}$ was up-regulated more than two-fold by methoprene, a juvenile hormone analog, as determined by using an in vitro system. This suggested the $\mathrm{SiVgR}$ gene is JH regulated. 


\section{ACKNOWLEDGMENTS}

I would like to recognize my committee co-chairs, Dr. Larry L Keeley and Dr. Patricia V. Pietrantonio, for their support, direction and insightful comments throughout my studies. I hope to emulate their standard of excellence in both research and technical writing in my future endeavors. I would also like to acknowledge my committee members, Drs. Summers and MacKenzie for their interest and direction in my work.

To Danielle Lewis and Yolande Yang, I offer my gratitude and friendship. They saw me at my worst and my best and accepted me through it all. I also thank all of my friends and lab mates who gave me all kinds of assistance. Thanks also to my family for everything they have done for me along the way.

To the Fire Ant Research and Management Plan for support of my research assistantship. 
TABLE OF CONTENTS

Page

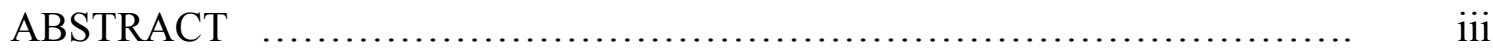

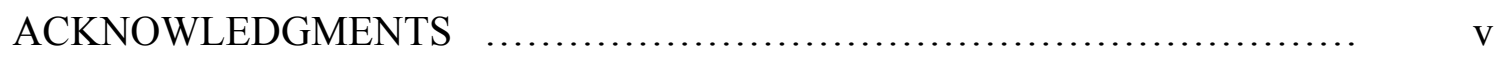

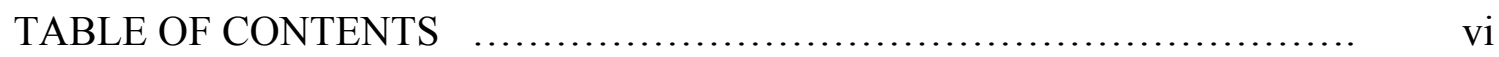

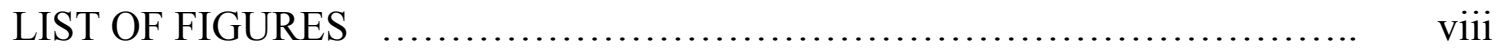

CHAPTER

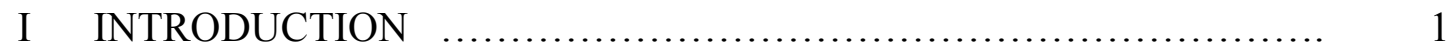

II LITERATURE REVIEW: THE LOW-DENSITY LIPOPROTEIN

RECEPTOR SUPERFAMILY .........................................

1. Characteristics and Structural Features of the Low-Density Lipoprotein Receptors (LDLR) …......................................

2. The LDLR Superfamily Members................................... 14

III CDNA CLONING AND SEQUENCE ANALYSIS OF THE VITELLOGENIN RECEPTOR FROM THE IMPORTED FIRE ANT, SOLENOPSIS INVICTA BUREN (HYMENOPTERA: FORMICIDAE) 35

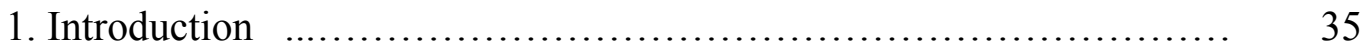

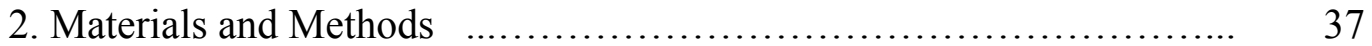

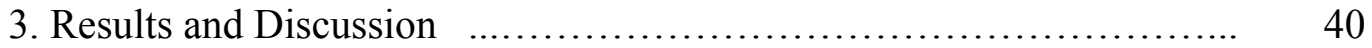

IV LOCALIZATION OF THE FIRE ANT VITELLOGENIN RECEPTOR

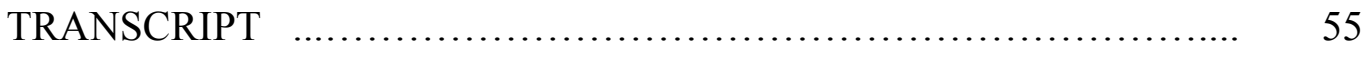

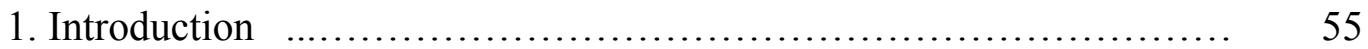

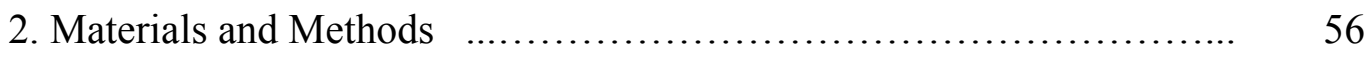

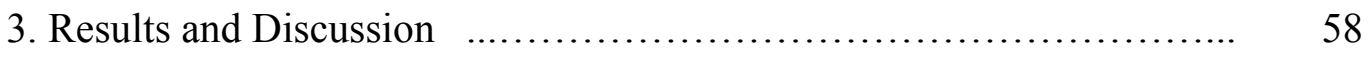

V TRANSCRIPTIONAL REGULATION OF THE FIRE ANT

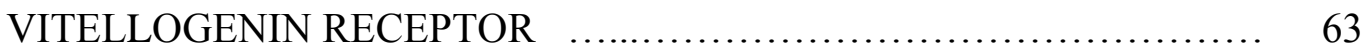

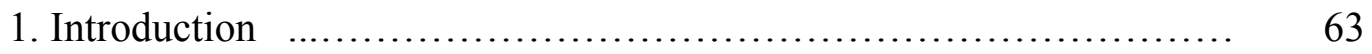

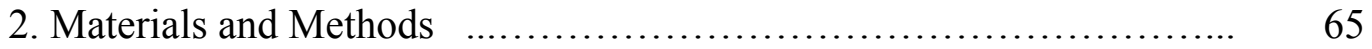

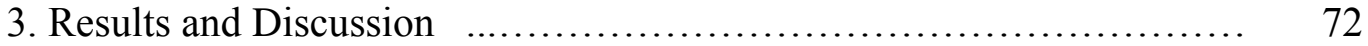


CHAPTER

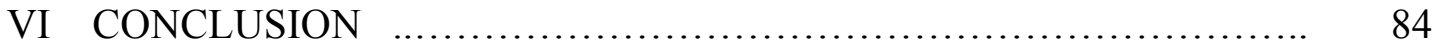

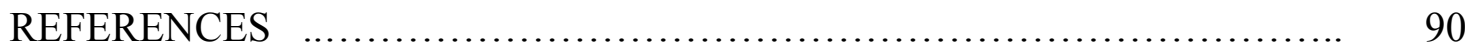

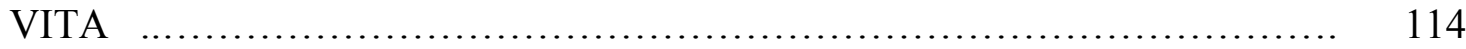




\section{LIST OF FIGURES}

FIGURE

Page

1-1 Schematic interpretation of the endocytotic pathway and subsequent route of $\mathrm{Vg}$ and $\mathrm{VgR}$ during Vg internalization by mosquito oocytes

2-1 Model of lipid mobilization and transport by lipophorin in insects which rely on lipid as their principle flight energy source

2-2 The arrangement of protein domains in the prototype receptor, the human LDLR

2-3 The members of LDLR superfamily

3-1 Nucleotide sequence and deduced amino acid sequence of the vitellogenin receptor cDNA of $S$. invicta

3-2 The arrangement of modular domains for insect VgRs and the schematic alignment of $S i \mathrm{VgR}$ modular domains with those $A a \mathrm{VgR}$ and $\mathrm{Dm} \mathrm{YPR}$

3-3 Alignment of deduced amino acid sequence of $S i \mathrm{VgR}, A a \mathrm{VgR}$ and $D m \mathrm{YPR}$

3-4 Schematic modular domain alignment among LDLR family members $\ldots . . . \quad 52$

3-5 The phylogram of sixteen LDLR superfamily members $\ldots \ldots \ldots \ldots \ldots \ldots \ldots . \ldots 3$

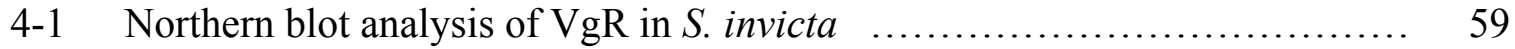

4-2 RT-PCR analysis of VgR in $S$. invicta reveals receptor transcript amplification only from ovaries

5-1 The incubation chambers for newly mated queens $\quad \ldots \ldots \ldots \ldots \ldots \ldots \ldots \ldots . \quad 70$

5-2 Temporal profiles of VgR transcription in alate females of $S$. invicta $\quad \ldots \ldots \ldots . \quad 73$

5-3 Temporal profiles of VgR transcription in field-collected newly mated queens of $S$. invicta

5-4 Effect of the juvenile hormone analog, methoprene, on $\mathrm{SiVgR}$ transcription by in vitro ovaries from day-0 alate female $S$. invicta

5-5 Effect of the 20-hydroxyecdysone on SiVgR transcription by in vitro ovaries from day-0 alate female $\mathrm{S}$. invicta 
FIGURE $\quad$ Page

6-1 A general hypothetical model of juvenile hormone $(\mathrm{JH})$ regulation of the egg

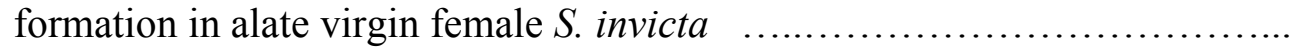




\section{CHAPTER I}

\section{INTRODUCTION}

Since its introduction into the southeastern USA, the red imported fire ant, Solenopsis invicta Buren (Hymenoptera: Formicidae), has established itself as a serious urban, agricultural and medical pest of the south, and it is now expanding its range into additional northern and western states (Vinson, 1997). The total annual costs of damages and expenditures attributed to the fire ants in Texas only are about 1200 million dollars. (Texas A\&M University, 2001).

Mating flights are the primary means of colony propagation. Mating flights occur in the proper environmental conditions. Usually, flights begin around 10:00 AM, one or two days after a rain, and when the temperature is above $24^{\circ} \mathrm{C}$, it is not too windy, and it is generally sunny. Just before the mating flight, workers become very active on and around the surface of the nest and open small holes on the mound surface into the nest's interior. Alate males first emerge from these openings and fly away or first climb surrounding vegetation to facilitate flight. Alate females begin to emerge an hour or so later and join the males in flight (Vinson, 1997). Mating occurs during flight and the males die soon after mating with females. Once the alate females have mated, they land, dealate and lay eggs within 24 hours.

This dissertation is presented in the style of the Insect Biochemistry and Molecular Biology. 
Colonies of imported fire ants are divided into two types based on the number of queens. Monogyne colonies contain a single queen, while polygyne colonies contain multiple, inseminated functional queens. In studies characterizing egg production, Fletcher et al. (1980) reported that physogastric (enlarged abdomen) queens in monogyne colonies produced about 200 eggs per day. In contrast, an individual polygyne queen may produce only 20 or 30 eggs per day. Queens from polygyne colonies are less physogastric and lay fewer eggs per individual than queens from monogyne colonies, but total egg production in polygyne colonies is several-fold higher than in monogyne colonies due to the presence of multiple reproductive queens (Fletcher et al., 1980; Greenberg et al., 1985; Vargo and Fletcher 1989).

The $S$. invicta queen is the center of colony existence. She controls the colony through the production of eggs by controlling the type of eggs she produces and by releasing pheromones that influence the physiology and behavior of the workers and other reproductives (Vinson, 1997; Vargo, 1998). There are three types of eggs. Sterile or trophic eggs are eaten, fertilized eggs produce sterile female workers or females capable of reproduction and unfertilized eggs develop into males (Vinson, 1997). In colonies, workers are completely sterile, but alate virgin females are capable of dealating and laying unfertilized (haploid) eggs. In normal colonies, a queen primer pheromone prevents alate virgin females from shedding their wings and developing their ovaries. However when removed from queen pheromonal influences, alate virgin females shed their wings and ovaries develop (Fletcher and Blum, 1981, 1983; Vargo, 1999). Topical applications of synthetic juvenile hormone (JH) I, II and III (Kearney et al., 1977) or the JH mimic, methoprene (Vargo and Laurel, 1994), induce dealation and 
ovary development, even in the presence of the queen (primer pheromone present). This suggests that the queen pheromone may act by suppressing JH titers in co-habiting alate virgin females (Vargo and Laurel, 1994).

Vitellogenin $(\mathrm{Vg})$ is the general name for a unique group of proteins that are synthesized extra-ovarially, transported to the ovaries, taken up and become the major egg yolk protein, vitellin (Vn) (Hagedorn and Kunkel, 1979). In most insects, Vgs are large oligomeric glycolipophosphoproteins consisting of two or more subunits. They are synthesized in the fat body as single or multiple precursors before being processed for secretion into the hemolymph. After Vgs are selectively taken up by the oocytes, they are stored in a crystalline form and referred to as Vns. Receptor-mediated endocytosis of $\mathrm{Vg}$ deposition into the oocyte has been studied in the blood sucking bug, Rhodnius prolixus (Oliveira et al., 1986), the cockroach, Nauphoeta cinerea (Kindle et al., 1988), the German cockroach, Blattella germanica (Konig et al., 1988), the locust, Locusta migratoria (Ferenz and Lubzens, 1981), the saturniid moth, Hyalophora cecropia (Kulakosky and Telfer, 1987), the tobacco hornworm, Manduca sexta (Osir and Law, 1986), the mosquito, Aedes aegypti (Koller et al., 1989), and the fruit fly, Drosophila melanogaster (Schonbaum et al., 1995). It is likely the mode of action for $\mathrm{Vg}$ uptake in S. invicta, as well.

The pathway of $\mathrm{Vg}$ internalization and $\mathrm{Vg}$ receptor $(\mathrm{VgR})$ recycling has been studied (Fig. 1-1). Coated vesicles, the cellular structures associated with selective endocytosis were first observed in A. aegypti (Roth and Porter, 1964). In 1997, Snigirevskaya et al. reported the route of $\mathrm{Vg}$ and $\mathrm{VgR}$ during $\mathrm{Vg}$ internalization in $A$. aegypti oocytes. At the onset of $\mathrm{Vg}$ accumulation into the oocyte, the follicle cells that 


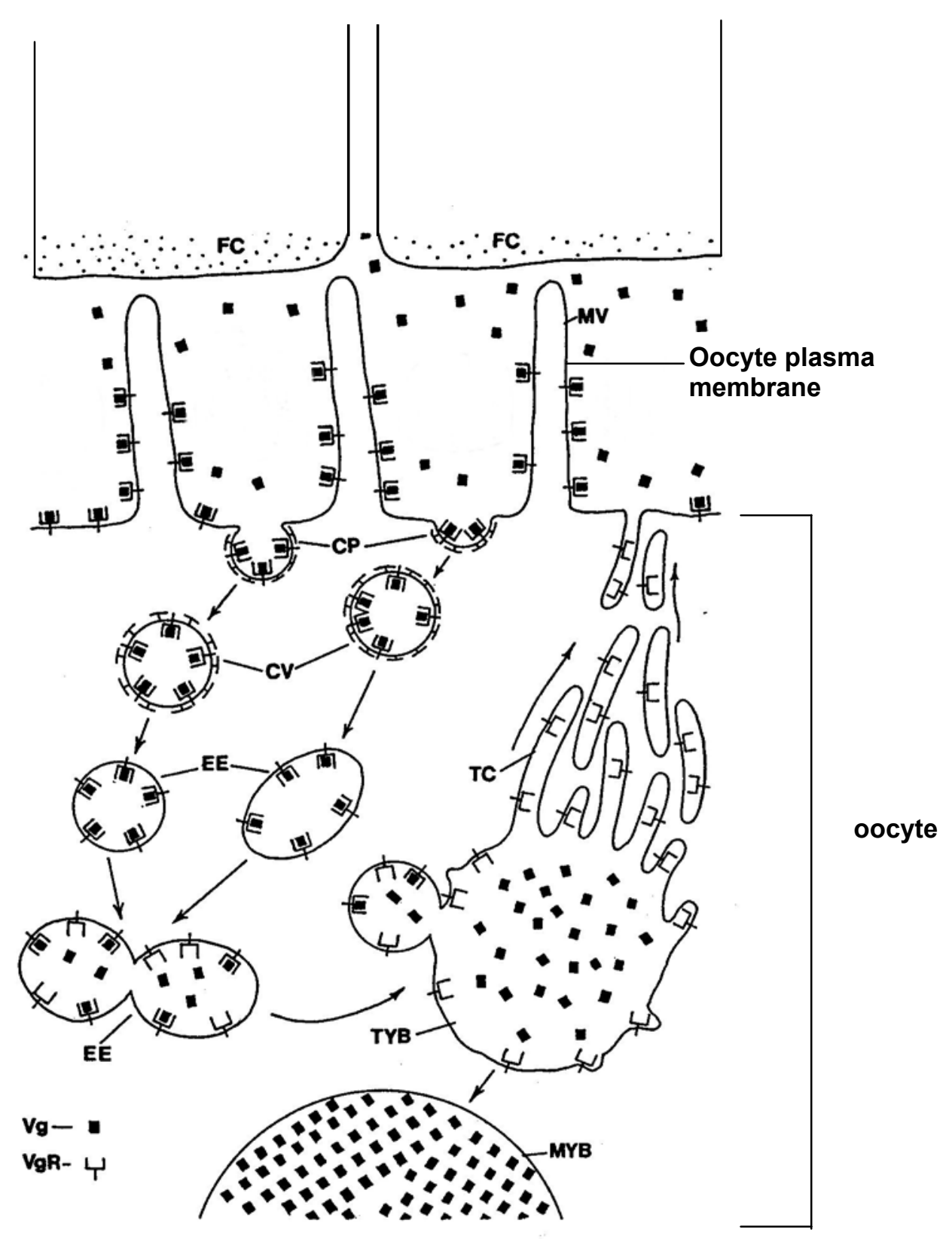

Fig. 1-1. Schematic interpretation of the endocytotic pathway and subsequent route of $\mathrm{Vg}$ and $\mathrm{VgR}$ during $\mathrm{Vg}$ internalization by mosquito oocytes. FC: follicle cell; MV: microvillus; CP: clathrin-coated pit; CV: coated vesicle; EE: early endosome; TYB: transitional yolk body; TC: tubular compartments; MYB: mature yolk body (modified after Snigirevskaya et al., 1997). 
surround the oocyte, shrink and develop extensive intercellular spaces. Vg is delivered to the oocyte in the hemolymph through these intercellular spaces and binds to its receptor which is located in the binding microdomains of the oocyte plasma membrane. $\mathrm{Vg} / \mathrm{VgR}$ complexes cluster in the clathrin-coated pits, which invaginate into the cytoplasm and pinch off to form coated vesicles. After losing their clathrin coats, the vesicles are transformed into early endosomes which fuse with endosomes to form late endosomes or transitional yolk bodies (TYB). Dissociation of Vg from its receptor likely occurs simultaneously with fusing of the early endosomes and their transformation into TYBs. In the TYB, the sorting and accumulating compartment, $\mathrm{Vg}$ is found free inside the vesicular reservoir, whereas $\mathrm{VgR}$ remains in the TYB membrane. The recycling of $\mathrm{VgR}$ from TYB to the oocyte surface occurs via the tubular compartment. In contrast, $\mathrm{Vg}$ is delivered to the mature yolk bodies where it is crystallized and stored until the onset of embryonic development.

Molecular cloning of $\mathrm{VgR}$ genes is necessary for further analyses of the mechanisms underlying $\mathrm{Vg}$ accumulation in insect oocytes. At the beginning of this work only two dipteran VgRs cDNA have been sequenced, the mosquito and the fruit fly, A. aegypti and D. melanogaster, respectively (Schonbaum et. al., 1995; Sappington et al., 1996). Both the VgRs of $A$. aegypti and D. melanogaster are members of the lowdensity lipoprotein receptor (LDLR) superfamily, and they share $42 \%$ amino acid identity and 63\% similarity to each other (Sappington et al., 1996). By the end of this work, there are two more known insect VgR sequences, the American cockroach, Periplaneta americana (accession number BAC 02725) and the mosquito Anopheles gambiae (accession number XP_310672). 
$\mathrm{Vg}$ is present in the hemolymph of all female caste members of the red imported fire ant, Solenopsis invicta, including workers, alate (virgin) females and mated queens (Lewis et al., 2001). Vg titers are comparable in mated queens and alate females, although no egg maturation is observed in alate females (Vargo and Laurel, 1994; Lewis et al., 2001). This suggests that the Vg gene is active constitutively, and regulations of yolk formation could perhaps occur at the level of $\mathrm{Vg}$ uptake into the oocyte, rather than at the level of Vg synthesis by the fat body. Hence, understanding VgR biology may be key to understanding imported fire ant queen reproduction.

The S. invicta $\operatorname{VgR}$ (SiVgR) cDNA cloning, sequencing and ensuing studies are presented in chapters, each covering a different aspect of the project. Chapter III focuses on isolation of $\mathrm{SiVgR}$ cDNA leading to Chapters IV and V. Chapter IV presents the tissue- and caste-specific transcriptional expression of SiVgR. Chapter V includes the $\mathrm{SiVgR}$ transcriptional expression timing profiles in virgin alate females and newly mated queens, and contains the study of the endocrine regulation of SiVgR transcriptional expression in vitro. 


\section{CHAPTER II}

\section{LITERATURE REVIEW: THE LOW-DENSITY LIPOPROTEIN RECEPTOR SUPERFAMILY}

Lipid transport via the circulatory system of animals constitutes a vital function that generally requires lipoprotein complexes. Lipoproteins have been studied extensively in vertebrates, especially mammals. Vertebrates rely on so-called high- and low-density lipoproteins to transport lipid in blood. Insect hemolymph generally contains a single major lipoprotein, lipophorin, which is found in relatively large quantities (Ryan, 1990). A characteristic feature of lipophorin is an ability to function as a reusable lipid shuttle by the selective loading and unloading of lipids at different target tissue sites (Ryan, 1990; Van der Horst, 1990). The major lipid components of insect lipophorins are diacylglycerides (DAG) and phospholipids. As a function of physiological or developmental needs for lipid distribution, lipophorin may exist in several forms with respect to relative lipid content and apolipophorin composition, leading to differences in size and density of the particle. The apolipophorin is the protein component of lipophorin. The apolipophorin is synthesized in the fat body where it is combined with phospholipids and released into the hemolymph as nascent lipophorin particles. Highdensity lipophorin (HDLp) contains relatively little lipid; low-density lipophorin (LDLp) contains more lipids. HDLp and LDLp are not discrete categories. During metabolism, addition of lipid to HDLp converts it to LDLp while only small changes occur in the volume and density of the particle (Ryan, 1994). 


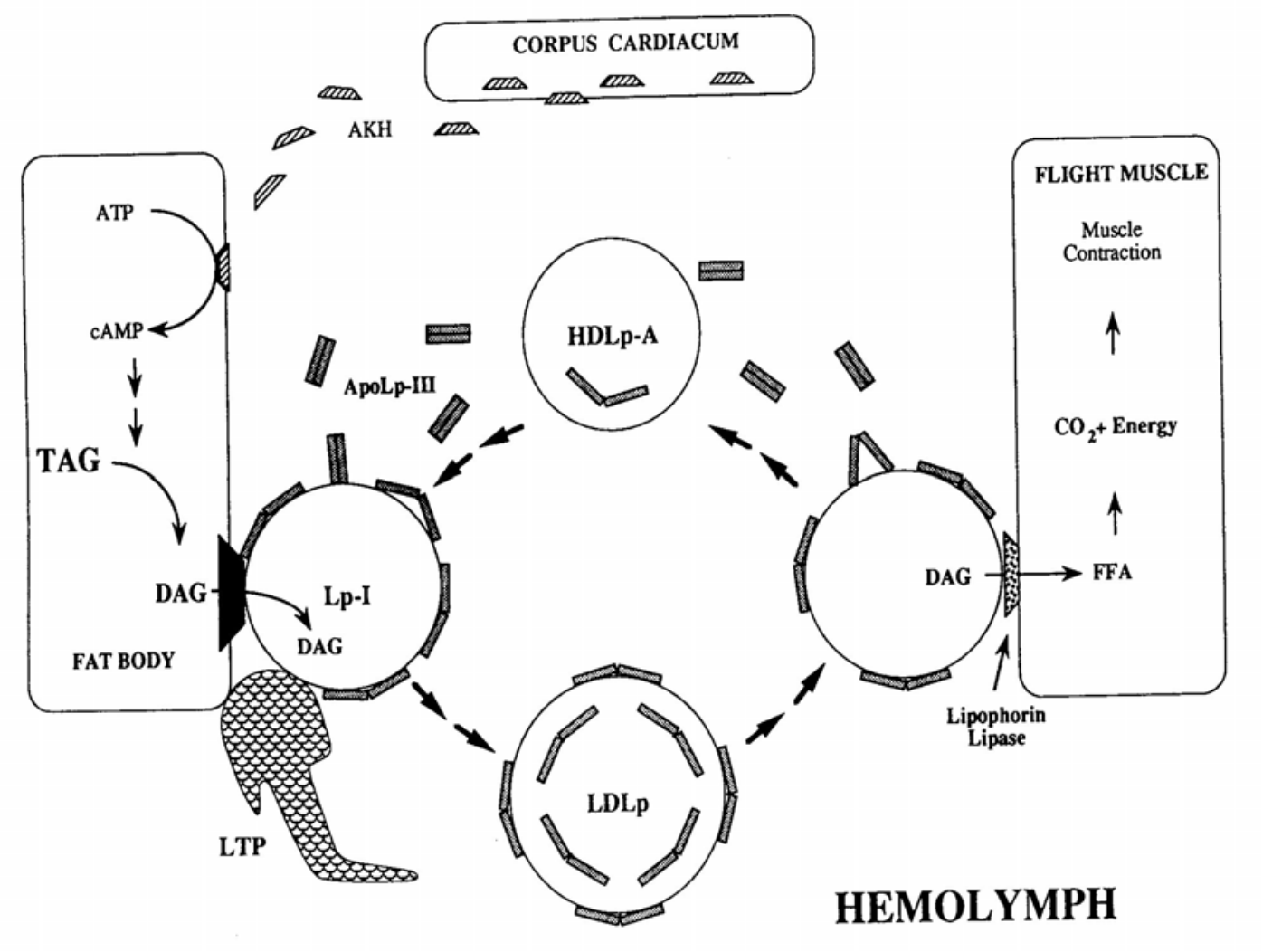

Fig. 2-1. Model of lipid mobilization and transport by lipophorin in insects which rely on lipid as their principle flight energy source. AKH: adipokinetic hormone; TAG: triacylglycerol; DAG: diacylglycerol; ApoLp-III: apolipophorin III; HDLpA: high-density lipophorin-adult; LDLp: low-density lipophorin; Lp-I, lipophorin loading intermediate; FFA: free fatty acid; LTR: lipid transfer particle (Ryan, 1990).

Lipophorin transports lipid from the midgut to the fat body, from the fat body to the flight muscles and also delivers lipids to the developing oocytes (Blacklock and Ryan, 1994). Flight-induced lipid loading (Fig. 2-1) onto HDLp is accompanied by association of multiple copies of the exchangeable apolipophorin III (ApoLp-III), which serve to stabilize the lipids and modulate metabolism of the lipophorin particle. Adipokinetic hormone $(\mathrm{AKH})$ is released from the corpus cardiacum and binds to receptors in the fat body, where it activates lipolysis of triacylglycerol (TAG) to diacylglycerol (DAG). 
The DAG leaves the fat body with the assistance of a lipid transfer particle (LTP) and is taken up by HDLp-A to form the lipophorin-loading intermediate (Lp-I). The capacity of HDLp-A to carry DAG is increased by binding ApoLp-III to its surface. Ultimately, LDLp is formed and carries the DAG to the flight muscle, where a lipophorin lipase hydrolyzes the DAG to produce free fatty acids and regenerates HDLp-A and ApoLpIII. The free fatty acids enter the flight muscle and are oxidized to produce the ATP required to power flight. HDLp-A and ApoLp-III circulate back to the fat body to repeat the cycle (Ryan, 1990). In this way, lipophorins are essential for insect energy metabolism when lipids are the main source of flight fuel.

Lipophorins are also important for insect reproduction, and employ endocytosis to transmit the lipid to the oocyte. HDLp-A (high-density lipophorin-adult) is taken up selectively by the developing oocyte. Within the ooctye, HDLp-A is converted to VHDL-E (very high-density lipophorin-egg) due to lipid unloading (Telfer et al., 1991). Also vitellogenin (Vg), the major egg yolk protein precursor, is a lipophorin and is taken up by the oocyte through receptor-mediated endocytosis as shown in several insects (Ferenz and Lubzens, 1981; Osir and Law, 1986; Oliveira et al., 1986; Kulakosky and Telfer, 1987; Kindle et al., 1988; Konig et al., 1988; Koller et al., 1989).

\section{CHARACTERISTICS AND STRUCTURAL FEATURES OF THE LOW- DENSITY LIPOPROTEIN RECEPTORS (LDLR)}

The LDLRs share structural and functional properties and interact with a diverse group of ligands. There are several characteristic features of the LDLR superfamily 
(Hussain et al., 1999; Schneider et al., 1999): cell surface expression; an extracellular ligand binding domain consisting of Class A cysteine-rich repeats (also called ligandbinding or complement-type repeats); a requirement of $\mathrm{Ca}^{2+}$ for ligand binding; recognition of receptor-associated protein (RAP); an epidermal growth factor (EGF) precursor homology domain containing Class B cysteine-rich repeats (also called EGF repeats) and YWXD amino acid repeats; a single membrane-spanning region; receptormediated endocytosis of various ligands, and the fact that the structurally and functionally distinct modules are often defined by distinct exons in the corresponding genes.

The LDLRs are highly conserved consisting of five domains after cleavage of the signal sequence (Fig. 2-2). These domains are: 1) the ligand binding domain, 2) the EGF precursor homology domain, 3) an O-linked carbohydrate domain, 4) a transmembrane domain, 5) a cytoplasmic tail (Goldstein et al., 1985; Schneider, 1996).

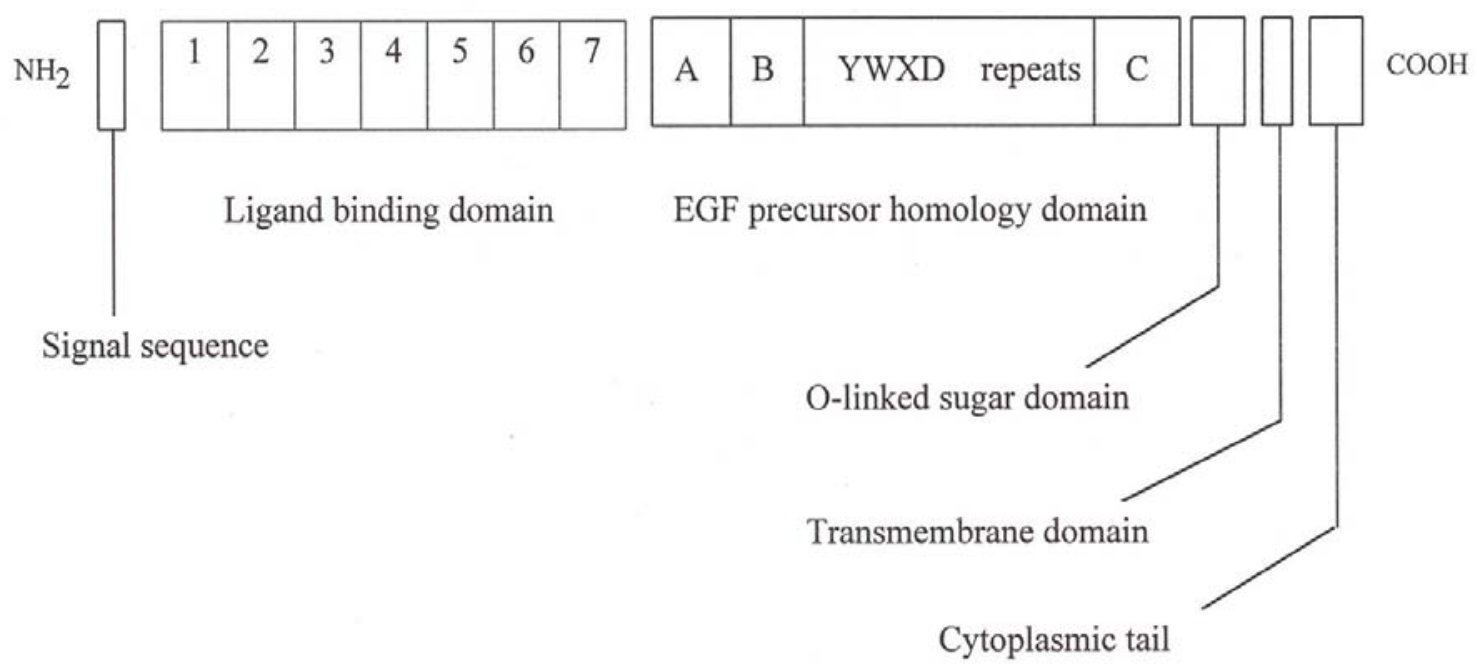

Fig. 2-2. The arrangement of protein domains in the prototype receptor, the human LDLR. 1-7: Class A cysteine-rich repeat. A, B and C: Class B cysteine-rich repeat. 
In LDLR superfamily, there are two types of cysteine-rich repeats, Class A and Class B, respectively. The differences between these two classes are based on the disulphide bond structure and the presence or absence of the negatively-charged amino acid sequence (SDE).

\subsection{The ligand binding domain}

It consists of Class A cysteine-rich repeats of about 40 amino acids each. Each repeat contains six cysteine residues which are disulphide bonded in the pattern one to three, two to five and four to six (Bieri et al., 1995). Reduction of these disulphide bonds destroys the structure and abolishes binding activity (Daniel et al., 1983). A striking feature of the C-terminus of each repeat sequence is a cluster of negativelycharged amino acids (SDE). These sequences are putatively complementary to positively-charged sequences distributed on the surface of the ligand (Goldstein et al., 1985). The intriguing fact is that based on nuclear magnetic resonance (NMR) studies (Daly et al., 1995) and crystallographic studies (Fass et al., 1997) the negativelycharged residues are buried in the core coordinated with $\mathrm{Ca}^{2+}$. Thus the binding activity may be contributed by the overall three-dimensional structure. For human LDLR, the repeat 5 is required for binding of apolipoprotein $\mathrm{E}$ (apoE), and repeats 3-7 cooperatively bind to apoB (Schneider, 1996). Both ligands differ in amino acid sequence and have no known structural relationship other than their common affinity for negatively charged polymers. So different combinations of repeats allow a single receptor to recognize structurally diverse ligands (Brown et al., 1997). 


\subsection{The EGF precursor homology domain}

The EGF precursor homology domain consists of Class B cysteine-rich repeats and YWXD repeats. Compared to Class A cysteine-rich repeats, the Class B cysteine-rich repeats in this domain are arranged in a different disulphide bond pattern as follows: one to three, two to four and five to six (Campbell and Bork, 1993), and they also lack the negatively-charged residues (SDE) at the C-terminus. The Class B cysteine-rich repeats are usually separated by the YWXD repeats that are found as a group of five in a module of about 50 amino acids (Hussain et al., 1999) (Fig. 2-2). Within endosomes, following endocytosis, this domain contributes to ligand dissociation from the receptors. When the EGF precursor domain is deleted from the LDLR, the receptor can not bind LDL, but it still binds lipoproteins that contain apoE. The bound apoE enter the cell normally, but they are not released in the endosome. Instead, the receptor is degraded along with the ligand (Davis et al., 1987).

\subsection{An O-linked sugar domain}

The O-linked sugar domain of the human LDLR is highly enriched in serine and threonine residues and located just outside the plasma membrane (Yamamoto et al., 1984). Deletion of this domain in the LDLR does not affect ligand binding, internalization, recycling, or receptor half-life in cultured cells (Davis et al., 1986). It suggests that this domain is not required for receptor function. 


\subsection{A transmembrane domain}

All the members of the LDLR superfamily contain a single transmembrane domain consisting of a stretch of hydrophobic residues that anchors them into membranes. The sequence of this domain is the least conserved of all the receptor domains among seven mammalian species (Schneider, 1996). Comparison of the amino acid sequences of the mosquito and fruit fly VgRs also reveals that the membrane-spanning region is poorly conserved (Sappington et al., 1996).

\subsection{A cytoplasmic tail}

Compared to signaling receptors, which often contain large intracellular domains with kinase activities, the cytoplasmic tails of the LDLR superfamily members are relatively short with no kinase domain. The cytoplasmic domain of the LDLR plays an important role in clustering coated pits, either through interaction with clathrin itself or with some protein associated with clathrin on the cytoplasmic side of the membrane (Goldstein et al., 1985). The internalization signal, NPXY, is identified within the LDLR (Chen et al., 1990). The di-leucine motif is another well-known internalization signal that is present within many transmembrane cell surface proteins (Letourneur and Klausner, 1992; Dittrich et al., 1994). For insect vitellogenin receptors (VgRs), mosquito VgR contains one leucine-isoleucine, and fruit fly VgR contains two dileucine motifs in the cytoplasmic tails as internationalization signal (Sappington et al., 1996). However, recent studies indicate that in addition to the internalization signals, the cytoplasmic tails of LDLRs contain critical elements for interaction with a set of 
cytoplasmic adaptors and scaffold proteins, and mediate signal transduction (Strickland et al., 2002).

\section{THE LDLR SUPERFAMILY MEMBERS}

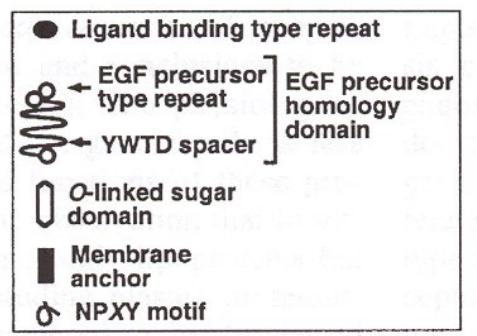

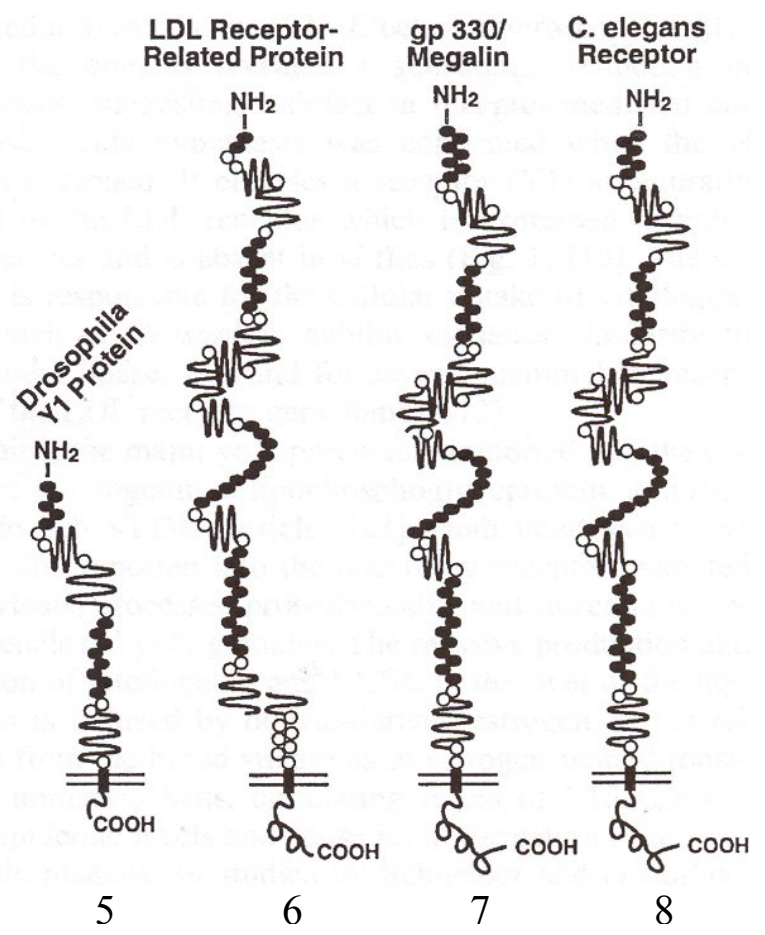

Fig. 2-3. The members of LDLR superfamily (modified after Willnow, 1999).

\subsection{The human LDLR}

Since 1974, the discovery of a cellular pathway for the binding, internalization and degradation of plasma low-density lipoprotein (LDL) led to the identification of the human LDLR (Goldstein and Brown, 1974; Yamamoto et al., 1984). LDLRs are under intense investigation because of their importance in human heart disease. The human 
LDLR gene is more than $45 \mathrm{~kb}$ in length and contains eighteen exons, most of which correlate with functional domains (Sudhof et al., 1985). The nucleotide sequence of a cloned $5.3 \mathrm{~kb}$ cDNA for the human LDLR reveals five domains in the 839 amino acid protein (Yamamoto et al., 1984). The N-terminal ligand binding domain is characterized by the presence of seven Class A cysteine-rich repeats also designated as ligand binding type repeats (Fig. 2-3). See number 1. The major function of the LDLR is cholesterol homeostasis, which is accomplished by controlling plasma LDL levels. Mutations in the LDLR gene cause familial hypercholesterolemia characterized by increased plasma cholesterol levels, arcus cornea, tendon xanthomas, and coronary heart disease (Goldstein et al., 1995). Four classes of mutations that disrupt the structure and function of the LDLR cause familial hypercholesterolemia (Goldstein et al., 1985). Class 1 mutations: no receptors synthesized. This is the most common class of mutant alleles. The genetic defects in the LDLR may include nonsense mutations; mutations in the promoter that block transcription of mRNA; point mutations in intron-exon junctions that alter the splicing of mRNA and large deletions. Class 2 mutations: receptors synthesized but transported slowly from ER to Golgi. Class 3 mutations: receptors are processed and reach the cell surface, but fail to bind LDL normally. Class 4 mutations: receptors reach cell surface and bind LDL, but fail to cluster in coated pits. The failure of these internalization defective receptors to localize to coated structures results from mutations that directly or indirectly disrupt the cytoplasmic tail of the receptor, in particular, the sequence FDNPXY (Lehrman et al., 1985).

Although most of the mutations map in the coding region of the gene, an increasing number of mutations in the regulatory regions are currently being described (Peeters et 
al, 1998; Scholtz et al., 1999; Mozas et al., 2002). The basic regulatory region of the LDLR gene is located within $177 \mathrm{bp}$ of the proximal promoter. The 177-bp fragment of the receptor gene contains all of the detectable signals for positive expression as well as for negative regulation by sterols. This fragment contains the three direct repeats, each of which is required for mRNA expression. It also contains the two TATA-like sequences, only one of which is required for expression (Sudhof et al., 1987b).

The direct repeats are homologous to the consensus sequence recognized by the transcription factor Sp1 (Sudhof et al., 1987b). Repeats 1 and 3 contain binding sites for the transcription factor Sp1 and contribute to the basal expression of the LDLR gene. DNase I footprint analysis indicates that the mutation, a 3-bp deletion in repeat 1, abolished binding of Sp1 to repeat 1. Transcription studies in transfected cells using normal and repeat 1 mutant promoter fragments linked to a luciferase reporter gene demonstrate that the repeat 1 mutant promoter has approximately $10 \%$ of normal promoter activity (Peeters et al., 1998). Specific binding of purified Sp1 to repeat 3 was demonstrated by electrophoretic mobility shift assays (EMSA) and DNase I footprinting assays (Dawson et al., 1988).

Sterol-dependent repression of transcription is mediated by a 42-bp region encompassing repeats 2 and 3 (Sudhof et al., 1987a). Repeat 2 harbors a special element that is directly responsible for regulation by sterols and does not bind $\mathrm{Sp} 1$. The sterol regulatory element (SRE-1) within repeat 2 was identified by mutational studies as a 10-bp sequence that binds a family of proteins called the sterol regulatory element binding proteins (SREBPs) (Briggs et al., 1993). SRE-1 functions as a conditionally positive element activating expression only when sterol levels are low (Briggs et al., 
1993). SREBPs binding at repeat 2 increased the binding of Sp1 to the adjacent repeat 3. The $\mathrm{Sp} 1$ has a dual role in the LDLR promoter. It provides a basal activation required for a low suppressed level of promoter activity, and it also participates in sterol regulation of the LDLR. Its role in sterol regulation requires that it interact with SREBP bound to the adjacent repeat 2 (Sanchez et al., 1995).

In addition to sterol, LDLR transcription can also be regulated by nonsterol mediators. Cytokine oncostatin $\mathrm{M}(\mathrm{OM})$ is a growth regulatory protein secreted by macrophages and activated by $\mathrm{T}$ lymphocytes. OM increases the expression of LDLR protein and mRNA independent of intracellular cholesterol (Grove et al., 1991). To elucidate regulatory mechanisms, specific mutants in repeats 1,2 , and 3 were made to facilitate the mapping of the OM effect on the promoter. The mutation within the SRE-1 element of repeat 2 totally abolished cholesterol regulation but had no effect on OM inducibility. Instead, mutations within repeats 1 and 3 impaired OM activity (Liu et al., 1997). The OM-responsive element to promoter region contains the repeat 3 and two TATA-like sequences (Li et al., 1999a). Within the two TATA-like promoter regions, a sterol-independent regulatory element (SIRE) was designated. The 17-bp-SIRE contains an active CCAAT/enhancer-binding protein (C/EBP)-binding site and a functional cAMP-responsive element (CRE) (Liu et al., 2000). Electrophoretic mobility shift assays confirm the specific binding of transcription factors C/EBP and cAMPresponsive element-binding protein to the SIRE. Mutations within either the C/EBP or CRE site have no impact on basal or cholesterol-mediated repression of LDLR transcription, but they completely abolish OM-mediated activation of LDLR transcription (Liu et al., 2000). 
2.2. Very-low-density lipoprotein receptor (VLDLR)

\subsubsection{Vertebrate}

The structure of the VLDLR is similar to the LDLR (Fig. 2-3). See number 2. The major difference is that there is an additional Class A cysteine-rich repeat containing in the VLDLR ligand binding domain (Sakai et al., 1994). Both cDNA and the gene structures of these two receptors are similar. The different functional motifs in the VLDLR are also encoded by different exons as observed in the LDLR (Sakai et al., 1994). However, the tissue distribution of the VLDLR is different from that of the LDLR. The VLDLR is not present in liver but is abundant in skeletal muscle, heart, adipose tissue and brain (Takahashi et al., 1992; Webb et al., 1994). The VLDLR was originally thought to play a role in triglyceride metabolism, but the triglyceride, total plasma cholesterol, and free fatty acid levels of VLDLR homozygous knockout mice are indistinguishable from wild type controls (Frykman et al., 1995). It is because of overlapping ligands with other LDLR family members. The role for VLDLR in triglyceride metabolism is revealed by cross breeding VLDLR-deficient mice and VLDLR-over-expressing mice with LDLR homozygous knockout mice. On the LDLR deficient background, absence of the VLDLR results in a significant increase in serum triglyceride levels when mice are fed a high fat diet. In contrast, overexpression of the VLDLR results in a significant decrease of serum triglyceride levels under similar conditions (Tacken et al., 2000). These observations indicate that the VLDLR affects peripheral uptake of triglyceride.

The VLDLR shows a high degree of identity among different species. Within mammals, there is a $95 \%$ identity between the corresponding proteins. In addition, even 
the proteins of more distant species such as the chicken and Xenopus laevis share $84 \%$ and $73 \%$ identity respectively with the human VLDLR (Schneider et al., 1999).

\subsubsection{Invertebrate}

In the locust, L. migratoria, a high-affinity HDLp binding site $\left(\mathrm{Kd} \sim 10^{-7} \mathrm{M}\right)$ has been characterized in intact fat body tissue as well as in fat body membranes of larval and adult locusts (Van Antwerpen et al., 1989; Dantuma et al., 1996). The lipoprotein binding site was identified as an endocytotic receptor involved in receptor-mediated uptake of HDLp. The putative receptor involved in endocyteic uptake of HDLp in the locust fat body has been cloned and sequenced (Dantuma et al., 1999). This receptor contains eight cysteine-rich repeats in its putative ligand-binding domain like the vertebrate VLDLR does. This receptor shows high similarity to rabbit and human VLDLR, 58.6\% and 58.0\%, respectively. Northern blot analysis revealed one transcript of approximately $4.8 \mathrm{~kb}$ in locust fat body, oocytes, brain and midgut, but the transcript was absent from flight muscle (Dantuma et al., 1999). Expression of the receptor mRNA in fat body cells is down-regulated during adult development, which is consistent with the down-regulation of receptor-mediated endocytosis of lipophorins in fat body tissue (Dantuma et al., 1997, 1999). The function of receptor-mediated endocytosis remains unclear because inhibition of endocytosis did not reduce the exchange of DAG or cholesterol between HDLp and the fat body cell (Dantuma et al., 1997). 


\subsection{ApoE receptor 2}

Apolipoprotein E (ApoE)-mediated lipid metabolism in the central nervous system plays an important role in cholesterol and phospholipid homeostasis of this system. ApoE receptor 2, or LR7/8B, was cloned from brain cDNA libraries of human, mice, and chickens (Kim et al., 1996; Novak et al., 1996). The human receptor contains seven ligand binding repeats, whereas mouse and chicken receptors contain eight ligand binding repeats. The variants observed in different species probably arise because of differential splicing (Brandes et al., 1997). The EGF precursor homology domain, an Olinked glycosylation motif, a transmembrane region and the cytoplasmic domains are similar to those of the LDLR and VLDLR (Fig. 2-3). See number 3. With respect to sequence homology and restricted tissue expression, the apoE receptor 2 is closer to VLDLR than to LDLR. Thus, it is expected to have broad ligand binding ability, similar to that observed for VLDLR, rather than the restricted specificity observed for vertebrate LDLR.

\subsection{Vertebrate Vg receptor}

\subsubsection{Chicken Vg receptor}

An interesting VLDLR is the chicken VgR relative to its role in the reproductive effort of the hen. This receptor is termed LR8 with eight Class A cysteine-rich repeats in the ligand binding domain (Bujo et al., 1994) (Fig. 2-3). See number 4. Splice variant forms of the chicken LR8 gene produce an oocyte-specific VLDLR/VgR without an Olinked sugar domain or a soma-specific variant containing an O-linked domain (Bujo et al., 1995a). The functional absence of LR8 leads to female sterility via lack of oocyte 
growth and premature atherogenesis due to the severe hyperlipidemia (Bujo et al., 1995b). During vitellogenesis the oocytes accumulate large amounts of macro- and micronutrients required for the embryo. In chickens, triglyceride-rich, VLDLs and Vg comprise the major part of yolk (Perry and Gilbert, 1979). The single major chicken oocyte plasma membrane receptor, VLDLR/VgR has a molecular mass of $95 \mathrm{kDa}$ as determined by SDS-PAGE under nonreducing conditions and is the receptor for both of these ligands (Stifani et al., 1990). The isolated receptor had the capacity to bind ${ }^{125} \mathrm{I}-$ VLDL and ${ }^{125} \mathrm{I}-\mathrm{Vg}$ with high affinity and in saturable fashion when analyzed by a solid phase filtration assay (Barber et al., 1991). This receptor reacts with antibodies to mammalian LDLR and surprisingly recognizes apoE, which is not produced in birds (Steyrer et al., 1990). However Vg and apoE have certain common biochemical properties and regions of sequence similarities and have been suggested to be functional analogs (Steyrer et al., 1990). These properties predicted that the oocyte receptor for VLDL and Vg would be a homolog of mammalian LDLR.

\subsubsection{Frog Vg receptor}

During Xenopus laevis oocyte growth, $80-90 \%$ of total yolk protein is derived from the specific uptake of Vg from the maternal blood stream (Wallace et al., 1972). The rate of $\mathrm{Vg}$ uptake in oocytes regulates overall oocyte growth and differentiation and can be modulated by gonadotropins and insulin (Wallace and Misulovin, 1978; Wiley and Dumont, 1978). Xenopus VgR is probably developmentally regulated, since neither stage I nor II oocytes appear to be able to incorporate Vg. It is quite possible that these cells do not possess VgRs at this stage of development (Dumont, 1972). A Xenopus 3.6 
kb cDNA clone contains the entire open reading frame and 5' and 3' noncoding regions. The deduced amino acid sequence is $72 \%$ homologous to the chicken VLDLR/VgR and the characteristic domains are highly conserved (Okabayashi et al., 1996). The Xenopus VgR has eight Class A cysteine-rich repeats which is characteristically conserved among the VLDLR and vertebrate VgR family. In addition, the amino acid sequence of Xenopus is more similar to the chicken VLDLR/VgR sequence $(72 \%$ identity) than to the Xenopus LDLR sequence (44\% identity) (Mehta et al., 1991; Okabayashi et al., 1996). Radiolabeled Xenopus Vg binds to the membrane VLDLR/VgR in the chicken oocyte. Similarly only one $115 \mathrm{kDa}$ membrane protein from Xenopus oocytes interacted with ${ }^{125}$ I-labeled Xenopus Vg (Stifani et al., 1990). The binding of radiolabeled $\mathrm{Vg}$ to both chicken and Xenopus oocyte membrane proteins is totally abolished when membrane proteins are exposed to reducing agents for disulfide-bonds. This agrees with the fact that intrachain disulfide bonds within the receptor molecule are necessary for retention of receptor activity (Stifani et al., 1990; Barber et al., 1991).

\subsubsection{Fish Vg receptor}

The VgR of the coho salmon (Oncorhynchus kisutch) was characterized from oocytes. In direct binding studies, the receptor exhibits high affinity for salmonid $\mathrm{Vg}$ $\left(\mathrm{K}_{\mathrm{d}}, 180 \mathrm{nM}\right)$ and binding is saturable. Ligand blotting with radiolabeled $\mathrm{Vg}$ under nonreducing conditions, reveal a protein with an apparent $\mathrm{Mr}$. of $100 \mathrm{kDa}$. The piscine receptor showed cross-reactivity with the chicken and frog receptors both in terms of 
ligand recognition and immunoreactivity (Stifani et al., 1990). Salmon VgR shares key structural elements with VgRs from chicken and Xenopus.

In the rainbow trout, Oncorhynchus mykiss, $\mathrm{Vg}$ uptake constitutes $>80 \%$ of the growth of the oocyte and accounts for most of the 1000-fold increase in size that takes place during vitellogenesis (Tyler and Sumpter, 1996). Studies on VgR protein in the rainbow trout have shown that it is present in oocytes throughout the major part of ovarian development, and that it can be detected even before the onset of vitellogenesis (Lancaster and Tyler, 1994). The expression of VgR mRNA varied throughout ovarian development and is highest in previtellogenic ovaries and in ovaries at the onset of vitellogenesis containing ovarian follicles from 35 to $600 \mu \mathrm{m}$ in diameter (Perazzolo et al., 1999).

Tyler and Lubberink (1996) showed by ligand blotting that rainbow trout ovarian follicles contained four receptor proteins of Mrs. 220, 210, 110 and $100 \mathrm{kDa}$, respectively. These receptors have a high affinity for $\mathrm{Vg}$ but did not appear to bind other homologous plasma lipoproteins (VLDL, LDL and HDL). Furthermore, these binding sites for Vg were specific to the ovary. At that stage, the authors cannot say whether the receptor for $\mathrm{Vg}$ in the rainbow trout is comprised of two associated $\sim 100$ $\mathrm{kDa}$ proteins or forms dimeric structures on its removal from the membrane. In the same year, Nunez Rodriguez et al. (1996) reported that the ligand blotting with ${ }^{125} \mathrm{I}-\mathrm{Vg}$ after SDS-PAGE revealed the existence of one major binding component corresponding to a protein of $113 \mathrm{kDa}$.

A rainbow trout oocyte-specific receptor cDNA has been cloned (Davail et al., 1998). In vitro translation of the full-length cDNA produces a $97 \mathrm{kDa}$ protein and 
transient expression in mammalian COS-1 cells showed that the cDNA encodes a protein of the same size that binds Vg in ligand blots (Davail et al., 1998). The cloned $\mathrm{VgR}$, a 826-residue type I membrane protein, is a member of the LDLR superfamily. It closely resembles the mammalian VLDLR, in that its N-terminal ligand binding domain consists of a cluster of eight Class A cysteine-rich repeats. The short cytoplasmic tail contains the internalization signal, FDNPVY, typical for the LDLR superfamily. Notably, the receptor lacks a domain with a high density of potential O-glycosylation sites often found in somatic cell-specific members of the LDLR family. A transcript of $3.9 \mathrm{~kb}$ is abundant in ovary, but undetectable in muscle and heart, which are the major sites of expression of VLDLRs in mammals (Davail, et al., 1998).

In the rainbow trout ovary, cDNA encoding for a second lipoprotein receptor has been partially characterized from the ovary, which differs only in sequence from the VgR by an additional 105 base pairs that constitutes the O-linked sugar domain (Prat et al., 1998). This receptor has been referred to as the somatic lipoprotein receptor, and it is expressed both in the ovary and in somatic tissues. The precise function of the somatic lipoprotein receptor is not known, but the ovary lipoprotein receptor is thought to mediate the uptake of lipoproteins other than Vg, for example, VLDL that could be a component of yolk proteins (Prat et al., 1998).

2.5. Invetebrate vitellogenins and vitellogenin receptors (VgR)

\subsubsection{Insect Vgs}

Like all oviparous animals, insects provision their eggs with proteins, lipids, carbohydrates and other resources for the sustenance of the developing embryo. Insect 
$\mathrm{Vg}$ is synthesized extraovarially and becomes the major egg yolk protein. Vgs are large (200-700 kDa) phosphoglycolipoproteins that are often oligomeric in their native state with monomers consisting of one to four subunits. The Vg monomers of most insects are composed of one large $(>150 \mathrm{kDa})$ and one small $(<65 \mathrm{kDa})$ subunit (Raikhel and Dhadialla, 1992). Although the primary function of $\mathrm{Vg}$ is to provide a pool of amino acids for the embryo, it also functions as a carrier of carbohydrates, lipids, phosphates, vitamins, metals, and hormones. Such transport functions, along with the necessity for specifically binding a VgR, presumably place constraints on Vg structure (Sappington and Raikhel, 1998). The most striking feature of vertebrate and some insect Vg primary structures are the presence of one to three domains containing long runs of serine residues. The serine residues probably serve as substrates for kinases. Phosphoserine tracts represent extreme concentrations of negative charge, which may promote solubility of the $\mathrm{Vg}$ or provide a region for chelating essential metal ions such as $\mathrm{Ca}^{2+}$ and $\mathrm{Fe}^{3+}$ (Sappington and Raikhel, 1998). Dephosphorylation of Vg reduces its uptake by oocytes, suggesting a role of phosphorylated residues in $\mathrm{VgR}$ recognition or maintenance of tertiary structure (Dhadialla et al., 1992).

Studies on binding of $\mathrm{Vg}$ to membranes isolated from follicles or ovaries have been made on a few insect species: L. migratoria (Rohrkasten and Ferenz, 1986a), N. cinerea (Konig and Lanzrein, 1985), M. sexta (Osir and Law, 1986), B. germanica (Konig et al., 1988), R. prolixus (Wang and Davey, 1992), and A. aegypti (Dhadialla and Raikhel, 1991). In all these studies, binding of Vg was characteristic of a receptor-ligand interaction in which it was saturable, ovary specific, selective for $\mathrm{Vg}$ and sensitive to changes in $\mathrm{pH}$ and $\mathrm{Ca}^{2+}$ concentration. In Rhodnius, binding of vitellin ( $\left.\mathrm{Vn}\right)$ is 
enhanced by JH-I, which appears to increase the number of receptors (Wang and Davey, 1992). Also an increase in Vg uptake by ovaries in vitro occurs in $N$. cinerea in the presence of JH-III (Kindle et al., 1988). On the other hand, the JH analog, ZR515, is without effect on endocytosis in locusts (Rohrkasten and Ferenz, 1985). Solubilization of VgRs has been achieved for L. migratoria (Rohrkasten and Ferenz, 1986b), N. cinerea (Indrasith et al., 1990) and A. aegypti (Dhadialla et al., 1992).

\subsubsection{Drosophila vitellogenin receptor, Yl protein}

To date, VgR cDNAs have been sequenced in three insects, the mosquito, $A$. aegypti, fruit fly, D. melanogaster, (Schonbaum et al., 1995; Sappington et al., 1996) and American cockroach, Periplaneta americana (accession number BAC 02725). In the fruit fly, an ovary-specific, $6.5 \mathrm{~kb}$ yolkless $(y l)$ mRNA encoding a protein of $\sim 210$ $\mathrm{kDa}$ was identified by a combination of complementation mapping, chromosome walking, and northern blotting (Schonbaum et al., 1995). Sterile mutant female fruit flies carrying the $y l$ gene fail to accumulate yolk protein in their oocytes (Waring et al., 1983; Perrimon, et al., 1986). When a genomic DNA fragment encompassing this 6.5 $\mathrm{kb}$ transcript was introduced into $y l$ flies, yolk uptake and fertility were restored (Schonbaum et al., 1995).

$y l$ RNA and protein are both expressed very early during the development of the oocytes, long before vitellogenesis begins. RNA in situ hybridization and lacZ reporter analyses show that $y l$ RNA is synthesized by the germ-line nurse cells and then transported to the oocyte. Yl protein is evenly distributed throughout the oocyte during the previtellogenic stages. The transition to the vitellogenic stages is marked by the 
accumulation of yolk via clathrin-coated vesicles. After this transition, VgR levels increase markedly at the cortex of the egg (Schonbaum et al., 2000).

The translation product of the 5844-nt open reading frame encoded for by the $y l$ cDNA is a 1984-residue protein that contains several repeats of the structural elements that typify the LDLR superfamily (Fig. 2-3). See number 5. There are thirteen Class A cysteine-rich repeats in two clusters of five and eight repeats each, respectively; seven Class B cysteine-rich repeats that flank three groups of five YWXD repeats each and a single membrane-spanning domain. In contrast to the extracellular domain, the putative cytoplasmic domain of Yl shows no similarity to other LDLR superfamily members. Most conspicuous is the absence of the NPXY sequence common to other LDLR proteins. However, the Yl cytoplasmic tail does have two di-leucine motifs that are identified as alternative internalization signals (Letourneur and Klausner, 1992; Dittrich et al., 1994). Y1 does not appear to be more closely related to the chicken VgR than to other LDLR superfamily members. A sequence comparison of the eight-repeat clusters in the chicken VLDLR/VgR and Drosophila Y1 reveals 38\% amino acid identity; while between rabbit and chicken VLDLR, there is $84 \%$ amino acid identity in this region (Bujo et al., 1994; Schonbaum et al., 1995).

Homology of VgRs and LDLRs has also been suggested by the similarity of their ligands, since Vgs from a broad range of species (e.g., birds, amphibia, and nematodes) have regions of sequence similarity to apoB-100, which is a ligand for LDLR (Baker, 1988). However, the yolk proteins of higher dipterans, such as Drosophila, Ceratitis, and Calliphora show similarity to lipoprotein lipase of higher animals, which are known to bind to LDLR-related proteins (LRP) (Terpstra and Ab, 1988; Beisiegel et al., 
1989; Rina and Savakis, 1991; Martinez and Bownes, 1994). In chickens, a $380 \mathrm{kDa}$ oocyte-specific LRP as well as the $95-\mathrm{kDa}$ VgR bind Vg (Stifani et al., 1991). Therefore more than one receptor of the LDLR superfamily may be responsible for the coordinated uptake of individual or structurally similar groups of yolk precursors.

\subsubsection{Mosquito Aedes aegypti ovary receptors}

The A. aegypti $\mathrm{VgR}(A a \mathrm{VgR})$, is identified as a $205-\mathrm{kDa}$ protein by ligand blotting under nonreducing conditions (Dhadialla et al., 1992). Native gel analysis suggests that it occurs as a non-covalent homodimer (Sappington et al., 1995).

The $\operatorname{VgR}$ is present only in ovarian tissue and immunocytochemical experiments revealed that it is present only in the oocyte, not in follicle cells or nurse cells (Dhadialla et al., 1992; Sappington et al., 1995). The full length $\mathrm{AaVgR}$ cDNA, 5544 bp, has been cloned (Sappington et al., 1996). The $7.3 \mathrm{~kb}$ transcript is present in oocytes and nurse cells of primary follicles and germ-line cells of the germarium as determined by northern blot analysis and in situ hybridization experiments. The level of VgR transcript starts to rise in the ovary one day post-eclosion. It continues to rise during the previtellogenic and vitellogenic period and reaches its peak at $24 \mathrm{~h}$ post-blood meal, suggesting the $A a \mathrm{VgR}$ gene is expressed early in oocyte differentiation (Sappington et al., 1996; Cho and Raikhel, 2001).

Analyses of the $A a \mathrm{VgR}$ deduced amino acid sequence indicate that it is a member of the LDLR superfamily. The modular arrangement is similar to that of Drosophila VgR except that $A a \mathrm{VgR}$ contains an O-linked sugar domain between the final extracellular cysteine residue in the Class $\mathrm{B}$ cysteine-rich repeats and the beginning of the 
transmembrane domain. The cytoplasmic tail of $A a \mathrm{VgR}$ lacks the conserved internalization signal, NPXY. Instead, it contains a leucine-isoleucine motif that is identified as an alternative internalization signal. The striking homology of the $A a \mathrm{VgR}$ to the Drosophila VgR (42\% amino acid identity and $63 \%$ similarity) is very surprising since the primary structures of their ligands are unrelated (Sappington et al., 1996).

The AaVgR gene structure has been determined (Cho and Raikhel, 2001). The VgR gene is separated by five introns that have an average length of $60 \mathrm{bp}$, except for the second intron, which is more than $20 \mathrm{~kb}$ long. The exon-intron organization of the $A a \mathrm{VgR}$ is quite different from other cloned genes of the LDLR superfamily. The introns of $A a \mathrm{VgR}$ are present in the N-terminal half, which contains the first ligand binding domain and the first EGF precursor homology domain (Cho and Raikhel, 2001). Nevertheless, nineteen introns of the human LDLR (Sudhof et al., 1985), VLDLR (Sakai et al., 1994) and eighteen introns of mouse VLDLR (Tiebel et al., 1999) interrupt the coding sequence all along different domains, such as the ligand binding domain, the EGF precursor homologous domain, the O-linked sugar domain, the transmembrane domain and the cytoplasmic domain. However, most of the introns interrupt the coding sequences at or close to boundaries between domains and between units within a domain. Sudhof et al. (1985) suggested that the presence of numerous introns at boundaries of Class A cysteine-rich repeats of the human LDLR gene could lead to the splicing of mRNAs coding for receptors with different ligand-binding characteristics.

Although Vgs are lipidated and oocytes internalize large amounts of Vgs, the amount of lipid associated with these proteins is far less than the total lipid in insect 
eggs. Another class of proteins, lipophorins (Lp), carry lipid to various tissues, including the eggs (Raikhel and Dhadialla, 1992). In lepidopteran vitellogenesis, Lp, the major lipoprotein in insect hemolymph, plays a dual role. It shuttles precursors from the fat body to the ovaries for the deposition of lipid yolk droplets, and in some species becomes one of the major constituents of the protein yolk bodies (Telfer et al., 1991). Lp functions as a yolk protein precursor in the mosquito A. aegypti and it is internalized via receptor-mediated endocytosis (Sun et al., 2000). A putative mosquito lipophorin receptor from ovaries (AaLpRov) cDNA has been cloned (Cheon et al., 2001). The AaLpRov cDNA has a length of 3468 bp coding for a 1156-residue protein with a predicted Mr. of $128.9 \mathrm{kDa}$. In situ hybridization and northern blot analysis indicate that the $4.5 \mathrm{~kb}$ transcripts are present only in female germ line cells. The $A a \mathrm{LpRov}$ transcripts are present in the previtellogenic stage and increase further after the onset of vitellogenesis with peak expression by $24 \mathrm{~h}$ post-blood meal. It is present in the ovary until $48 \mathrm{~h}$ post-blood meal, the time of termination of vitellogenic events in the female mosquito (Cheon et al., 2001).

The pattern of $A a \mathrm{VgR}$ mRNA expression in the ovaries is similar to that of $A a \mathrm{LpRov}$, but $A a \mathrm{VgR}$ mRNA is expressed at higher levels in both previtellogenic and early vitellogenic ovaries (Cheon et al., 2001; Cho and Raikhel, 2001). According to the deduced amino acid sequences, $A a$ LpRov has eight Class A cysteine-rich repeats in a ligand binding domain like the vertebrate VLDLR. Following the ligand binding domain is an EGF precursor homology domain and between the EGF precursor domain and the transmembrane domain, the receptor is serine- and threonine- rich thus containing multiple potential sites for O-linked sugar chains. Finally, the putative 
cytoplasmic tail of the receptor contains a highly conserved internalization signal, NPXY. The deduced amino acid sequence of $A a \operatorname{LpRov}$ is most similar to that of the locust lipophorin receptor (63\% identity) (Dantuma et al., 1999; Cheon et al., 2001) and is only distantly related to the $A a \mathrm{VgR}$ ( $18.3 \%$ identity) that has a different ligand (Sappington et al., 1996; Cheon et al., 2001).

\subsubsection{Caenorhabditis elegans $\mathrm{VgR}$}

Another reported invertebrate VgR is the RME-2 of the nematode, Caenorhabditis elegans. It was characterized based on its mutant phenotype, expression pattern, molecular nature and sufficiency to induce yolk binding in a heterologous cell type (Grant and Hirsh, 1999). The full-length rme-2 mRNA size of $2.9 \mathrm{~kb}$ encodes a protein of 925 amino acids in length with a Mr. of $\sim 110 \mathrm{kDa}$ shown by western blot analysis. RME-2 contains several repeated sequence motifs, with overall similarity to members of the LDLR superfamily. There are five, tandem Class A cysteine-rich repeats in the N-terminal ligand binding domain, each containing six cysteine residues with characteristic spacing and typical anionic SDE or DDE sequences. Following the ligand binding domain is an EGF precursor homologous domain and a transmembrane domain. Finally, within the predicted intracellular domain, there is an internalization signal of the NPXY type. Several mutants of rme-2 were sequenced. These mutants showed partial deletion of the YWTD region, the Class B cysteine-rich repeats 3 and 4 and the predicted transmembrane and intracellular domains. Such mutated proteins are unlikely to retain any endocytotic function (Grant and Hirsh, 1999). 


\subsection{The LDLR-related protein (LRP)}

The human LRP is a hetero-dimeric protein consisting of $515-$ and $85-\mathrm{kDa}$ subunits. It is synthesized as a single polypeptide of 4525 amino acids and is cleaved by an endoprotease, furin, in the Golgi compartment to produce two subunits of 3924 and 601 amino acids (Herz et al., 1990; Willnow et al., 1996). The 515-kDa subunit contains 31 Class A cysteine-rich repeats that are organized in four domains (Fig. 2-3). See number 6. LRP is a multi-ligand receptor and the ligands include lipoproteins (apoE, chylomicro remnants), protease inhibitors ( $\alpha 2$-macroglobulin) and plasminogen activators (Krieger and Herz, 1994). Studies suggest that LRP binds and internalizes proteins associated with Alzheimer's disease (AD) such as amyloid precursor protein (APP) (Jordan et al., 1998; Narita et al., 1997). AD is a neurodegenerative disease that results in impaired memory and cognition. The hallmarks of $\mathrm{AD}$ are amyloid plaques and neurofibrillary tangles deposited in the brain (Price et al., 1998). The major components of amyloid plaques are amyloid $\beta$-peptides $(\mathrm{A} \beta)$ that are proteolytically derived from the APP (Glenner and Wong, 1984). LRP ligands, such as apoE and $\alpha 2-$ macroglobulin, have been shown to bind $\mathrm{A} \beta$ and to mediate its clearance and degradation through LRP (Jordan et al., 1998; Narita et al., 1997). Reduced LRP expression in older adults and in $\mathrm{AD}$ patients is correlated with increased soluble $\mathrm{A} \beta$ levels and amyloid deposition (Kang et al., 2000). Thus the loss of LRP function to clear ligands, complexed with $\mathrm{A} \beta$, may contribute to the appearance of amyloid plaques in $\mathrm{AD}$ and aging populations.

Wnt (an amalgam of wingless and int) proteins form a family of highly conserved secreted signaling molecules that regulate cell-to-cell interactions during 
embryogenesis. The Wnt family of secreted molecules functions in cell-fate determination and morphogenesis during development in both vertebrates and invertebrates (Wodarz and Nusse, 1998). Drosophila Wingless is a member of this family, and the Frizzled (Fz) family of serpentine (7 TM; GPCRs) receptors function as Wnt receptors. In D. melanogaster, arrow encodes a single-pass transmembrane protein indicating that it may be part of a receptor complex with Fz family proteins (Wehrli et al., 2000). arrow phenocopies the wingless phenotype and encodes a protein of 1678 amino acids exhibiting a striking sequence conservation to the mammalian LRP5 and LRP6 (Wehrli et al., 2000). In mouse embryos homozygous for an insertional mutation in the LRP6 gene, developmental defects are seen that display a striking composite of those caused by mutations in individual Wnt genes (Pinson et al., 2000). In Xenopus embryos, LRP6 activates Wnt-Fz signaling, and induces Wnt-responsive genes, dorsal axis duplication, and neural crest formation (Tamai et al., 2000). Biochemical studies showed that the extracellular domain of LRP6 bound Wnt-1, and associated with Fz in a Wnt-dependent manner. An LRP6 mutant, lacking the carboxyl intracellular domain, blocked signaling by Wnt or Wnt-Fz, and inhibited neural crest development (Tamai et al., 2000). These studies thus demonstrate that LRP6 functions as a co-receptor for Wnt signal transduction with Fz.

\subsection{Megalin/gp330}

In vertebrates, megalin is essential for development of the forebrain by taking up apoB-containing lipoproteins into the embryonic neuroepithelium (Willnow et al., 1996). In vitro, megalin binds many of the ligands that are also known to bind to LRP 
including lipoproteins, lipoprotein lipase, and urokinase (Willnow et al., 1992). Despite their partial overlap in ligand spectrum, the spatial and temporal differences in the expression patterns for megalin and LRP suggest distinct physiological roles. Megalin is a single polypeptide of 4660 amino acids containing four clusters of ligand binding domains consisting of 7, 8, 10 and 11 Class A cysteine-rich repeats in the molecule that recognize several groups of ligands (Fig 2-3). See number 7. The intracellular domain contains two internalization signals, as observed in other members, but its overall sequence is different from that of other receptors. The intracellular domain of megalin contains Src (sarcoma)-homology binding regions, casein kinase II sites, and protein kinase phosphorylation sites, indicating that it may be involved in signal transduction (Christensen et al., 1998).

\subsection{Caenorhabditis elegans receptor}

A $>23 \mathrm{~kb}$ gene that encodes a large integral membrane protein with a predicted structure and function similar to those of megalin has been isolated and sequenced from the nematode $C$. elegans. The gene is called lrp-1 (LDLR-related protein-1) (Yochem and Greenwald, 1993; Yochem et al., 1999). The 4753-amino acid predicted C. elegans product shares a nearly identical number and arrangement of amino acid motifs with megalin (Fig. 2-3). See number 8. The LRP-1 is essential for growth and development of the nematode. The mutations of LRP-1 confer a striking defect: an inability to shed and degrade all of the old cuticle at each of the larval molts (Yochem et al., 1999). 


\section{CHAPTER III}

\section{CDNA CLONING AND SEQUENCE ANALYSIS OF THE VITELLOGENIN RECEPTOR FROM THE IMPORTED FIRE ANT, SOLENOPSIS INVICTA BUREN (HYMENOPTERA: FORMICIDAE)}

\section{INTRODUCTION}

Developing oocytes of oviparous animals accumulate large amounts of the extraovarian yolk protein precursor, vitellogenin $(\mathrm{Vg})$, during oogenesis. $\mathrm{Vg}$ is synthesized by the fat body of insects or the liver of vertebrates for release into the circulatory system and transport to the ovaries. The selective internalization of $\mathrm{Vg}$ by the growing oocyte is achieved through receptor-mediated endocytosis (Raikhel and Dhadialla, 1992). Receptor-mediated entocytosis of Vg into the oocyte has been described for a number of insect species including: Locusta migratoria (Rohrkasten and Ferenz, 1986b), Nauphoeta cinerea (Konig and Lanzrein, 1985), Manduca sexta (Osir and Law, 1986), Blattella germanica (Konig et al., 1988), Rhodnius prolixus (Wang and Davey, 1992), and Aedes aegypti (Dhadialla and Raikhel, 1991).

The sequences of several vertebrate and invertebrate VgRs are known. For vertebrates, VgRs are described for the chicken, Gallus gallus (Bujo et al., 1994); the toad, Xenopus laevis (Okabayashi et al., 1996); the rainbow trout, Oncorhynchus mykiss (Davail et al., 1998) and the fish, Oreochromis auresu (Li et al., 2003). For invertebrates, they are described for the fruit fly, Drosophila melanogaster (Schonbaum et al., 1995); the mosquito, A. aegypti (Sappington et al., 1996); the mosquito, 
Anopheles gambiae (accession number XP_310672); the American cockroach, Periplaneta americana (accession number BAC 02725) and the nematode, Caenorhabditis elegans (Grant and Hirsh, 1999). All of these VgRs are members of the low-density lipoprotein receptor (LDLR) superfamily. An aspect of this superfamily is that the physiological roles of its members are diverse as reflected by a wide range of ligands (Schneider et al., 1999; Nykjaer and Willnow 2002; Strickland et al., 2002), even though they have many structural elements in common. These common structural elements are: i) the ligand-binding domain comprised of Class A cysteine-rich repeats; ii) the epidermal growth factor (EGF) precursor homology domain containing Class B cysteine-rich repeats and YWXD repeats; iii) an O-linked carbohydrate domain; iv) a transmembrane domain; and v) a cytoplasmic tail (Goldstein et al., 1985; Schneider, 1996).

The size and structure of insect VgRs are different from those of vertebrate VgRs. Insect VgRs (190-214 kDa) are about twice the size of the vertebrate VgRs (95-115 kDa) (Dhadialla et al., 1992; Bujo et al., 1994; Okabayashi et al., 1996; Sappington et al., 1996; Davail et al., 1998). The A. aegypti $\mathrm{VgR}($ AaVgR) and D. melanogaster yolk protein receptor ( $D m \mathrm{YPR}$ ) each contains two ligand-binding domains comprised of five and eight Class A cysteine-rich repeats respectively, unlike vertebrate VgRs which have a single ligand binding domain comprised of eight Class A cysteine-rich repeats (Bujo et al., 1994; Okabayashi et al., 1996; Davail et al., 1998). In addition, the two insect VgRs contain two EGF precursor homology domains rather than only one as presented in the vertebrate $\mathrm{VgRs}$. 
In this chapter the $S$. invicta $\mathrm{VgR}(\mathrm{Si} \mathrm{VgR})$ cDNA is cloned and sequenced. The entire coding region sequence is analyzed and subjected to phylogenetic analyses.

\section{MATERIALS AND METHODS}

\subsection{Insects}

Polygyne colonies of $S$. invicta were obtained from the Fire Ant Research Laboratory in the Department of Entomology (Texas A\&M University, College Station, TX). All colonies were collected in Brazos County, Texas. The laboratory colonies of $S$. invicta were housed in plastic trays $(27 \times 40 \times 9 \mathrm{~cm})$ containing one nest in a $14 \mathrm{~cm}$ diameter Petri dish half-filled with damp Castone ${ }^{\circledR}$ (Dentsply International Inc., York, PA). The colonies were maintained at $27 \pm 2^{\circ} \mathrm{C}$ in a $12 \mathrm{~L}: 12 \mathrm{D}$ photoperiod and fed daily with $20 \%$ honey-water, cockroach carcasses (Blaberus discoidalis) and an artificial diet (Kuriachan \& Vinson, 2000). Water was given ad lib.

\subsection{Cloning the fire ant VgR cDNA by RT-PCR and RACE}

Ovaries were collected from queens 10 days after insemination, and total RNA was extracted using the guanidine-thiocyanate-phenol-chloroform method (Chomczynski and Sacchi, 1987; Puissant and Houdebine, 1990). The ovarian total RNA (1 $\mu \mathrm{g})$ provided templates for reverse transcription $(\mathrm{RT})$ reaction using oligo- $\mathrm{dT}_{16}$ primers with a GeneAmp ${ }^{\circledR}$ RNA PCR Core kit (Perkin Elmer, Vellesley, MA). To obtain cDNA fragments containing the coding region of $\mathrm{VgR}$, polymerase chain reaction 
(PCR) was applied following $\mathrm{RT}$ reaction using an oligo- $\mathrm{dT}_{16}$ and one degenerate oligonucleotide, which was designed based on the consensus sequences of the $A$. aegypti and D. melanogaster VgRs (Schonbaum et al., 1995; Sappington et al., 1996). PCR parameters were $94^{\circ} \mathrm{C}$ for $2 \mathrm{~min} ; 35$ cycles of $94^{\circ} \mathrm{C}$ for $30 \mathrm{~s}, 55^{\circ} \mathrm{C}$ for $1 \mathrm{~min}$, and $72^{\circ} \mathrm{C}$ for $2 \mathrm{~min} ; 72^{\circ} \mathrm{C}$ for $10 \mathrm{~min}$. The PCR product $(2.3 \mathrm{~kb})$ was purified using QIAEX II Gel Extraction kit (QIAGEN, Valencia, CA), and cloned into pGEM ${ }^{\circledR}$-T Easy Vector (Promega, Madison, WI). The cDNA fragment was sequenced using ABI PRISM ${ }^{\circledR}$ Big Dye Terminator Cycle sequencing Core kit with AmpliTaq ${ }^{\circledR}$ DNA Polymerase (Perkin Elmer) and the sequences were obtained by the Gene Technology Laboratory (Texas A\&M University, College Station, TX). Big Dye sequence results were compared with other protein sequences available through the database of the National Center for Biotechnology Information (NCBI) BLAST e-mail server (Altschul et al., 1990) (http://www.ncbi.nlm.nih.gov/BLAST).

The 5' end of the SiVgR cDNA fragment was produced using the 5' RACE system (Gibco BRL ${ }^{\circledR}$, Invitrogen, Carlsbad, CA) and Gene Racer $^{\mathrm{TM}}$ Kit (Invitrogen ${ }^{\mathrm{TM}}$, Carlsbad, CA). SiVgR-specific primers were designed based on the 5'-end sequence of the $2.3 \mathrm{~kb}$ fragment. Manufacturer's instructions were followed. The resulting bands were purified, cloned, and sequenced as described above.

The 3' end of the SiVgR cDNA fragment was produced using the Gene Racer ${ }^{\mathrm{TM}}$ Kit (Invitrogen ${ }^{\mathrm{TM}}$, Carlsbad, CA). mRNA was purified from ovaries using Dynabeads ${ }^{\circledR}$ mRNA DIRECT Kit (DYNAL ${ }^{\circledR}$, Oslo, Norway). SiVgR-specific primers were designed based on the 3 '-end sequence of the $2.3 \mathrm{~kb}$ fragment. PCR parameters were 
$94^{\circ} \mathrm{C}$ for $30 \mathrm{~s} ; 35$ cycles of $94^{\circ} \mathrm{C}$ for $30 \mathrm{~s}$, and $68^{\circ} \mathrm{C}$ for $2 \mathrm{~min} 30 \mathrm{~s} ; 68^{\circ} \mathrm{C}$ for $10 \mathrm{~min}$. Manufacturer's instructions were followed. The resulting bands were purified, cloned and sequenced as described above. All cDNA fragments were sequenced at least twice.

\subsection{Phylogenetic analysis and amino acid sequence comparison}

Translation of the nucleotide sequence was accomplished by the Translator through the MBS - Molecular Biology Shortcuts e-mail server (http://www.justbio.com/translator/index.php). The SMART (simple modular architecture research tool) (Schultz et al., 1998; Letunic et al., 2002) (http://smart.emblheidelberg.de) was used for identification of modular domains that were adjusted by eye, when necessary. Percent identity and similarity for subdomains were determined by the EMBOSS Pairwise Alignment Algorithms of EBI (European Bioinformatics Institute) (http://www.ebi.ac.uk/emboss/align).

The amino acid sequences of ten VgRs, four VLDLRs and two LDLR-related proteins (LRP) were multiple-aligned and the phylogram among the sixteen LDLR superfamily members listed above were performed using the Clustal W computer program (Thompson et al., 1994) (http://www.ebi.ac.uk/clustalw).

The accession numbers for the receptors used for multiple alignment and phylogenetic analyses are as follows: chicken VgR P98165, frog VgR JC4858, rainbow trout VgR CAD10640, fish VgR AAO27569, mosquito Aedes aegypti VgR T30347, mosquito Anopheles gambiae VgR XP_310672, fruit fly VgR P98163, American cockroach BAC02725, fire ant VgR AY262832, nematode VgR NP500815, human 
VLDLR P98155, rabbit VLDLR P35953, mosquito VLDLR AAK72954, locust VLDLR CAA03855, human LRP Q07954, and nematode LRP, CAA98124.

\section{RESULTS AND DISCUSSION}

\subsection{Cloning and sequence analysis of the cDNA for the $S$. invicta $\mathrm{VgR}$}

S. invicta VgR cDNA was cloned using RT-PCR, 5' and 3' RACE as described in Materials and Methods. Comparisons were made with other protein sequences available through the National Center for Biotechnology Information BLAST e-mail server (Altschul et al., 1990). The deduced amino acid sequence of the first PCR fragment obtained $(2.3 \mathrm{~kb})$ indicated that it was highly similar to mosquito and fruit fly VgRs. The $2.3 \mathrm{~kb}$ fragment was used to design specific primers to extend the 5' and 3 ' ends of the $\mathrm{SiVgR-cDNA.} \mathrm{cDNA} \mathrm{fragments} \mathrm{encompassing} \mathrm{the} \mathrm{entire} \mathrm{coding} \mathrm{region} \mathrm{were} \mathrm{cloned}$ and sequenced (Fig. 3-1).

The $5764 \mathrm{bp}$ cDNA sequence revealed an open reading frame of 5349 bp encoding a protein of 1782 amino acid residues. There were two possible start codons at the $5^{\prime}$ end at positions 107 and 113. Based on the Kozak sequence, the start codon at position 113 conformed most closely to the initiation site consensus sequence (Kozak, 1984). A stretch of 16 predominantly hydrophobic residues defined a signal peptide downstream of the methionine start codon (Fig. 3-1). The open reading frame predicted a protein with molecular mass of $201.3 \mathrm{kDa}$ and an isoelectric point of 5.5. There are several possible sites for co- and posttranslational modification of the SiVgR, including $13 \mathrm{~N}-$ linked glycosylation sites. The $\mathrm{SiVgR}$ colud be heavily phosphorylated on Ser with 


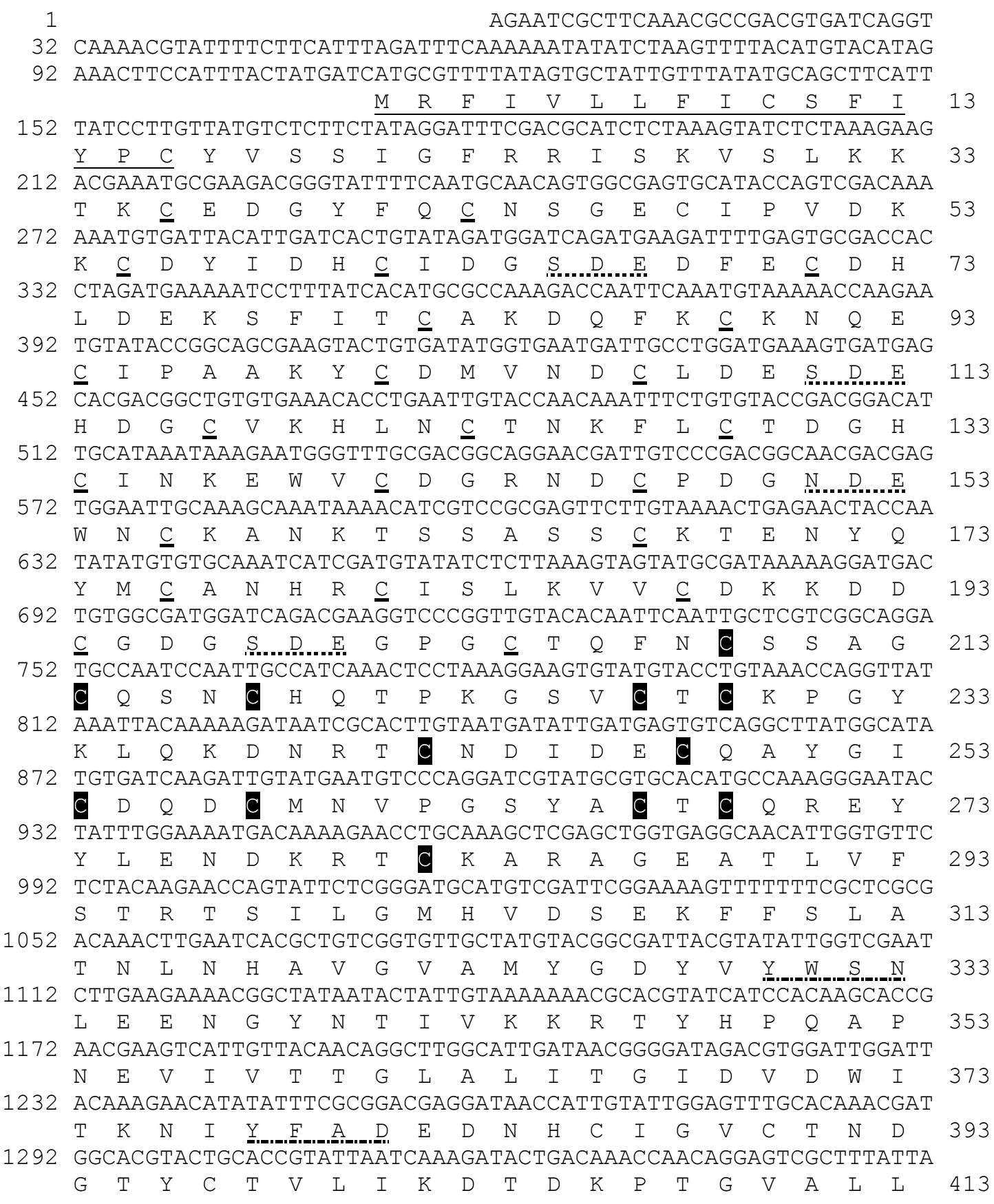

Fig. 3-1. Nucleotide sequence and deduced amino acid sequence of the vitellogenin receptor cDNA of $S$. invicta. The putative signal sequence at the $\mathrm{N}$-terminus and a presumed transmembrane sequence near the $\mathrm{C}$-terminus are underlined and double underlined, respectively. Class A cysteine residues are indicated as $\underline{\mathrm{C}}$ and Class B cysteine residues as $\mathrm{C}$. The SDE sequences are present as SDE. The YWXD or potentially related sequences present in YWXD. The internalization signal, NPSY is in boldface type. 
1352 CCAACCCAAGGAAAAATGTATTGGAGCGATTGGGGTACTTTTCCACATATAGCAGTGGCC $\begin{array}{lllllllllllllllllllll}P & T & Q & G & K & M & Y & W & S & D & W & G & T & F & P & H & I & A & V & A & 433\end{array}$

1412 GGAATGGATGGTAAAAACGTCCGTATATTCGTCAATGTAAAGTTAGAATGGCCGAAAAGT $\begin{array}{lllllllllllllllllllll}G & M & D & G & K & N & V & R & I & F & V & N & V & K & L & E & W & P & K & S & 453\end{array}$

1472 GTCACTATTGATTATCCGAACGAGAGATTATATTGGGTGGATGCCAAGTCAAAGATGATC

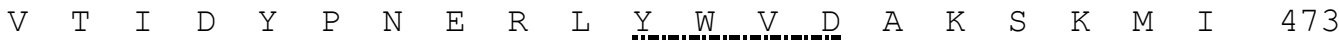

1532 GAATCTGTACGCTTAGACGGCACTGATCGAAGAATAGTGTTACATGATATAATACAAGAG

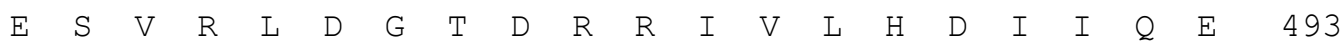

1592 CCATTCTCTATGACGGTCTTTCAAAATAAATTATACTGGAGCGATTGGGAATCCAATGGG $\begin{array}{lllllllllllllllllllll}P & F & S & M & T & V & F & Q & N & K & \text { L } & Y & W & S & D & W & E & S & N & G & 513\end{array}$

1652 ATACAGACCTGCAATAAATTTACTGGAAAGGATTGGAAGATCTTAATTCGTAATCATAAT $\begin{array}{lllllllllllllllllllll}I & Q & T & C & N & K & F & T & G & K & D & W & K & I & L & I & R & N & H & N & 533\end{array}$

1712 AAACCTTATAGCGTGCACATGGATCATTCAGCGATAAAACCTAATATTGACAATCCATGT $\begin{array}{lllllllllllllllllllll}K & P & Y & S & V & H & M & D & H & S & A & I & K & P & N & I & D & N & P & C & 553\end{array}$

1772 TACTCTAATCCGTGTTCTCAATTATGCATGTTGAATCAGAATAAAGGTTACACGTGCGGC $\begin{array}{lllllllllllllllllllll}Y & S & N & P & C & S & Q & L & C & M & L & N & Q & N & K & G & Y & T & C & G & 573\end{array}$

1832 TGCACTTTGGATAAGAAATTAAATGCCGACAAACATACTTGTCAAGATGTGAAGAAGAAT $\begin{array}{llllllllllllllllllllll}\text { C } & T & \text { L } & D & K & K & L & N & A & D & K & H & \text { T } & \text { C } & \text { Q } & \text { D } & \text { V } & K & K & \text { N } & 593\end{array}$

1892 CAGCATTTATTAATTATTCAAGGAAGAAAATTCATTAACTACTATCACGAATTCTTAGGA $\begin{array}{lllllllllllllllllllll}Q & H & L & L & I & I & Q & G & R & K & F & I & N & Y & Y & H & E & F & L & G & 613\end{array}$

1952 AAGCCAAAAGTAATGACATTGTCACTGCAACACATGTCACAACAATCATATAACAATCTA $\begin{array}{lllllllllllllllllllll}K & P & K & V & M & \text { T } & \text { L } & \text { S } & \text { L } & \text { Q } & \text { H } & \text { M } & \text { S } & \text { Q } & \text { Q } & \text { S } & \text { Y } & \text { N } & \text { N } & \text { L } & 633\end{array}$

2012 GTGAATATAATATCTGATCCGCTCTCAGGTCAGATAATTATTTGCCATCTGCAATTATCA $\begin{array}{lllllllllllllllllllll}V & N & I & I & S & D & P & L & S & G & Q & I & I & I & C & H & L & Q & L & S & 653\end{array}$

2072 ACGCCTTTCTTAACGTCAACGACAGACATCTTACGCTATGATCCAGTCCACCACAGTTCG $\begin{array}{lllllllllllllllllllll}T & P & F & \text { L } & \text { T } & \text { S } & \text { T } & \text { T } & \text { D } & \text { I } & \text { L } & \text { R } & \text { Y } & \text { D } & \text { P } & \text { V } & \text { H } & \text { H } & \text { S } & \text { S } & 673\end{array}$

2132 GAAAAAATAGTGACGATCAATAAGATATTTTTCGAATTAGCATTTGATTATATTGGCAAT $\begin{array}{lllllllllllllllllllll}E & K & I & V & T & I & N & K & I & F & F & E & L & A & F & D & Y & I & G & N & 693\end{array}$

2192 AACTTGTACACAACAAATACTGTAAACCAATCTATCGAGGTAATCAACTTAAACACCAAG $\begin{array}{lllllllllllllllllllll}N & \mathrm{~L} & \mathrm{Y} & \mathrm{T} & \mathrm{T} & \mathrm{N} & \mathrm{T} & \mathrm{V} & \mathrm{N} & \mathrm{Q} & \mathrm{S} & \mathrm{I} & \mathrm{E} & \mathrm{V} & \mathrm{I} & \mathrm{N} & \mathrm{L} & \mathrm{N} & \mathrm{T} & \mathrm{K} & 713\end{array}$

2252 GCAATGACGGCCTTTTATTTTAAGGATGAGGTTCCTAAATATATTGCACTAGCTCCTGAA $\begin{array}{lllllllllllllllllllll}A & M & T & A & F & Y & F & K & D & E & V & P & K & Y & I & A & L & A & P & E & 733\end{array}$

2312 GAAAGCAAGATGTTCGTAGCCTTTCAAAAATCAATGCATTCGATCAGTGGTTTGACTTTA $\begin{array}{lllllllllllllllllllll}\text { E } & \text { S } & \text { K } & \text { M } & \text { F } & \text { V } & \text { A } & \text { F } & \text { Q } & \text { K } & \text { S } & \text { M } & \text { H } & \text { S } & \text { I } & \text { S } & \text { G } & \text { L } & \text { T } & \text { L } & 753\end{array}$

2372 TATGAGATGCAAATGAACGGACTCGGTAAAAGAAAGCTAATTAGGGAAGGATTAATTGGT $\begin{array}{lllllllllllllllllllll}Y & E & M & Q & M & N & G & L & G & K & R & K & L & I & R & E & G & L & I & G & 773\end{array}$

2432 CCACAATTACCAATGTACTATGACAGAGATAGTAAAACACTTTTTGTGAGTGATTTGCTC $\begin{array}{lllllllllllllllllllll}P & Q & L & P & M & Y & Y & D & R & D & S & K & T & L & F & V & S & D & L & L & 793\end{array}$

2492 CCAGGTTACATTTACTCGCATTCGGCCCAAGACACGCGTATACTTCGTTCTGGACTAAAG $\begin{array}{llllllllllllllllllllll}P & G & Y & I & Y & S & H & S & A & Q & D & T & R & I & L & R & S & G & L & K & 813\end{array}$

2552 AGCCCCCACAGTCTTACTGTCGCCGGCGACAATCTTTTCTGGATCGAATCACAGAATAAA $\begin{array}{lllllllllllllllllllll}S & P & H & S & L & T & V & A & G & D & N & \text { L } & F & \text { W } & \text { I } & \text { E } & \text { S } & Q & \text { N } & \text { K } & 833\end{array}$

2612 TTATACTCGACAAATTTTAGAACAGCCTCTGTAAAACAGAAGACTGTTGAGTTTGATCTC $\begin{array}{lllllllllllllllllllll}L & \text { Y................. } & F & R & \text { T } & \text { A } & \text { S } & \text { V } & \text { K } & Q & \text { K } & \text { T } & \text { V } & \text { E } & \text { F } & \text { D } & \text { L } & 853\end{array}$

2672 TCTAAATTAAACGATAATATGACATCTTTACCTGGTCATTTGACACCTTATTCACGCGAT $\begin{array}{lllllllllllllllllllll}S & K & \text { L } & N & D & N & M & \text { T } & \text { S } & \text { L } & \text { P } & \text { G } & \text { H } & \text { L } & \text { T } & \text { P } & \text { Y } & \text { S } & \text { R } & \text { D } & 873\end{array}$

2732 GCACAGTATGTGGTAACTCTGCGCAAAGATGATATACCAAAGCACGATTGTCAGAAAAAT $\begin{array}{lllllllllllllllllllll}A & Q & Y & V & V & T & L & R & K & D & D & I & P & K & H & D & C & Q & K & N & 893\end{array}$

2792 AATGGAAATTGTTCACACGTGTGTTTGCCTTCTCTTATTACTTCATTTATCTGTGCTTGT $\begin{array}{lllllllllllllllllllllll}N & G & N & C & S & H & V & C & L & P & S & L & I & T & S & F & I & C & A & C & 913\end{array}$ 2852 CCTCCTGGAATGGAACTATCAAATGATAATCGTACATGCATTTCGCATCATGAATGTTCT $\begin{array}{llllllllllllllllllllll}P & P & G & M & E & L & S & N & D & N & R & T & C & I & S & H & H & E & C & S & 933\end{array}$

Fig. 3-1. Continued. 
2912 AAGAACGAATATAAATGTAGCGAGCACAACATCTGCATACAAAGAAACCAATTGTGTGAT $\begin{array}{lllllllllllllllllllll}K & N & E & Y & K & \underline{C} & S & E & H & N & I & \underline{C} & I & Q & R & N & Q & L & \underline{C} & D & 953\end{array}$

2972 GGCATCGAAAATTGCC CGAACGGTGAAGACGAAĀCGAGTGAATGCAGAATAAAA $\overline{\mathrm{C}}$ GAAGA

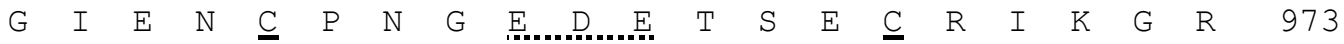

3032 TGCAAGGAAAATCAGTTCATGTGTAAAAATGGGGACTGCATCĀGGTTAAAAGATCGTTGT $\begin{array}{lllllllllllllllllllll}\underline{C} & K & E & N & Q & F & M & \underline{C} & K & N & G & D & \underline{C} & I & R & L & K & D & R & \underline{C} & 993\end{array}$

3092 ÄACTCGCGTTACGATTGTACCĞATCAATCGGACGAGCAGAACTGCGAGAAACCGAAAT $\bar{T}$

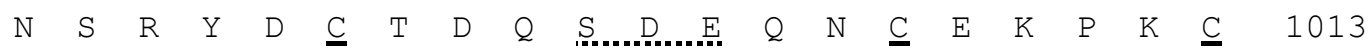

3152 AAAAGTGATGAATTTCAATGTAAATTTACTGAGÄ TTGCATAC̄CGAAGACCAAAATGT̄GC $\begin{array}{lllllllllllllllllllll}K & S & D & E & F & Q & \underline{C} & K & F & T & E & T & \underline{C} & I & P & K & T & K & M & \underline{C} & 1033\end{array}$

3212 GACAGCAATCCTGATTGTĞACGATTTAAGTGATGAGGAAGATTGCAGGAAAGTAGAGTG $\begin{array}{lllllllllllllllllllll}D & S & N & P & D & \underline{C} & D & D & L & \underline{S} & . . . . . . . E & E & D & \underline{C} & R & K & V & E & \underline{C} & 1053\end{array}$

3272 ACTTCAAACGAATTCĀAGTGCAACAATGGTAAATGCATTCCAĀACACATTTGTATGCĞAC $\begin{array}{llllllllllllllllllllll}T & S & N & E & F & K & \underline{C} & N & N & G & K & \underline{C} & I & P & N & T & F & V & \underline{C} & D & 1073\end{array}$

3332 AACGATAACGATTGTGAGĞATGGAGAGGATGAAĞCAGCCGAGAAATGTTACTCA ĀAGATA

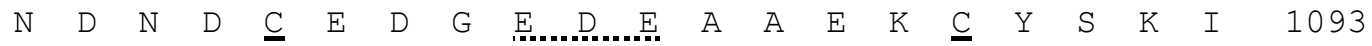

3392 GCATGTAAAATGC̄CTAAGATGTTTAAGTGCCCAAATGGTGATTGTÁTAAGTGACTCGTTA $\begin{array}{lllllllllllllllllllll}A & \underline{C} & K & M & P & K & M & F & K & \underline{C} & P & N & G & D & \underline{C} & I & S & D & S & L & 1113\end{array}$

3452 TTATGCAATGGCATAAACGATTGCAACGATGGTAGCGATGAGGTGCACTGCTTAAGTAAT

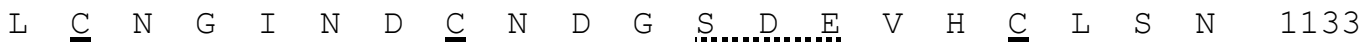

3512 GTAĀCAACTCATTTGGTTAATT̄GCAGTTTAAATGAATATCGGTGTCTCĞGCACTGATATA $\begin{array}{lllllllllllllllllllll}V & \text { T } & \text { T } & \text { H } & \text { L } & \text { V } & \text { N } & \underline{C} & \text { S } & \text { L } & \text { N } & \text { E } & \text { Y } & R & \underline{C} & \text { L } & G & \text { T } & \text { D } & \text { I } & 1153\end{array}$

3572 TGTCTTCCAAAAAATGTAAGATGCGACGGCAAAAATGATTGTC CGCAATCAGATGACGAG

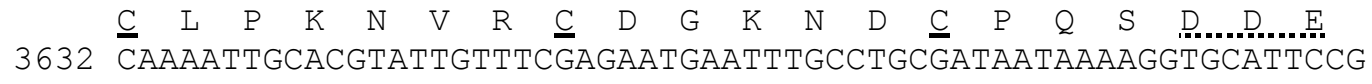
$\begin{array}{lllllllllllllllllllll}Q & N & C & T & Y & \underline{C} & F & E & N & E & F & A & \underline{C} & D & N & K & R & \underline{C} & I & P & 1193\end{array}$

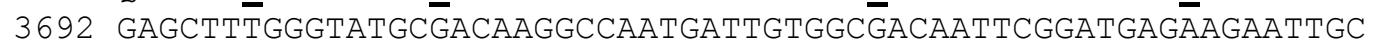
$\begin{array}{llllllllllllllllllllll}E & L & W & V & \underline{C} & D & K & A & N & D & \underline{C} & G & D & N & \text { S.......... } & K & N & \underline{C} & 1213\end{array}$

3752 GATGGCAGTAAĀ̄GGAACTTCATCGAATCTĀACGAATGTGATGAATTTÄAATGTTCTĞTC $\begin{array}{lllllllllllllllllllll}D & G & S & K & R & N & F & I & E & S & N & E & \underline{C} & D & E & F & K & \underline{C} & S & V & 1233\end{array}$

3812 GGCACTTGTTTGCCGTACAGCAAAGTATGCGACGGTÄATCGAGACTGTCCAĞATGGCAGC

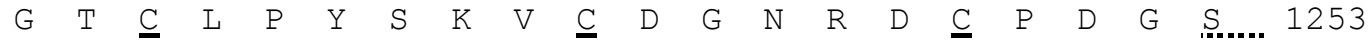

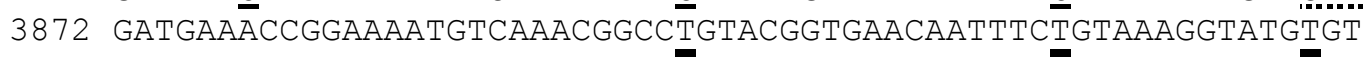

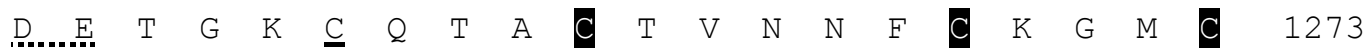

3932 TACAAGACACCAGCAGGCGCAGTTTGCGGATGTCAATCAGGATATCGCTTAGCTGTCGAC $\begin{array}{llllllllllllllllllllll}Y & K & T & P & A & G & A & V & C & G & C & Q & S & G & Y & R & L & A & V & D & 1293\end{array}$

3992 ATGATTTCCTGCGAGGACATAAATGAATGCGAATTAGATATTTGTTCGCAAATGTGTCGG $\begin{array}{lllllllllllllllllllll}M & I & S & C & E & D & I & N & E & C & E & L & D & I & C & S & Q & M & C & R & 1313\end{array}$ 4052 AACACTATAGGCTCTTACGAGTGTTTCTGTAAAGACGAATTTATTATTCGCAACGATAAA $\begin{array}{llllllllllllllllllllll}\mathrm{N} & \mathrm{T} & \mathrm{I} & \mathrm{G} & \mathrm{S} & \mathrm{Y} & \mathrm{E} & \mathrm{C} & \mathrm{F} & \mathrm{C} & \mathrm{K} & \mathrm{D} & \mathrm{E} & \mathrm{F} & \mathrm{I} & \mathrm{I} & \mathrm{R} & \mathrm{N} & \mathrm{D} & \mathrm{K} & 1333\end{array}$

4112 ACCTCTTGCAAAGCTGTCGGGCCGGCAATGGAATTTATCACTGTTACTGATAATGATATT $\begin{array}{lllllllllllllllllllll}T & S & C & K & A & V & G & P & A & M & E & F & I & T & V & T & D & N & D & I & 1353\end{array}$

4172 AGGAAGATGACGCACAATTTACATTCAACTACTCAATTACTCTTTCCGTTAATGGGCGTA $\begin{array}{lllllllllllllllllllll}R & K & M & \text { T } & \text { H } & \text { N } & \text { L } & \text { H } & S & \text { T } & \text { T } & \text { Q } & \text { L } & \text { L } & \text { F } & \text { P } & \text { L } & M & G & \text { V } & 1373\end{array}$

4232 AgAGTAAGTGGTCTCGACGTGAACGCAGTCAGTGATTCTGTTTATTGGAGTAATGATGAA $\begin{array}{lllllllllllllllllllll}R & V & S & G & \text { L } & D & V & N & A & \text { V } & \text { S } & \text { D } & \text { S } & \text { V } & \text { Y } & \text { W } & \text { S } & \text { N } & \text { D } & \text { E } & 1393\end{array}$

4292 TTCGGCACTATTAAAAAACTCAACATTAGAACGAATGAAATAGTGACAGTTAAAATTGTC

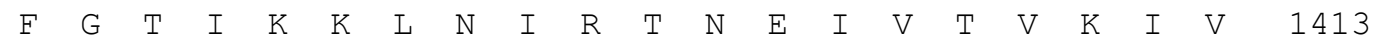

4352 GAGCATCCACAGGCACTCGCGGTTGATTGGATTACTGGTAACGTCTACGTCAATGATAAT

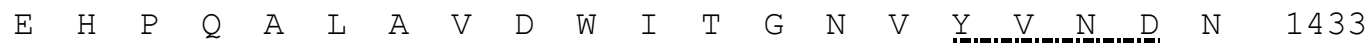
4412 AgCCATCTGAATACGATTAAgGTATGCAATTTGGAGAAAGGAAAATGTGCGACGCTTGTT $\begin{array}{lllllllllllllllllllll}S & H & L & N & \text { T } & I & K & \text { V } & C & \text { N } & \text { L } & \text { E } & \text { K } & \text { G } & \text { K } & \text { C } & \text { A } & \text { T } & \text { L } & \text { V } & 1453\end{array}$

Fig. 3-1. Continued. 
4472 AAAATACAGGATAAAATGAAAGTGGCGTCCGTCATAGTTGATTCGATTAACAGATGGTTA $\begin{array}{lllllllllllllllllllll}K & I & Q & D & K & M & K & V & A & S & \text { V } & \text { I } & \text { V } & \text { D } & \text { S } & \text { I } & \text { N } & \text { R } & \text { W } & \text { L } & 1473\end{array}$

4532 TTCTGGGCTGAAATATCTTTGGAGGCAGATCATCCAACCAGCAAAATATGTCGAACAGAT

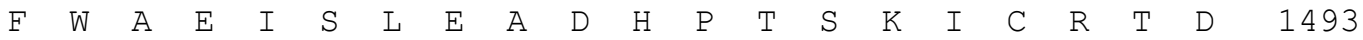

4592 ATGACGGGTGCTGACATGAAGATTATTGCTTCCGATCTGGGTTTTGTGAGAGGAATGACA $\begin{array}{lllllllllllllllllllll}M & T & G & A & D & M & K & I & I & A & S & D & L & G & F & V & R & G & M & T & 1513\end{array}$ 4652 ATCGATCATGTAAAATCTAAATTATATTGGTCGGACGATTTCTATAAAACCGTCGAGTCA $\begin{array}{lllllllllllllllllllll}I & D & H & V & K & S & K & L & Y & . W & S & D & D & F & Y & K & T & V & E & S & 1533\end{array}$

4712 TCTAATTTTGATGGAAGTCAACGCAAAGTGGTCTTAACTTTAAATATGAATCACGCGTTA $\begin{array}{lllllllllllllllllllll}S & N & F & D & G & S & Q & R & K & \text { V } & \text { V } & \text { L } & \text { T } & \text { L } & \text { N } & \text { M } & \text { N } & \text { H } & \text { A } & \text { L } & 1553\end{array}$

4772 AgCATTAGTATTTTTGAACAgTCTCTTTATTTTTTGAGTTCGGACAATCTACTAAGCAGC $\begin{array}{lllllllllllllllllllll}S & I & S & I & F & E & \mathcal{Q} & S & \text { L } & Y & F & \text { L } & \text { S } & \text { S } & \text { D } & \text { N } & \text { L } & \text { L } & \text { S } & \text { S } & 1573\end{array}$

4832 TGTAAGATGTACGGTAAAAGATCGTGTGAACACGTAAACATAGGCGCAAATAATGTTTTC $\begin{array}{lllllllllllllllllllll}C & K & M & Y & G & K & R & S & C & E & H & V & N & I & G & A & N & N & V & F & 1593\end{array}$

4892 AgGCTCTTCTCCATTCTTCATATTTCCAGACAGGTACCTTTCGCTAATCCTTGCGATGCA $\begin{array}{lllllllllllllllllllll}R & L & F & S & I & L & H & I & S & R & Q & V & P & F & A & N & P & C & D & A & 1613\end{array}$

4952 GAGTATTGCGATTATATGTGTGTTTTAAAGAAGGAGAACGCAACGTGCATTTGTTCAGAT $\begin{array}{lllllllllllllllllllll}E & Y & C & D & Y & M & C & V & L & K & K & E & N & A & T & C & I & C & S & D & 1633\end{array}$

5012 GGTGAATCAATAGAATCCAATAGCACGTGCAACATAAAAAATGACCTCAAATTTGTTGAA $\begin{array}{lllllllllllllllllllll}G & E & S & I & E & S & N & S & T & C & N & I & K & N & D & L & K & F & V & E & 1653\end{array}$

5072 AgCATTAATTTCTCGAGAAATACACGGAACATAAGCGGCATTTATAGCATAACCATAATC $\begin{array}{lllllllllllllllllllll}S & I & N & F & S & R & N & T & R & N & I & S & G & I & Y & S & I & T & I & I & 1673\end{array}$

5132 GTATTATTGGTTAGTGTTCTGTTATTATGCGTTTACTATTACTATCAGAAAAACAAATTA $\begin{array}{lllllllllllllllllllll}V & \text { L } & \text { L } & \text { V } & \text { S } & \text { V } & \text { L } & \text { L } & \text { L } & \text { C } & \text { V } & \text { Y } & \text { Y } & \text { Y } & \text { Y } & \text { Q } & \text { K } & \text { N } & \text { K } & \text { L } & 1693\end{array}$

5192 AAGTCGAAGCCAGCGAGCAATCTTAGTTGCAGCAGCATTCACTTCCAAAATCCGTCGTAC $\begin{array}{lllllllllllllllllllll}K & S & K & P & A & S & N & L & S & C & S & S & I & H & F & Q & \mathbf{N} & \mathbf{P} & \mathbf{S} & \mathbf{Y} & 1713\end{array}$

5252 GATCGAAGCGATGAAATTGAAGTAATGCTTGACTCCATGGCTTCTTCTGAATTATCTCCC $\begin{array}{lllllllllllllllllllll}D & R & S & D & E & I & E & V & M & \text { L } & D & S & M & A & S & S & E & L & S & P & 1733\end{array}$

5312 GGACAGCACGAATATATTAATCCTATTAACAATAAAGGTATGAAGGCTGCNGAAAATAAT $\begin{array}{lllllllllllllllllllll}G & Q & H & E & Y & I & N & P & I & N & N & K & G & M & K & A & A & E & N & N & 1753\end{array}$

5372 GCAAAGAAATCAAATCAATGCTCGGAGGGAAAGAATATTGAAGAGGAAAAACAGGATGCG $\begin{array}{lllllllllllllllllllll}A & K & K & S & N & Q & C & S & E & G & K & N & I & E & E & E & K & Q & D & A & 1773\end{array}$ 5432 TTAATTTATTTTGTACATAATTCAAAATAATTCAATTACAGTCGAAGAAATATCACAAAA

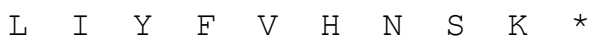

5492 ATTAATATTCAAATTGAATTTAAAATTAGTCAAATTTAAATTTAAAATTAGTCAACAAAA 5552 CCTTTTATGTGACGTTAGAAAATTTCTTACTATTTTGTATCATAAATTTCAAGACGTTGT 5612 TGGTGAATGTGTGCCTATAAATGCAATATATACATAAATATTGATATATGTAACTCAATA 5672 ATTTAGACATATTTGATCACTACGAAATCAAATGGGTTACAAAATGAACTATGATCTATG 5732 TCAAATATTTCCTATGCACGATCACTTATCTTT

Fig. 3-1. Continued. 
potential 54 sites, and there are $15 \mathrm{Thr}$ and $24 \mathrm{Tyr}$ potential phosphorylation sites. However, there are no predicted Tyr sulfation sites.

Analyses of the deduced amino acid sequence for $\mathrm{SiVgR}$ indicated that it was a member of the LDLR superfamily. Like other members of the LDLR superfamily, the $\mathrm{SiVgR}$ was characterized by a highly conserved arrangement of modular elements (Fig. 3-2, 3-4). SiVgR exhibited two ligand-binding domains with four Class A cysteine-rich repeats in the first domain and eight repeats in the second domain. Each repeat contained six cysteine residues and a conserved acidic residue region, SDE, required for ligand binding. Each ligand-binding domain was followed by EGF precursor homology domains (Fig. 3-2). A hydrophobic region representing a transmembrane domain was found at amino acid residues 1668-1690. In the cytoplasmic region, there was a signal sequence, NPSY, for receptor internalization (Goldstein et al., 1985; Chen et al., 1990) (Fig. 3-1).

The deduced amino acid sequence of $S i \mathrm{VgR}$ was aligned with the other two insect VgRs, $A a \mathrm{VgR}$ and $D m$ YPR (Fig. 3-2, 3-3). The deduced amino acid sequence of SiVgR showed $35 \%$ identity and $52 \%$ similarity to $\mathrm{AaVgR} ; 31 \%$ identity and $48 \%$ similarity to DmYPR. Percentages of identity and similarity were also assessed between different modular domains (Fig. 3-2).

The $S i \mathrm{VgR}$ differed structurally from the $A a \mathrm{VgR}$ and $D m \mathrm{YPR}$ in the first ligand binding domain and the cytoplasmic tail. SiVgR contains four Class A cysteine-rich repeats in the first ligand-binding domain rather than the five repeats that are found in $A a \mathrm{VgR}$ and $D m$ YPR (Fig. 3-2). In order to confirm that only four Class A cystine-rich repeats occur in the SiVgR, the 5' end of $S i \mathrm{VgR}$ cDNA was performed twice by 5' 


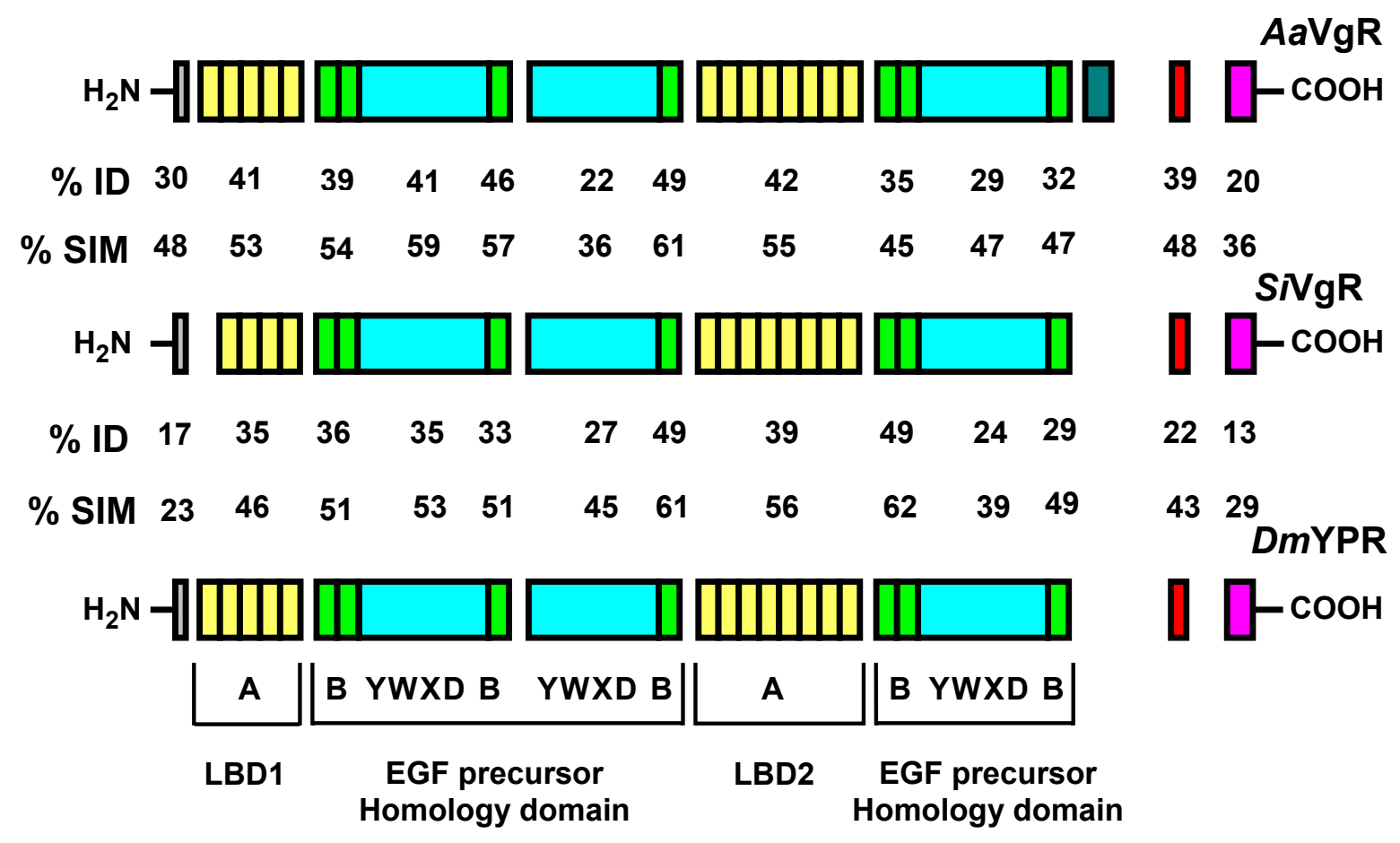

Fig. 3-2. The arrangement of modular domains for insect VgRs and the schematic alignment of $S i \mathrm{VgR}$ modular domains with those of $A a \mathrm{VgR}$ and $\mathrm{Dm}$ YPR. Pairwise alignment was performed with EMBOSS Pairwise Alignment Algorithms of EBI.

】 signal peptide (SP); Class A cysteine-rich repeat (A); Class B cysteine-rich repeat (B); $\square$ YWXD repeat; $\square$ O-linked sugar domain ( $\mathrm{AaVgR}$ only);

$\square$ transmembrane domain; $\square$ cytoplasmic tail. $\mathrm{LBD}=$ ligand binding domain; the epidermal growth factor (EGF) precursor homology domain contains Class B cysteine-rich repeats and YWXD repeats; $\% \mathrm{ID}=$ percent identity; $\% \mathrm{SIM}=$ percent similarity. 


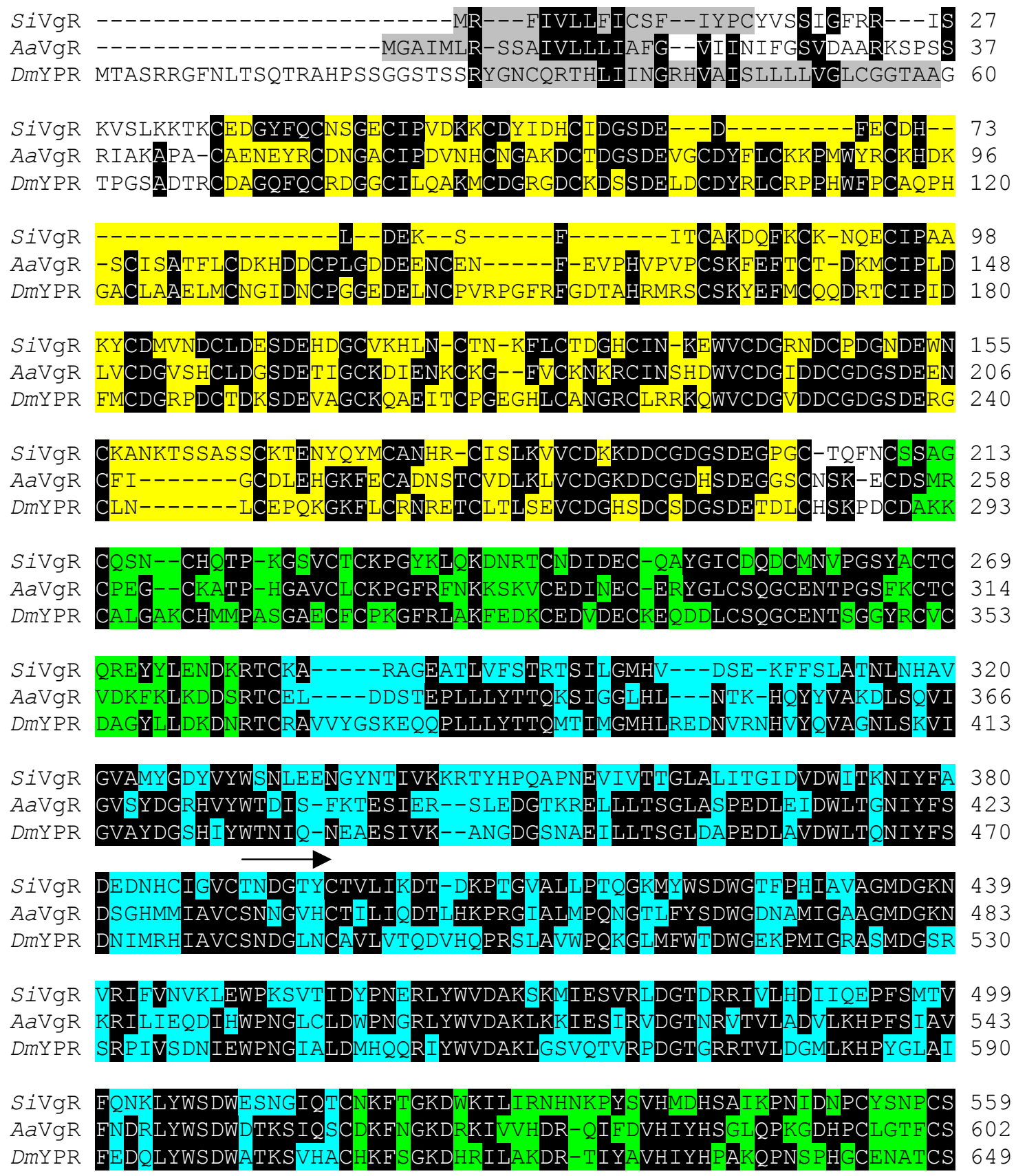

Fig. 3-3. Alignment of deduced amino acid sequence of $S i \mathrm{VgR}, A a \mathrm{VgR}$ and $D m \mathrm{YPR}$. Black boxes denote identical amino acids. Gray boxes indicate the signal peptide sequence. Yellow boxes indicate the ligand binding domains. Green boxes indicate the class B cysteine-rich repeats. Blue boxes indicate the YWXD repeats. The teal box indicates the O-linked sugar domain in $A a \mathrm{VgR}$ only. Red boxes indicate the transmembrane region. Pink boxes indicate the cytoplasmic tail. The color of boxes is consistent with that in Fig. 3-2. The two over-arrows indicate forward and reverse primers using for semi-QRT-PCR in Chapter V. 
SiVgR QLCMLNONKG--YTCGCTLDKKLNADKHTCODVKKNQHLLIIOGRKF INYYHEFLGKPKV 617 AaVgR HLCLLAPNDS--YSCACPYGMSLKADKHSCRETVKRQYLLVGIANYLVTLETQTFG---- 656 DMYPR HLCLLAEPEIGGHSCACPDGMRLAPDHRRCMLMEKRQRLFIGLGQVLLE IEHTAFG---- 705

SiVgR MTLSLQHMSQQS--YNNLVN-IISDPLSGQI I ICHLQLSTPELTSTTDILRYDPVHHSSE 674 AaVgR -- --RHESSQADAYQ I FFHRMA ENS IT GEIFVAD-------NRQKAIFTVDPKTKSSQ 703 DMYPR -----AHQVSKSYTLPCLINEMVYNRINGS I I IAD-------NDQRLILEFQPESHESN 752

SIVgR KIVTINK-IFFELAFDYIGNNLYTTNTVNQSIEVININT--KAMTAFYFKDEVPKYIALA 731 AaVgR KLITTGIGNISALAFDFLGNNLYWTDSERSTVEVFSLQTRHRAI LQHYLGQDIPVGLAIV 763 DMYPR VLVRSNLGNVSALAFDHLSRNLYWADTERAVIEVLSLQTRHRALIREFPGQEVPIGLTVM 812

SiVgR PEESKMFVAFQKSM---HSISGLTLYEMQMNGLGKR-KLIREGIIG-PQLPMYYDRDSKT 786 AaVgR SEMGKMFIALRSPLPVPHTH----IDRLDMTGRGPHLHVIEERLSGNGS FNFVIDRDLRT 819 DMYPR PAEGYLYVVLKAKR---HSH----IDKIPLSGKGEQVHVFEDDL-GDDDIKLVTDYETQT 864

SiVgR LFVSDLLPGYI-YS-HSAQDTRILRSGLKSPHSLTVAGDNLFWIESQN-KLYSTNFRTAS 843 AaVgR VYWNDMGSSKIEFTSYEGDTRHLFREFLRLPVSIAIVGDSIFWTCYRSKRLYWSDKHNLG 879 DMYPR IFWSDSDLGRISYSNYRVPHSQIFRGKLRRPYSLAMVHHDLFWNELGTPRIYWTHKSNMG 924

SIVgR VKQKTVEFDLSKLNDNMTSLPGHLTPYS--RDAQYVVTLRKDDIPK--HDCQKNNGNCSH 899 AaVgR VTKK---ITI---DK-----P----PYG--AFPDEIVLIGSQPLQRYDHPCMKQNGGCSH 922 DMYPR PRKV---IDIMEKDD-----PAAIMPYVPVATPNGIPLAAS SPVGQESHPCQQQNGGCSH 976

SIVgR VCLPSLITSEICACPPGMELSN-DNRTCISHHECSKNEYKCSEHNICIQRNNLCDGIENC 958 AaVgR ICVPAGMYSSACICPTGMI FSS PKNTTCIDAIDC---EFKCTSG-ECLTISKRCNGNKDC 978 DMYPR ICVGEGPYHS ICLCPAGFVYRDAGNRTCVEALDC---EFRCHSG-ECLTMNHRCNGRRDC 1032

SiVgR PNGEDETSECRIKGR------CKENQFMCKNGD-CIRLKDRCNSRYDCTDQSDEQNCEK- 1010 AaVgR ADGSDEK-GCDEAGQPK-QLHCQYDEFMCADKSKCIDQTRRCDEHVDCGDGSDEMKCEGY 1036 DMYPR VDNSDEM-NCDEEHRHKPKVLCSPSQFACHSGEQCVDKERRCDNRKDCHDHSDEQHCEKF 1091

SiVgR ---PKCKSDEFQCKFTETCIPKTKMCDSNPDCDDLSDEEDCRKVE--------CTSNEFK 1059 AaVgR DRGTGCHEHQHACP-DGMCIDVNTLCDGFPDCLDGSDEVGCTDLTNEKSNATTCGPLMFR 1095 DMYPR DKSKKCHVHQHGCD-NGKCVDSSLVCDGTNDCGDNSDELLCEATLR-------CEPGMFQ 1143

SiVgR CNNGKCIPNTFVCDNDNDCEDGEDEAAEKCYSKIACKMPKMFKCPNGDCISDSLLCNGIN 1119 AaVgR CNMGQCIPKWWECDGNPDCTDGSDE-HDKCLTKTDCG-AGFTKCALGHCIEDRLLCDGNN 1153 DMYPR CGSGSCIAGSWECDGRIDCSDGSDE-HDKCVHRS-CP-PDMHRCLSGOCLDRSLVCDGHN 1200

SiVgR DCNDGSDEVHCLSNVTTHLVNCSLN---EYRCLGT-DICLPKNVRCDGKNDCPQSDDEQN 1175 AaVgR DCGDNSDELNCKVELEPC-VGLEDDNPTKYLCPRSGK-CLDIAVRCNGTAECPDGEDEAG 1211 DMYPR DCGDKSDELNCGTDSSTMNISCAED---QYOCTSNLKICLPSAVRCNGTTECPRGEDEAD 1257

SiVgR CTY-CFENEFACDNKR-CIPELWVVCDKANDCGDNSDEKNCDG-SKRNFIESN-E------ 1225 AaVgR CSN-CGLQEFQCKSGK-CIRKEWRCDKEVDCDDGSDEVDCVNGTAAEHLEVHVA------ 1263 DMYPR CGDVCSIYEFKCRSGRECIRREFRCDGQKDCGDGSDELSCEL-EKGHHNQSQIQPWSTSS 1316 SiVgR --CDE--FKCSVGTCLPYSKVCDGNRDCPDGSDETGKCOTACT---VNNECKGMCYKTPA 1278
AaVgR --CGEGTECKPGVCIEMSOVCNGKKDCDDGKDEGKGCDDAC----AKSPCEHKCIKTPT 1317
DMYPR RSCRPHLEDCQDGECVDLSRVCNNF PDCTNGHDEGPKATACRSASGRQVCOHKCRATPA 1376

Fig. 3-3. Continued. 
SiVgR GAVCGCOSGYRLAVDMISCEDINEC-ELDICSQMCRNTIGSYECFCKDEFIIRNDKTSCK 1337

AaVgR GAICECREGFTLAPNKKSCLDVDECAEGRPCAQQCRNTFGSYRCSCNPGFMLRSDKISCK 1377 DMYPR GAVCSCFDGYRLDADQKSCLDIDECQEQQPCAQLCENTLGGYQCQCHADFMLRQDRVSCK 1436

SiVgR AVGPAMEFITVTDNDIRKMTHNLHSTTQLLFPLMGVRVSGLDVNAVSDSVYWSNDEFGTI 1397 AaVgR AVGPSRYVLYTSYNQIRKLEVN-PPSIRILMQANGSRITSMDVDIRRQMLYFTDEYNPVI 1436 DMYPR SLQSGATLLFSSFNEVRNLSEQ-PVMLNVAWSANDSRITGFDLAMHRQMGYFSAEDEGIV 1495

SIVGR KKLNIRTNEIVTVKIVEHPQALAVDWITGNVYVNDNSHLNTIKVCNLEKGKCATLVKIQD 1457 AaVgR YEHDMERNTTHVLYNVGHPEHLAVDWITGNVYFYDRSEP-SIKLCSVQRQLCSRIITFAS 1495 DMYPR YQVDLQTKVIVRALGLPAPTKLSVDWVTGNVYVLSGAQ--EIQACSFVGRMCGRIVHVKS 1553

SiVgR KMKVASVIVDSINRWLFWAEISLEA-DHPTSKICRTDMTGADM-KIIASDLGEVRGMTID 1515 AaVgR QVFVKAVVVDPVNRILFYS LMHFWIFQVPHSI IYRADMDGQNQ-LVITKDVSHVTSIQVD 1554 DMYPR PRHVKHLAVDGYHARIFYIVIRTEGYGQTSSEIHMARLDGSRRDMLLQRSESFMTALTTD 1613

SiVgR HVKSKLYWSDDFYKTVESSNFDGSQ---R--KVVLTLN--MNHALS IS IEEQSLYELS-S 1568 AaVgR TENKLLYIADISSRTINALDYEGKK--LR--TVIENQNLAVSKPIGIMIYENQALVLNMA 1610 DMYPR PHQQLLYFVDQHMRTLERISYRLKTGPMRRPE IMLQKSNALMHPSGLSVYENNAFIVNLG 1673

SIVgR DNLLSSCKMYGKRSCEHVNIGANNVFRLFSILHISRQVP-FANPC--DAEYCDYMCVLKK 1625 AaVgR SSTVGQCKLYGDFECRLMELNVHNSNQLL-IVQESRQPE-AENVCDTKQINCSHVCVPGA 1668 DMYPR SMEAVQCALYGSRICHKISINVLNAQDIV-VAGRSRQPQKASHPC--AHAHCHGLCLQAD 1730

SiVgR ENA-TCICSDGESIESNSTC-----NIKNDLKEVESINFS----RNTRNISGIYSIT--I 1672 AaVgR DGHGVCICHNGERIHGTDICPQTS-NVMTPLVKTHLGEAAPNVHDSSDESSTGSTIANVF 1727 DMYPR YGY-ECMCGNRLVAEG-ERCPHGSGNEVAVLGAVNSLELE---HEHEQNGHFHWLMA--L 1783

SiVgR IVLLVSVLLLCVYY-YYQKNKLKSKPASNLSCSS IHFQNP---------SYDRSDE-- 1718 AaVgR LVLLILALVGVAG--GYI---YRRRYQHKEDIG-MHFHNP----------ELSTADA-- 1768 DMYPR EVLAAGSLIAGLGYMYYQ---YRQRGHTDLNIN-MHFQNPLATLGGTKAFLEHERAEAGV 1839

SiVgR ---IEV-------------------ML-----DSMASSELSPGQH----EYIN- 1740 AaVgR ---AEV-------------------KMF-----QKVPRLNQTTTHN----ELTLE 1792 DMYPR GFTTETGTVSSRGSNDTFTTTSASSSFAAQQESVPNALQRLLRPRQSASGDPMAQELLLE 1899

SiVgR -PINNKGMKAAENNAKKSNQ----CSEGKNIE-----EEKQDALIYF----------VHN 1780 AaVgR TPPHRPPCQG-DPNSSESTGQNNVTSTALELENMSDVDSMEDAYDCR--------DDPL 1842 DMYPR SPSRESKLHALDGGGAGGDG-DGGCGVGRQVPDILVADMDDDAAKSAGQFGGNYAGNDAN 1958

SiVgR SK--- 1782

AaVgR QRLIL 1847

DMYPR ARFVS 1963

Fig. 3-3. Continued. 
RACE and that produced several clones containing a $>420$ base-pair region of overlap between 5' RACE clones and the $2.3 \mathrm{~kb}$ fragment. All clones showed the same sequence. Therefore, it is likely that $\mathrm{SiVgR}$ contains only four Class A cysteine-rich repeats in the first ligand-binding domain instead of the five reported for the mosquito and fruit fly receptors. The $S i \mathrm{VgR}$ contained the typical LDLR internalization signal, NPSY, in the cytoplasmic tail, but both dipteran VgRs contain di-leucine or leucineisoleucine motifs which are also identified as internalization signals in some receptors (Letourneur and Klausner, 1992; Dittrich et al., 1994; Sappington et al., 1996) (Fig. 33).

Si VgR and DmYPR do not contain an O-linked sugar domain between the last Class B cysteine-rich repeat and the transmembrane, the consensus position for such regions in LDLR superfamily members, but $A a \mathrm{VgR}$ does. Sakai et al. (1994) reported two splicing forms of the human VLDLR, one of which lacked the O-linked sugar domain. The splicing variants happen in other vertebrate $\mathrm{VgR}$ also. The chicken $\mathrm{VgR}$ gene produces an oocyte-specific VgR without an O-linked sugar domain or a soma-specific variant containing a 30-residue O-linked region (Bujo et al., 1995b). Alternative splicing of the Xenopus VgR gene produces an ovary-specific VgR with an O-linked sugar domain or a brain variant that is $40 \mathrm{bp}$ shorter without an O-linked sugar domain (Okabayashi, et al., 1996). The rainbow trout VgR contains an O-linked sugar domain that is expressed in both the ovary and somatic tissues, whereas a VgR without an $\mathrm{O}$ linked sugar domain is ovary-specific (Prat, et al., 1998). The function of the O-linked sugar domain is not known and is not universal among LDLRs (Bujo et al., 1995b; Sappington and Raikhel, 1998). 
The size and structure of the SiVgR place it in between the LDLR/VLDLR groups with seven or eight Class A cyteine-rich repeats (such as chicken VgR), and the LRPs with 31 to 36 repeats, respectively (Fig. 2-3, 3-4). Thus, the insect VgRs form the intermediate size group in the LDLR superfamily.

\subsection{VgR phylogenetic analysis}

The SiVgR amino acid sequence was multiple-aligned with other fifteen LDLR superfamily members and the phylogram of sixteen LDLR supterfamily members was generated using the Clustal W computer program (Thompson et al., 1994). The result showed that all invertebrate VgRs including AaVgR, AgVgR, DmYPR, PaVgR, SiVgR and $\mathrm{CeVgR}$ formed a separate clade from vertebrate VgR and VLDLR (Fig. 3-5). The mosquito VLDLR (AaVLDLR) and the locust VLDLR (LmVLDLR) share 63\% amino acid identity (Dantuma et al., 1999; Cheon et al., 2001) and clustered the vertebrate VgRs and VLDLRs into a larger clade, but were distantly related to insect VgRs (Fig. 3-5). Four insect VgRs of AaVgR, AgVgR, DmYPR and PaVgR have LL or LI amino acid sequence in the cytoplasmic tail as an internalization signal (first four VgRs in Fig. 3-5). However, all the other receptor members in the Fig. 3-5 have the typical LDLR internalization signal, NPXY. It will be interesting to see what type of internalization signal the honey bee VgR contains since the honey bee and the fire ant are both eusocial insects.

The ancient origin of LRPs was revealed by the discovery of a nematode LRP (Yochem and Greenwald, 1993). As a corollary, the discovery suggests that the original LDLR superfamily progenitor arose in an acoelomate. This ancestral molecule may have been a large LRP-like receptor from which smaller LDLR superfamily members 


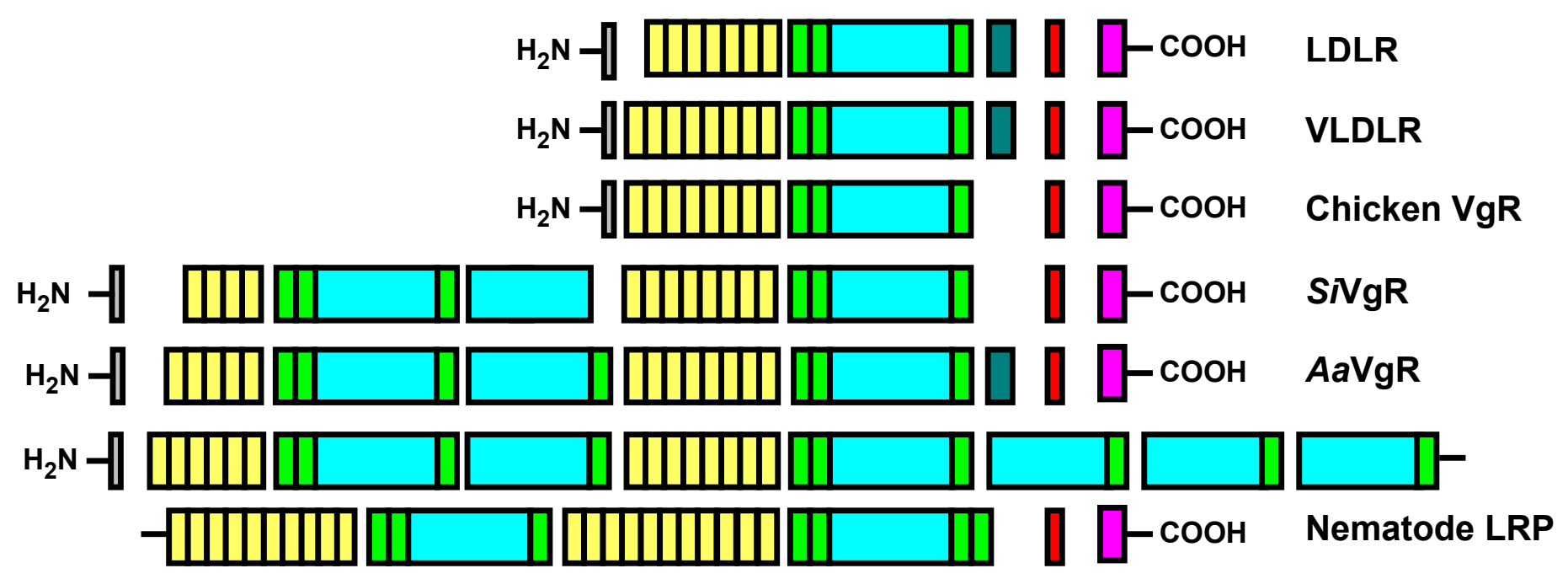

Fig 3-4. Schematic modular domain alignment among LDLR family members. Black boxes denote identical amino acids. Gray boxes indicate the signal peptide sequence. Yellow boxes indicate the ligand binding domains. Green boxes indicate the class B cysteine-rich repeats. Blue boxes indicate the YWXD repeats. The teal box indicates the O-linked sugar domain in $A a \mathrm{VgR}$ only. Red boxes indicate the transmembrane region. Pink boxes indicate the cytoplasmic tail. (for citations, see text). 


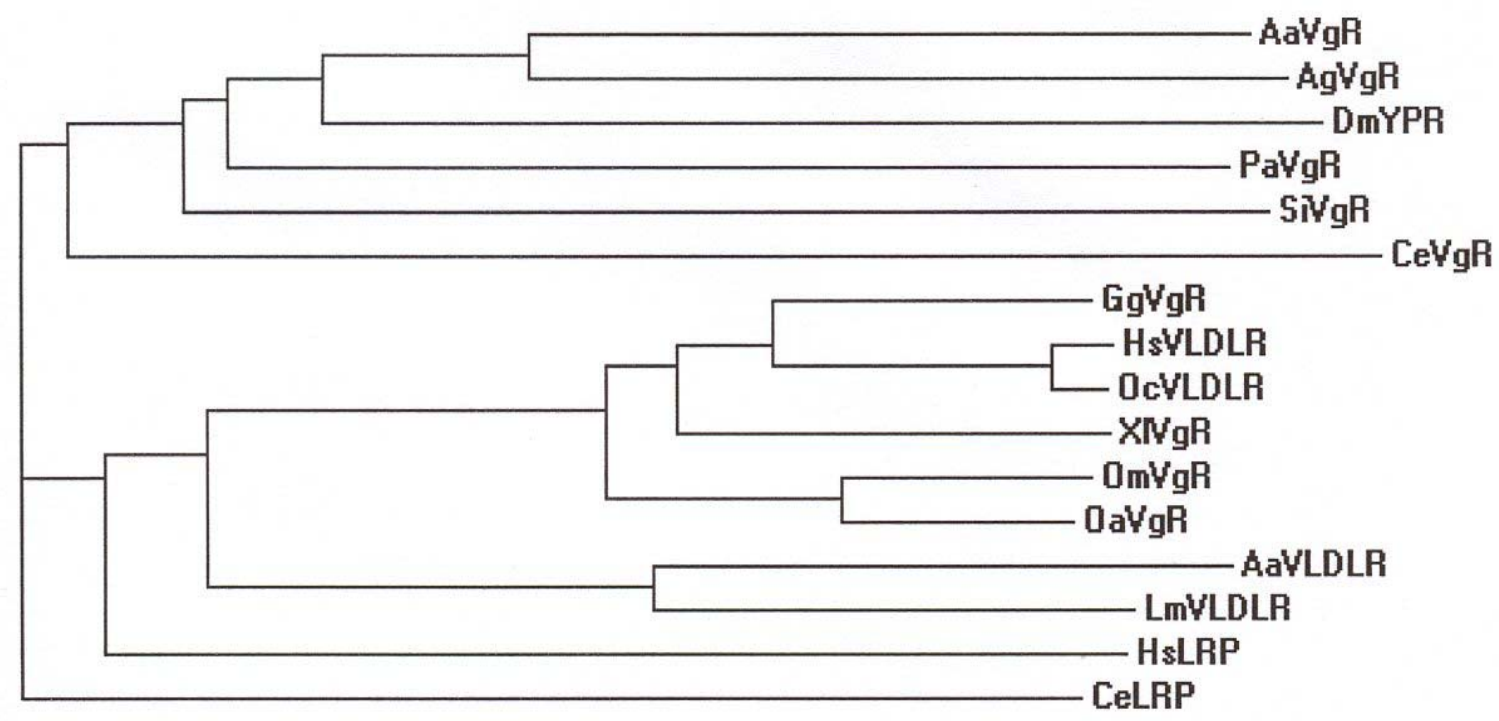

Fig. 3-5. The phylogram of sixteen LDLR superfamily members. The phylogram was generated based on amino acid seuquences alignment by the Clustal $\mathrm{W}$ computer program. $A a \mathrm{VgR}=$ mosquito (Aedes aegypti) $\mathrm{VgR}$ (vitellogenin receptor); $A g \mathrm{VgR}=$ mosquito (Anopheles gambiae) $\mathrm{VgR} ; D m \mathrm{YPR}=$ fruit fly (Drosophila melanogaster) $\mathrm{VgR} ; \mathrm{PaVgR}=$ roach (Periplaneta americana) $\mathrm{VgR} ; \mathrm{SiVgR}=$ fire ant (Solenopsis invicta) $\mathrm{VgR} ; \mathrm{Ce} \mathrm{VgR}=$ nematode (Caenorhabditis elegans) $\mathrm{VgR} ; \mathrm{GgVgR}=$ chicken (Gallus gallus) VgR; Hs VLDLR= human (Homo sapiens) VLDLR (very low-density lipoprotein receptor); OcVLDLR= rabbit (Oryctolagus cuniculus) VLDLR; XlVgR= frog (Xenopus laevis) VgR; Om $\mathrm{VgR}=$ rainbow trout (Oncorhynchus mykiss) VgR; $O a \mathrm{VgR}=$ fish (Oreochromis aureus) $\mathrm{VgR} ; A a \mathrm{VLDLR}=$ mosquito VLDLR; Lm VLDLR = locust (Locusta migratoria) $\mathrm{VLDLR} ; H_{s} \mathrm{LRP}=$ human LRP (LDLR Related Protein); $C e \mathrm{LRP}=$ nematode LRP 
are derived (Schonbaum, et al., 1995). Alternatively, it is hypothesized that vertebrate VgRs and VLDLR may represent primordial, multifunctional, yolk-protein precursor receptors from which more specialized receptors, such as LDLRs and LRPs, are derived (Hiesberger et al., 1995). Sappington et al. (1996) point to a third possibility that must be considered now, that the intermediate-sized insect VgRs represent the primordial type from which both the larger and smaller receptors are derived. 


\section{CHAPTER IV}

\section{LOCALIZATION OF THE FIRE ANT VITELLOGENIN RECEPTOR TRANSCRIPT}

\section{INTRODUCTION}

Accumulation of massive amounts of the extra-ovarian yolk protein precursor, vitellogenin (Vg), by developing oocytes during oogenesis is a characteristic phenomenon of all oviparous animals (Stifani et al., 1990; Raikhel and Dhadialla, 1992). Internalization of $\mathrm{Vg}$ by the oocyte is achieved through receptor-mediated endocytosis. Consequently, the properties of vitellogenin receptors (VgRs) are of great interest to developmental biologists and much effort has been put into their study in several species.

The presence of a specific VgR in the oocyte membrane has been demonstrated in a number of insect species through studies of Vg uptake by cultured ovaries. Biochemical characterization of a few $\mathrm{VgRs}$ has been accomplished through their progressive isolation from solubilized membrane extracts. In all the insect VgRs, binding of Vg was saturable; ovary specific; showed high Vg affinity and was sensitive to changes in $\mathrm{pH}$ and $\mathrm{Ca}^{2+}$ concentration (Ferenz and Lubzens, 1981; Rohrkasten and Ferenz, 1985; Oliveira et al., 1986; Osir and Law, 1986; Kulakosky and Telfer, 1987; Kindle et al., 1988; Konig et al., 1988; Koller et al., 1989). Finally, VgR cDNAs were cloned from the fruit fly, Drosophila menlogaster, the yellow-fever mosquito, Aedes aegypti 
(Schonbaum et al., 1995; Sappington et al., 1996) and the American cockroach, Periplaneta americana (accession number BAC02725).

To date, all cloned vertebrate and insect VgRs have shown that the VgR transcripts are expressed abundantly in ovaries. In this chapter, caste- and tissue-specific transcription of $\mathrm{SiVgR}$ are determined.

\section{MATERIALS AND METHODS}

\subsection{Insects}

S. invicta were reared as described in Chapter III.

\subsection{Northern Blot Analysis}

Total RNA was extracted for analysis of receptor transcript levels based on tissue, gender and caste specificities. To test the gender and caste specificity of the VgR gene expression, total RNA $(10 \mu \mathrm{g})$ was extracted from whole workers, the fat body of males and from the ovaries and fat body of mated queens and alate females. Tissue specificity of $\operatorname{VgR}$ gene expression was determined from total RNA $(10 \mu \mathrm{g})$ extracted from the head, flight muscle, midgut, fat body and ovary of alate virgin females. The RNA samples were electrophoresed in a $1.2 \%$ agarose gel containing $0.7 \mathrm{M}$ formaldehyde and $1 \mathrm{X}$ MOPS at $80 \mathrm{~V}$ for 90 min, then transferred to a positively charged nylon membrane (Hybond XL, Amersham Pharmacia, Piscataway, NJ) with 10X SSC as transfer buffer. The $\sim 500 \mathrm{bp}$ specific probe was prepared by digesting the $2.3 \mathrm{~kb}$ fragment with AcsI and HindII restriction enzymes and labeled with ${ }^{32} \mathrm{P}$. For labeling, 
the Ambion DECAprime II Random Priming DNA labeling kit (Ambion, Austin, TX) was used with $\alpha-{ }^{32} \mathrm{P}$ dCTP (specific activity $3000 \mathrm{Ci} / \mathrm{mmol}$, Perkin Elmer, Vellesley, MA) following the instructions manual. The membrane was hybridized with the ${ }^{32} \mathrm{P}$ labeled probe at concentrations of $1 \times 10^{6} \mathrm{cpm} / \mathrm{ml}$ of hybridization solution (Ultrahyb, Ambion, Austin, TX). Hybridization was performed at $42{ }^{\circ} \mathrm{C}$ for $16 \mathrm{~h}$. Following hybridization, the membrane was washed twice for $5 \mathrm{~min}$ at low stringency (2X SSC, $0.1 \%$ SDS) at $42{ }^{\circ} \mathrm{C}$ and twice for $15 \mathrm{~min}$ at high stringency (0.1X SSC, $0.1 \%$ SDS) at $65^{\circ} \mathrm{C}$. After washing to remove non-specific radioactivity, the membrane was exposed to X-ray film and developed.

\subsection{Reverse Transcription Polymerase Chain Reaction (RT-PCR)}

RT-PCR was used to determine tissue-specific transcription of SiVgR. Total RNA $(1 \mu \mathrm{g})$ was extracted from head, flight muscle, midgut, fat body and ovaries of alate virgin females and from male fat body and whole workers using the guanidinethiocyanate-phenol-chloroform method (Chomczynski and Sacchi, 1987; Puissant and Houdebine, 1990). The total RNA was provided as templates for the reverse transcription (RT) using oligo-d $\mathrm{T}_{16}$ primer with GeneAmp ${ }^{\circledR}$ RNA PCR core kit (Perkin Elmer, Wellesley, MA). PCR amplification of SiVgR cDNA was performed using primer set 2.3-13 (forward), 5'-CAAGGAAGAAAATTCATTAACTACTATCACG-3' and $2.3-7 \mathrm{R}$ (reverse), 5'-TAAGGTGTCAAATGACCAGG-3'. The sequence was obtained from the SiVgR cDNA sequence (Chapter III). The gene for $\beta$-actin from the tick, Boophilus microplus, was used as a control to determine the uniformity of the RT 
reactions. PCR amplification of $\beta$-actin cDNA was performed using primer set Act-3F (forward), 5'-TCCTCGTCCCTGGAGAAGTCGTAC-3' and Act-4R (reverse), 5'CCACCGATCCAGACCGAGTACTTC-3' (Holmes et al., 2000). Reactions contained $1 \mu 1$ of the synthesized cDNA, $0.2 \mu \mathrm{M}$ of each primer, $200 \mu \mathrm{M}$ of dNTPs, $1 \mathrm{X}$ reaction buffer (Perkin Elmer) and $0.2 \mu \mathrm{l}$ Taq polymerase in a final volume of $20 \mu \mathrm{l}$. PCR parameters were $94{ }^{\circ} \mathrm{C}$ for $2 \mathrm{~min} ; 40$ cycles of $94{ }^{\circ} \mathrm{C}$ for $30 \mathrm{sec}, 55^{\circ} \mathrm{C}$ for $1 \mathrm{~min}$, and 72 ${ }^{\circ} \mathrm{C}$ for $2 \mathrm{~min} ; 72{ }^{\circ} \mathrm{C}$ for $10 \mathrm{~min}$.

\section{RESULTS AND DISCUSSION}

Northern blot analysis was carried out to study the caste, gender and tissue specificity of $\mathrm{SiVgR}$ gene expression. The $\mathrm{SiVgR}$ transcript was detected as a single 7.4 $\mathrm{kb}$ band restricted to the ovarian tissue of reproductive females -- both queens and alate virgin females (Fig. 4-1). Both $A a \mathrm{VgR}$ and $D m \mathrm{YPR}$ transcripts are similar in size, 7.3 $\mathrm{kb}$ and $6.5 \mathrm{~kb}$ respectively, to the $S i \mathrm{VgR}$ transcript and both transcripts are present in only the ovaries of their species (Schonbaum et al., 1995; Sappington et al., 1996). No $\mathrm{SiVgR}$ message was present in males or workers (Fig. 4-1A) and no SiVgR transcript was detected in total RNA from head, flight muscle, midgut or fat body (Fig. 4-1B). Major expression in the ovaries is observed for all cloned vertebrate and insect VgRs (Sappington et al., 1996; Schonbaum et al., 1995; Bujo et al., 1994; Okabayashi et al., 1996; Davail et al., 1998).

In $S$. invicta, the $\mathrm{VgR}$ transcript was present at higher levels in virgin alate females than in reproductively active queens (Fig. 4-1A). This observation appears opposite of 
A

Queen Alate
OV FB OV FB FB WB

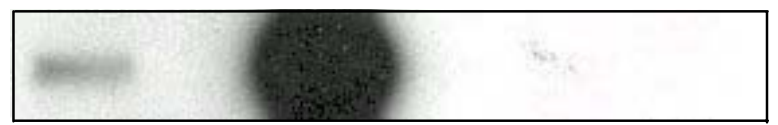

$\operatorname{VgR} 7.4$ kb

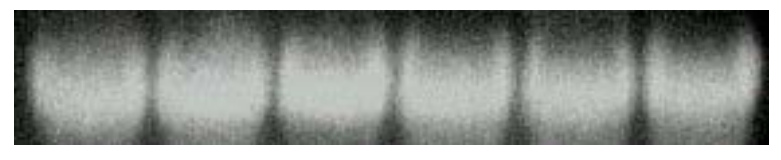

rRNA

B

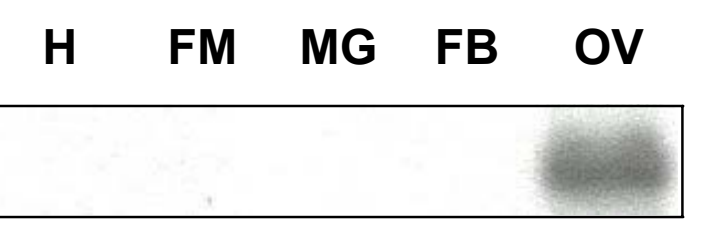

$\operatorname{VgR} 7.4 \mathrm{~kb}$

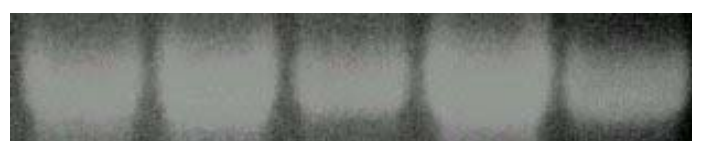

rRNA

Fig. 4-1. Northern blot analysis of VgR in S. invicta. Total RNA (10 $\mu \mathrm{g})$ was extracted from all castes and several major tissues. Blots were probed with a ${ }^{32} \mathrm{P}$ labeled, SiVgR-cDNA fragment. Ribosomal RNA (rRNA) is shown as an internal control after staining with ethidium bromide. (A) Caste profile of $\mathrm{Si} \mathrm{VgR}$ expression. (B) Tissue-specific expression of $\mathrm{SiVgR}$ transcripts in alate females. OV = ovary; $\mathrm{FB}=$ fat body; $\mathrm{H}=$ head; $\mathrm{FM}=$ flight muscle; $\mathrm{MG}=$ midgut; $\mathrm{W}=$ worker; $\mathrm{WB}=$ whole body. 
what might be predicted; assuming its expression would be highest during active egg formation. However, in the chicken, the levels of $\mathrm{VgR}$ transcripts are high in the ovaries of immature hens, before producing fully grown oocytes $(0.3 \mathrm{~cm}$ of oocyte), and the VgR transcript levels drop during the final growth phase of the oocytes $(2.0 \mathrm{~cm}$ of oocyte) (Bujo et al., 1995a). In rainbow trout, VgR transcript levels are high in the stage that precedes the beginning of internalization of $\mathrm{Vg}$ into the oocytes, and there is no detectable VgR signal in the larger, fully vitellogenic ooctyes of rainbow trout (Davail et al., 1998). In mosquito, $\mathrm{VgR}$ mRNA is expressed at higher levels in both previtellogenic and early vitellogenic ovaries (Cheon et al., 2001). These common findings suggest that during the previtellogenic period, $\mathrm{VgR}$ transcripts are transcribed at a high level. During rapid yolk formation, vitellogenesis -- receptor-mediated uptake of $\mathrm{Vg}$-- occurs at a maximal rate but without the synthesis of new $\mathrm{VgR}$ since $\mathrm{VgRs}$ recycle (Goldstein et al., 1985; Snigirevskaya et al., 1997).

Based on SDS-polyacrylamide gel electrophoresis analysis of hemolymph proteins, $\mathrm{Vg}$ is present in fire ant queens, alate virgin females and workers (Lewis et al., 2001). The presented northern blot analysis showed that there was $\mathrm{SiVgR}$ expression in queens and alate virgin females, but not in workers (Fig. 4-1A). The northern blot analysis was confirmed by RT-PCR, and the RT-PCR results showed that $\mathrm{SiVgR}$ was expressed only in ovaries of alate females, and not in the head, flight muscle, midgut or fat body. It was also not expressed in males and workers (Fig. 4-2). Therefore, the ovarian-specificity of $\mathrm{Si} \mathrm{VgR}$ suggested that the function of $\mathrm{SiVgR}$ was related to reproductive processes, likely vitellogenesis. In the honeybee, Apis mellifera, workers contain a vitellogenin receptor in the membrane of the hypopharyngeal gland and Vg or Vg-derived products 


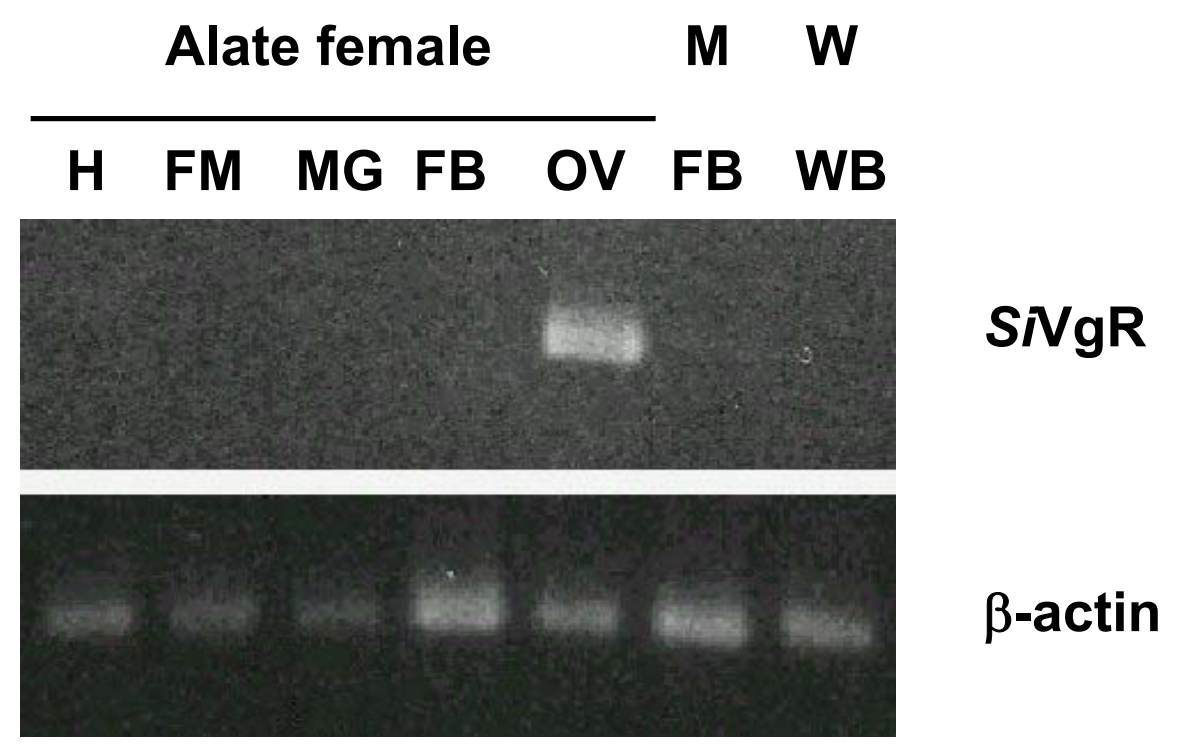

Fig. 4-2. RT-PCR analysis of $\mathrm{VgR}$ in $S$. invicta reveals receptor transcript amplification only from ovaries. cDNA was made from several major tissues and males and workers. $\beta$-actin is shown as an internal control after staining with ethidium bromide. $\mathrm{H}=$ head; $\mathrm{FM}=$ flight muscle; $\mathrm{MG}=$ midgut; $\mathrm{FB}=$ fat body; $\mathrm{OV}$ = ovary; $\mathrm{M}=$ male; $\mathrm{W}=$ worker; $\mathrm{WB}=$ whole body. 
accumulate in the heads of young honeybee workers suggesting that Vg is used as food for the brood (Amdam et al., 2003). The function of Vg in S. invicta workers is not clear. It is possible that another $\mathrm{VgR}$, different from the ovary-specific $\mathrm{VgR}$ of reproductives, may exist to internalize $\mathrm{Vg}$ in workers. 


\section{CHAPTER V}

\section{TRANSCRIPTIONAL REGULATION OF THE FIRE ANT VITELLOGENIN RECEPTOR}

\section{INTRODUCTION}

Oogenesis is a complex process that involves several organs and is under hormonal control. One of the most common regulatory mechanisms for insect egg maturation is the stimulation of Vg synthesis by juvenile hormone (JH) (Engelmann, 1983; Koeppe et al., 1985). JH also plays a role in the regulation of $\mathrm{Vg}$ uptake by the oocytes (Bell and Barth, 1971; Davey, 1981).

In Rhodnius prolixus, JH stimulates both $\mathrm{Vg}$ synthesis by the fat body and $\mathrm{Vg}$ uptake by the ovaries. The main role of $\mathrm{JH}$ in $\mathrm{Vg}$ uptake is to bind to a putative $\mathrm{JH}$ receptor in the follicle cell membranes and stimulate the development of spaces between the follicle cells thus permitting Vg to access the oocyte -- a process known as patency (Davey, 1981; Ilenchuk and Davey, 1985). Patency results from a reduction in the volume of the follicle cells caused by $\mathrm{JH}$ activation of a membrane-bound $\mathrm{Na}^{+}-\mathrm{K}^{+}$ ATPase via a pathway involving protein kinase C (Davey, 1996).

In the locust, L. migratoria, both Vg synthesis and uptake are stimulated by JH. The follicle cells of $L$. migratoria respond to $\mathrm{JH}$ in the same manner as those of $R$. prolixus (Davey et al., 1993). The addition of the JH analog, methoprene, enhanced Vg uptake by more than $25 \%$ (Ferenz and Lubzens, 1981). 
In Aedes aegypti, $\mathrm{JH}$ acts on the ovary at adult eclosion to make it competent to secrete ecdysteroids in response to the egg-development neurohormones released after feeding (Shapiro and Hagedorn, 1982). JH also acts on the fat body to make the fat body competent to convert the ovarian ecdysone into 20-hydroxyecdysone (20-OHE). The 20-hydroxyecdysone then stimulates the fat body to synthesize Vg (Flanagan and Hagedorn, 1977).

In Drosophila melanogaster, $\mathrm{JH}$ is also implicated in the regulation of vitellogenesis and vitellogenic oocyte developement (Jowett and Postlethwait, 1980; Wilson, 1982; Soller et al., 1999). JH stimulates yolk protein (YP) synthesis and uptake by the developing oocyte; ecdysteroids produced by follicle cells in the ovary and other tissues stimulate fat body YP synthesis (Koeppe et al., 1985; Bownes et al., 1993). This model is supported by observations of the $\mathrm{JH}$-deficient mutant, apterous ${ }^{4}$, in which little vitellogenesis occurs; a condition partially rescued by the application of the $\mathrm{JH}$ analog methoprene (Postlethwait and Weiser, 1973). Furthermore, when methoprene was applied to starved wild-type adults or isolated abdomens, conditions under which YP synthesis would be low, YP transcript became elevated (Jowett and Postlethwait, 1980). Methoprene also stimulated fat body YP transcript levels in fed flies (Bownes et al., 1987) further supporting the postulate that $\mathrm{JH}$ is required for vitellogenesis. Richard et al. (1998) presented evidence that this may not be due to the direct effect of the $\mathrm{JH}$ analog upon YP synthesis by fat body, but rather due to JH-stimulation of ovarian ecdysteroid synthesis, the latter in part responsible for YP production and uptake. Richard et al. (2001) presented further evidence that a role for $\mathrm{JH}$ is to regulate early 
YP synthesis and uptake from follicle cells, and that in the absence of $\mathrm{JH}$, late YP synthesis by the fat body is possibly under the control of ecdysteroids.

In species of primitively eusocial wasps and bumble bees, $\mathrm{JH}$ acts as a gonadotropin in the regulation of $\mathrm{Vg}$ synthesis in the fat body and the incorporation of $\mathrm{Vg}$ into developing oocytes in the ovary. JH may also play this role in the advanced eusocial fire ants (Bohm, 1972; Röseler, 1977; Röseler et al., 1980; Robinson and Vargo, 1997). However, there is no evidence that $\mathrm{JH}$ acts as a traditional gonadotropin in the honey bee and it clearly does not stimulate vitellogenin synthesis. Rather it appears to serve as an integrative element in social behavior and colony function (Hartfelder and Engel, 1998; Robinson and Vargo, 1997).

In this chapter, the temporal regulation of $\mathrm{SiVgR}$ transcription is determined in alate virgin females and mated queens. The regulatory roles of both juvenile hormone and 20-hydroxyecdysone in $\mathrm{SiVgR}$ transcription are examined in alate virgin females in vitro.

\section{MATERIALS AND METHODS}

\subsection{Insects}

S. invicta were reared as described in Chapter III.

2.2. Semiquantitative reverse transcription polymerase chain reaction (semi-QRT-PCR) for measuring the relative $\mathrm{SiVgR}$ transcriptional expression 
Methods used for semi-QRT-PCR were similar to those described by Dozois et al. (1997). Total RNA ( $1 \mu \mathrm{g})$ was extracted from ovaries of different ages of alate virgin females and mated queens, and cultured ovaries from endocrine regulation studies using the guanidine-thiocyanate-phenol-chloroform method (Chomczynski and Sacchi, 1987; Puissant and Houdebine, 1990). The total RNA was provided as templates for the reverse transcription (RT) using oligo-dT 16 primer with GeneAmp ${ }^{\circledR}$ RNA PCR core kit (Perkin Elmer, Vellesley, MA). The final volume of RT reaction was increased to $50 \mu \mathrm{l}$ with diethylpyrocarbonate (DEPC)-treated water.

PCR amplification of filamin cDNA was performed using primer set Fil-F, 5'TTCAATGATCAGCACATCCC-3' and Fil-R, 5'-TTGTAACCCTCCTCGACCTC-3'. The sequence was obtained from S. invicta (Pietrantonio et al., 2002; Pietrantonio, unpublished). The filamin gene was used as a control to determine the uniformity of the RT reactions.

PCR amplification of receptor cDNA was performed using primer set 2.3-2 (forward), 5'-AAACGATGGCACGTACTG C-3' and 2.3-14 (reverse), 5'AAGAAAGGCGTTGATAATTGCAGATGGC-3' (corresponding to amino acid sequence of 391-397 and 648-657, Chapter III, Fig. 3-3). Reactions contained one-tenth $(5 \mu \mathrm{l})$ of the synthesized cDNA, $0.2 \mu \mathrm{M}$ of each primer, $200 \mu \mathrm{M}$ of dNTPs, $1 \mathrm{X}$ reaction buffer (Perkin Elmer) and $0.2 \mu \mathrm{l}$ Taq polymerase in a final volume of $20 \mu 1$.

PCR parameters were $94{ }^{\circ} \mathrm{C}$ for $2 \mathrm{~min} ; 30$ cycles of $94{ }^{\circ} \mathrm{C}$ for $30 \mathrm{~s}, 62{ }^{\circ} \mathrm{C}$ for $1 \mathrm{~min}$, and $72{ }^{\circ} \mathrm{C}$ for $2 \mathrm{~min} ; 72{ }^{\circ} \mathrm{C}$ for $10 \mathrm{~min}$. Five microlitres of each reaction was electrophoresed on 1\% agarose gel and stained with ethidium bromide. Gels were 
photographed with Polaroid film and images were scanned with a Hewlett Packard ScanJet 5370C. The intensity of the bands was determined using Kodak 1D Image Analysis Software v3.5 (Kodak Scientific Imaging Systems, New Haven, CT). To compare the relative mRNA expression levels from each of the samples, the values were presented as the ratio of the band intensities of the receptor RT-PCR product over the corresponding filamin RT-PCR product.

\subsection{Southern blot analysis}

To assure that the RT-PCR products corresponded to the cloned receptor, each was re-amplified using the same primer set, 2.3-2 and 2.3-14, designed based on the sequence of the first cloned receptor PCR product obtained of $2.3 \mathrm{~kb}$ (Chapter III). PCR reactions were performed using the same reagents, concentrations and PCR parameters as the original RT-PCR. $5 \mu$ l of each reaction was run on a $1 \%$ agarose gel and stained with ethidium bromide. DNA was transferred to a positively charged nylon membrane (Hybond XL, Amersham, Pharmacia, Piscataway, NJ) with 10X SSC as transfer buffer following alkaline denaturation. After transfer, the membrane was illuminated with UV $(300 \mathrm{~nm})$ to fix the DNA. The membrane was hybridized with the ${ }^{32} \mathrm{P}$-labeled SiVgR $2.3 \mathrm{~kb}$ cDNA fragment (Chapter III) corresponding to the region of RT-PCR products at a concentration of $1 \times 10^{6} \mathrm{cpm} / \mathrm{ml}$ of hybridization solution (Ultrahyb, Ambion, Austin, TX). Hybridization was performed at $42{ }^{\circ} \mathrm{C}$ for $16 \mathrm{~h}$. Following hybridization, the membrane was washed $2 \times 5 \mathrm{~min}$ at low stringency ( $2 \mathrm{X} \mathrm{SSC}, 0.1 \% \mathrm{SDS}$ ) at $42{ }^{\circ} \mathrm{C}$ and 2 x 15 min at high stringency $(0.1 \mathrm{X} \mathrm{SSC}, 0.1 \% \mathrm{SDS})$ at $65^{\circ} \mathrm{C}$. After the membrane was 
washed to remove non-specific radioactivity, it was exposed to X-ray film and developed.

\subsection{Effects of age on $\mathrm{SiVgR}$ transcription}

\subsubsection{Alate virgin females}

Reproductive pupae were maintained separately from the nest in a 24-well Falcon ${ }^{\circledR}$ tissue culture plate (Becton Dickinson Labware, Franklin Lakes, NJ). Holes were melted into the lid of the plate with a hot needle to allow workers access to the pupae. The plate was placed within the colony so that the pupae could receive care from workers and be exposed to primer pheromone from queens, until eclosion. In order to determine age, following eclosion, alate virgin females were marked by spraying them with different colors of Krylon ${ }^{\circledR}$ enamel paint. The result showed that the colors of maize, dust pink, yellow, sun yellow, purple, grape and candy red were lasting long on alate virgin females. The marked alate females were returned to the colony.

The relative $S i \mathrm{VgR}$ transcriptional expression was determined in ovaries pooled from five insects. Ovaries were collected from untanned pupae (the pupal cuticle is white), pharate adults (the adult cuticle is completely developed and remains under the cover of the pupal cuticle), newly eclosed adults (day 0 ), and alate adults at 5, 10, 15, 20, 25, 30, 40, 50 and 60 days post-eclosion. Three replicate pools of five pairs of ovaries ( 3 replicates x 5 ovary pair each) were analyzed per age group using semi-QRTPCR. The expression ratio (receptor/filamin) data were converted by the logarithm transformation (Montgomery, 1997) and analyzed by ANOVA followed by a Tukey 
multiple comparison test to identify differences between individual means. Statistical analyses were performed using Prism ${ }^{\mathrm{TM}} 2.0$ (GraphPad Software, San Diego, CA).

\subsubsection{Inseminated queens}

Newly inseminated queens were field collected directly after a mating flight (College Station, TX). Queens were held separately in test tubes. The queens were held in a humid incubation chamber created by filling the test tubes half-full with water then plugging them in the middle with cotton and with another loose cotton plug at the top (Fig. 5-1). Ovaries were collected and pooled from ten queens each age point starting on the day of dealation (day 0 ) and on days 2, 4, 10, 15, 20, 25, 30 and 35 after mating; and on days 5 and 10 following eclosion of adult nanitics. Nanitics are a unique, uniformly small worker caste produced only in newly founded colonies (Vinson, 1997). Three replicate pools of ten pairs of ovaries (3 replicates x 10 ovary pair each) were analyzed per age group using semi-QRT-PCR. The expression ratio (receptor/filamin) data were converted by the logarithm transformation (Montgomery, 1997) and analyzed by ANOVA followed by a Tukey multiple comparison test to identify differences between

individual means. Statistical analyses were performed using Prism ${ }^{\mathrm{TM}} 2.0$ (GraphPad Software, San Diego, CA).

\subsection{Endocrine regulation study}

Ovaries were dissected from newly-eclosed alate females (day 0) and incubated in a medium containing 20 amino acids at their physiological concentrations for S. invicta plus $19 \mathrm{mM}$ glucose and $34 \mathrm{mM}$ trehalose (Cônsoli and Vinson, 2002). Salts were 


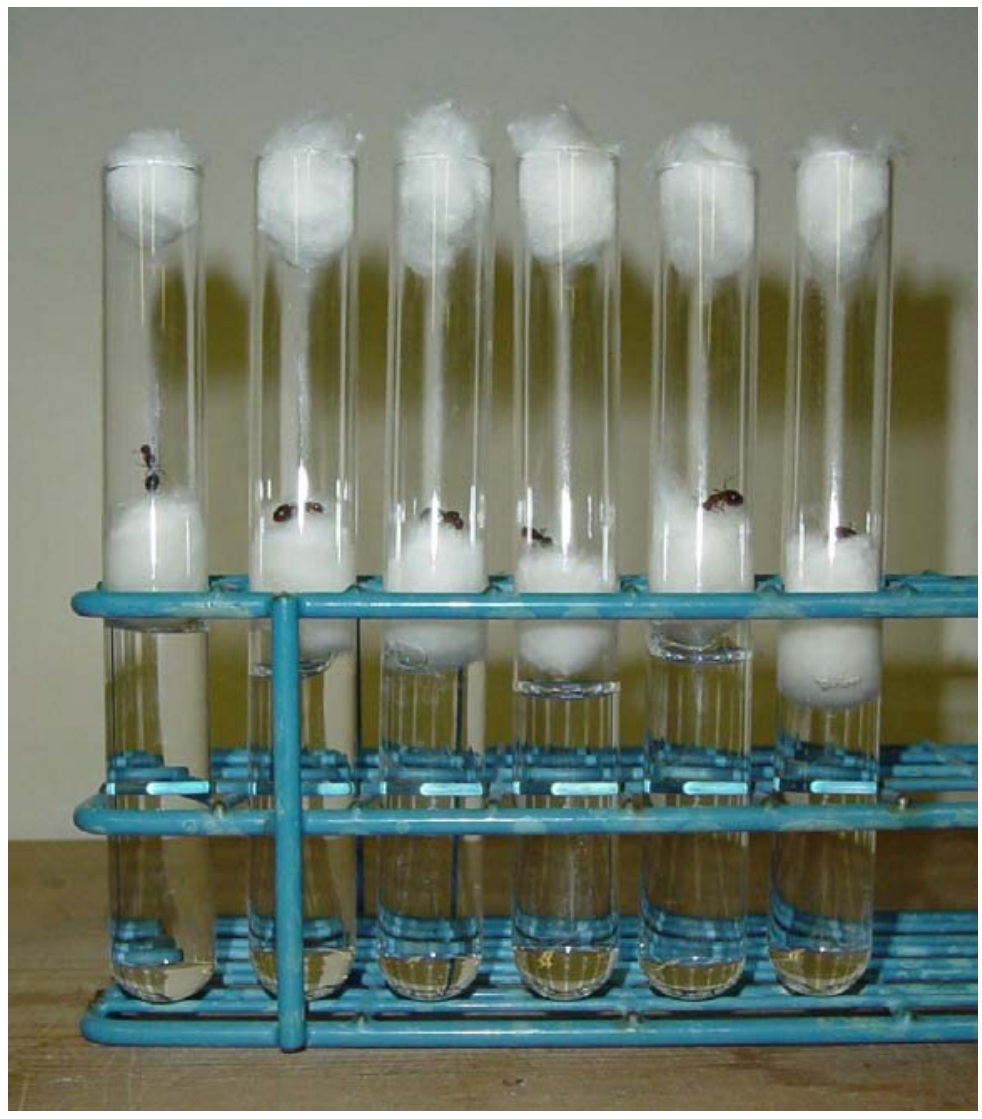

Fig. 5-1. The incubation chambers for newly mated queens. The chambers were created by filling the test tubes half-full with water then plugged newly mated queens in the middle with cotton and with another loose cotton plug at the top. 
added equivalent to a cockroach Ringer (Keeley et al., 1995) and adjusted to pH 7.0. The medium was filter- sterilized and stored at $4{ }^{\circ} \mathrm{C}$. Gentamicin $(50 \mathrm{mg} / \mathrm{L})$ was added at the time of use.

Pools of seven pairs of ovaries were incubated in a disposable, sterile, polystyrene, 24-well Falcon ${ }^{\circledR}$ tissue culture plate (Becton Dickinson Labware, Franklin Lakes, NJ) for $1 \mathrm{~h}$ at $27^{\circ} \mathrm{C}$. After $1 \mathrm{~h}$ pre-incubation, methoprene was added to the treatment well for a final concentration of $10^{-6} \mathrm{M}$ using $1 \mu$ of dimethylsulfoxide (DMSO) as a carrier. For controls, ovaries were incubated in plain culture medium or medium containing $1 \mu 1$ of DMSO. All samples were incubated for $24 \mathrm{~h}$ at $27{ }^{\circ} \mathrm{C}$. Six replicates of each treatment were performed, and the transcriptional expression of $S i \mathrm{VgR}$ was measured using semi-QRT-PCR. Mean values for experimental and control groups were based on six replicate samples (6 replicates $\mathrm{x} 7$ ovary pair each). The expression ratio (receptor/filamin) data were converted by the logarithm transformation (Montgomery, 1997) and analyzed by ANOVA followed by a Tukey multiple comparison test to identify differences between individual means. Statistical analyses were performed using Prism ${ }^{\mathrm{TM}} 2.0$ (GraphPad Software, San Diego, CA).

Experiments to assess the effect of ecdysone were performed in similar fashion with pools of seven ovary pairs as the experimental unit. 20-Hydroxyecdysone (20-OHE) (Sigma, St. Louis, MO) was applied to the same incubation system using ethanol as the hormone carrier. Three replicates of each treatment were performed. The expression ratio (receptor/filamin) data were converted by the logarithm transformation (Montgomery, 1997) and analyzed by ANOVA followed by a Tukey multiple 
comparison test to identify differences between individual means. Statistical analyses were performed using Prism ${ }^{\mathrm{TM}} 2.0$ (GraphPad Software, San Diego, CA).

\section{RESULTS AND DISCUSSION}

Temporal expression of SiVgR mRNA was examined by semiquantitative RT-PCR. $\mathrm{Si} \mathrm{VgR}$ cDNA samples were obtained from alate virgin females of various ages ranging from untanned pupae to 60 days after eclosion. The $S i \mathrm{VgR}$ sequence used for semiQRT-PCR experiments and synthesis of the probe for Southern blot corresponds to the least similar region among VgRs and thus, it should identify SiVgR specifically (Chapter III, Fig. 3-3, arrows). The amount of amplified SiVgR cDNA (750 bp) produced by RT-PCR was compared with the amplification of $S$. invicta filamin (500 bp) (Fig. 5-2A). Filamin is an actin-binding protein in Drosophila melanogaster (Li et al., 1999b). During oogenesis filamin is in the ring canal structures that fortify arrested cleavage furrows and establish cytoplasmic bridges between cells of the germline (Li et al., 1999b). The expected, amplified 750-bp products were confirmed by Southern blot to hybridize to the cloned receptor (Fig. 5-2D). Fig. 5-2A and 5-2B shows that $S i \mathrm{VgR}$ transcripts were present in alate virgin females of all ages and continuously increased with age. $\mathrm{SiVgR}$ transcripts statistical significantly increased in old alate virgin females during the first 60 days of adult life (Fig. 5-2C, D 0 and D 60).

Semi-QRT-PCR was also performed to determine relative $\mathrm{SiVgR}$ transcription for different ages of field-collected, newly mated queens. Ovarian filamin again served as a control (Fig. 5-3A). Qualitative identification of amplified receptor transcripts (750-bp) 
A

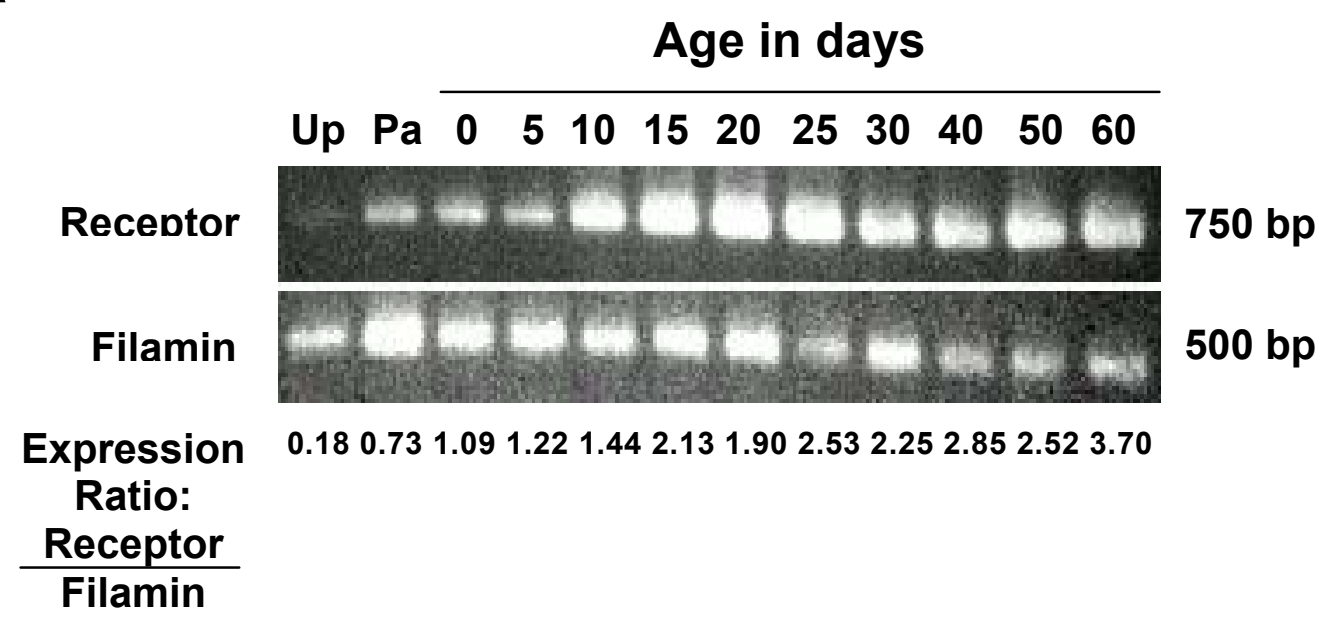

B

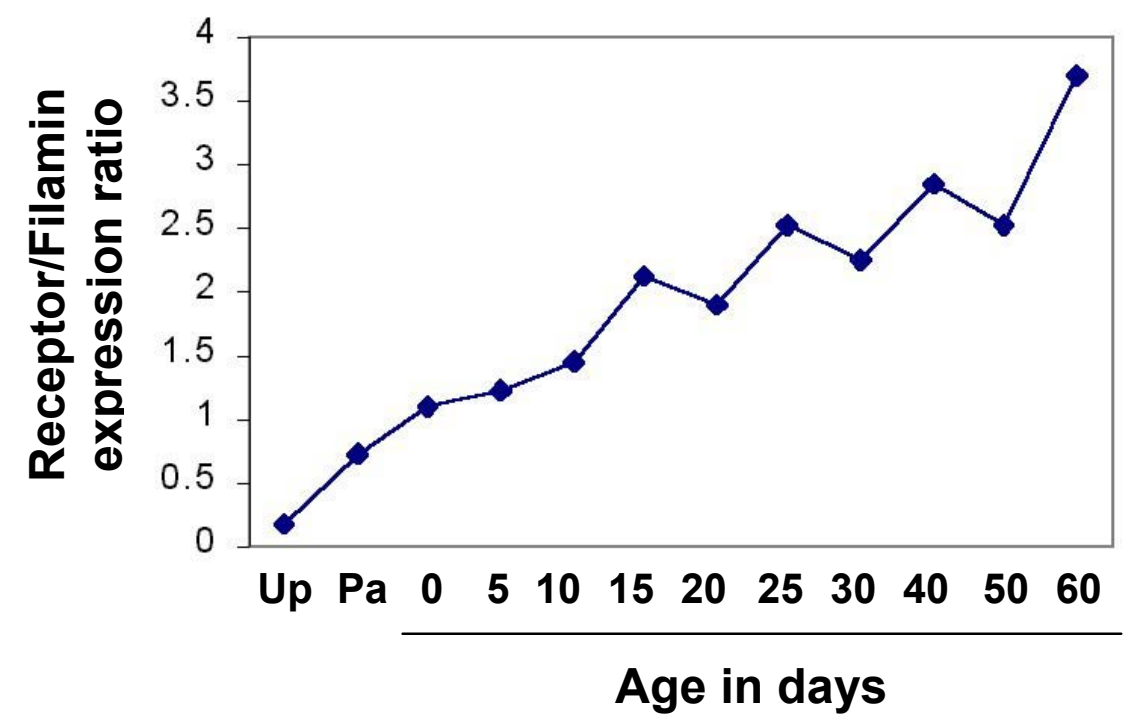

Fig. 5-2. Temporal profiles of VgR transcription in alate females of S. invicta. Alate females from a polygene colony were monitered following pupal eclosion. Up: untanned pupae, Pa: pharate-adult, and alate females (days 0-60) after eclosion. (A) Semiquantitative RT-PCR shows the relative amount of amplified receptor transcripts compared to amplified filamin transcripts for different ages. (B) Expression ratio (receptor/filamin) plotted against ages. (C) Statistical analysis results of relative $\mathrm{SiVgR}$ transcription with different ages. (D) Qualitative identification of amplified receptor transcripts. Panel 1: Agarose electrophoresis of PCR amplified receptor products for Southern blot. Panel 2: Autoradiograph of the Southern blot of DNA in panel 1. (-) = negative control containing DNA unrelated to the receptor. 
C

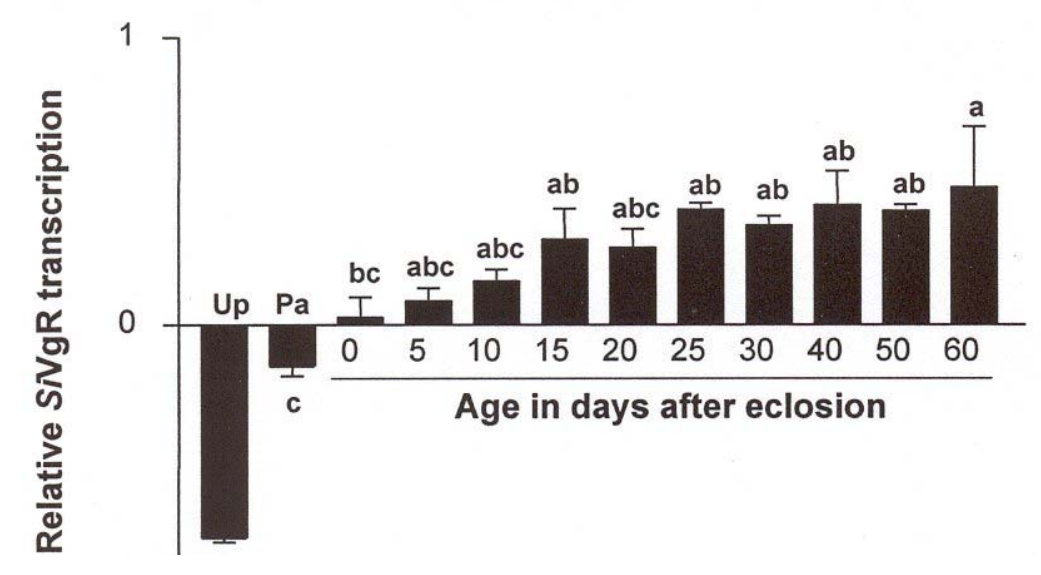

D

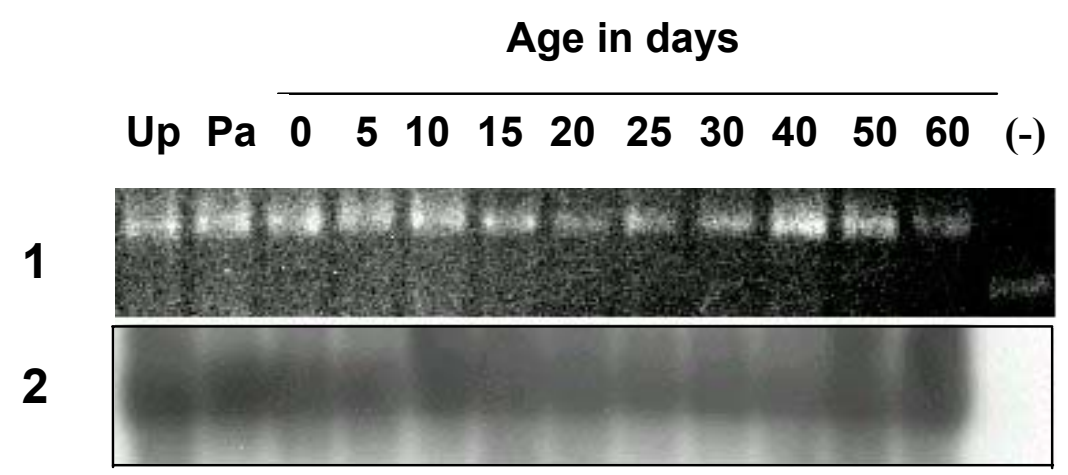

Fig. 5-2. Continued. 
A

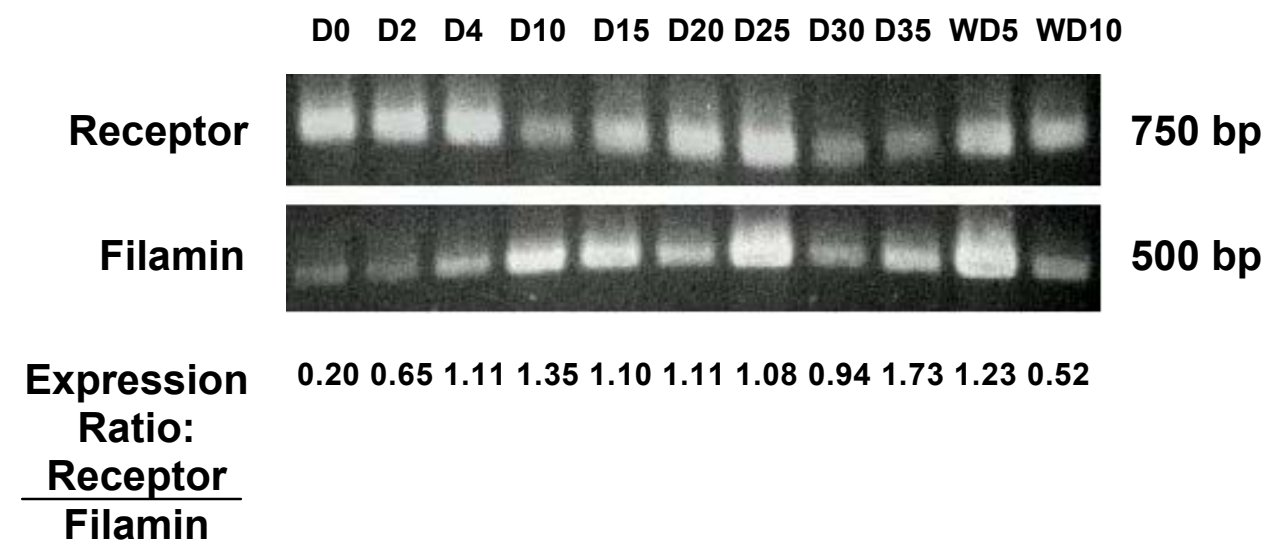

B

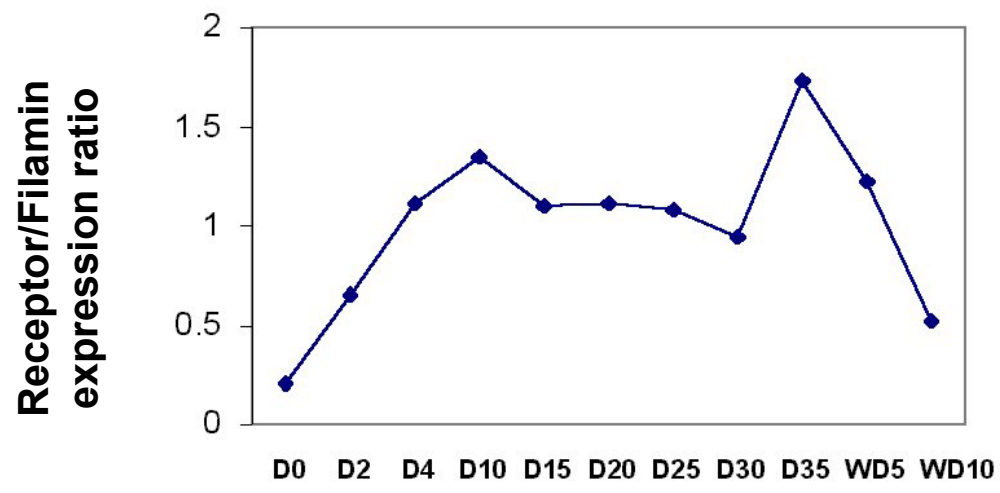

Age in days

Fig. 5-3. Temporal profiles of VgR transcription in field-collected newly mated queens of $S$. invicta. Ovaries were collected at dealation (D0) and at intervals of 5 (WD5) to 10 days following nanitic emergence (WD10). (A) Semiquantitative RTPCR shows the relative amount of amplified receptor transcripts compared to amplified filamin transcripts for different ages. (B) Transcriptional expression ratio (receptor/filamin) plotted against age. (C) Statistical analysis results of relative $\mathrm{SiVgR}$ transcription with different ages. (D) Qualitative identification of amplified receptor transcripts. Panel 1: Agarose electrophoresis of PCR amplified receptor products for Southern blot. Panel 2: Autoradiograph of the Southern blot of DNA in panel 1. (-) = negative control containing DNA not related to the receptor. 
C

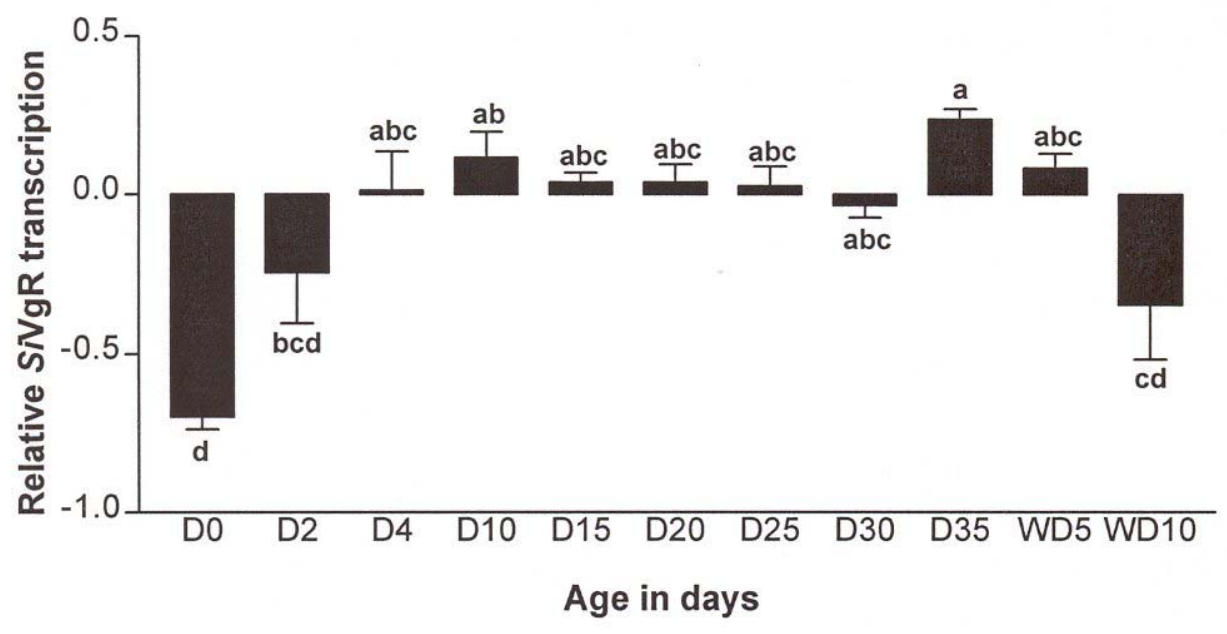

D

D0 D2 D4 D10 D15 D20 D25 D30 D35 WD5WD10 (-)

1

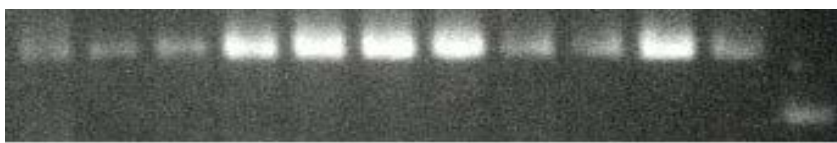

2

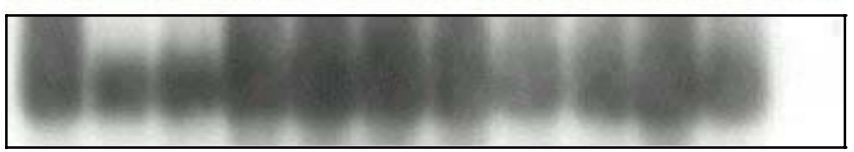

Fig. 5-3. Continued. 
was confirmed by Southern blot analysis (Fig. 5-3D). The results showed that the $\mathrm{SiVgR}$ transcripts increased from days 0 to 10 and remained at the day-10 level until day 30. $\mathrm{SiVgR}$ transcripts increased by day 35 from day 10 , then $\mathrm{SiVgR}$ transcripts declined following nanitic emergence (Fig. 5-3B). The reasons for this decline are unclear. The statistical analysis result showed that $S i \mathrm{VgR}$ transcripts in D 35 significantly increased from D 0, D 2 and 10 days after nanitic emergence (Fig. 5-3C). It is difficult to propose how $\mathrm{SiVgR}$ transcription is temporally regulated in newly mated queens, since the existing receptor proteins are believed to recycle. Comparison of relative $\mathrm{Si} \mathrm{VgR}$ transcription between alate virgin females and newly mated queens showed that the level of $S i \mathrm{VgR}$ transcription was higher in all ages of alate virgin females than the level on D0 of newly mated queens. Untanned pupae showed similar levels of expression as in day-0 newly mated queens (Fig. 5-2A, 5-3A).

There is no data to indicate that alate virgin females are of a particular age when they mate and dealate to become queens. Whenever the environmental conditions are optimum, mating flights occur (Vinson, 1997). After mating, females land, dealate and lay 10-20 eggs within the first 24 hours. The low levels of $S i \mathrm{VgR}$ transcripts at dealation suggest that the $\mathrm{SiVgR}$ protein is either synthesized from existing transcripts or has already been synthesized and is ready to start uptake of $\mathrm{Vg}$ for yolk formation.

Ovaries from newly eclosed alate females were incubated in vitro at $27^{\circ} \mathrm{C}$ for $24 \mathrm{~h}$ in the presence or absence of $10^{-6} \mathrm{M}$ methoprene (a JH analog). Cultured ovaries were analyzed by semi-QRT-PCR using filamin as an internal control (Fig. 5-4A). The expected, amplified 750-bp products were confirmed by Southern blot to hybridize to the cloned receptor (Fig. 5-3C). Treatment of ovaries with methoprene increased $\mathrm{SiVgR}$ 
A

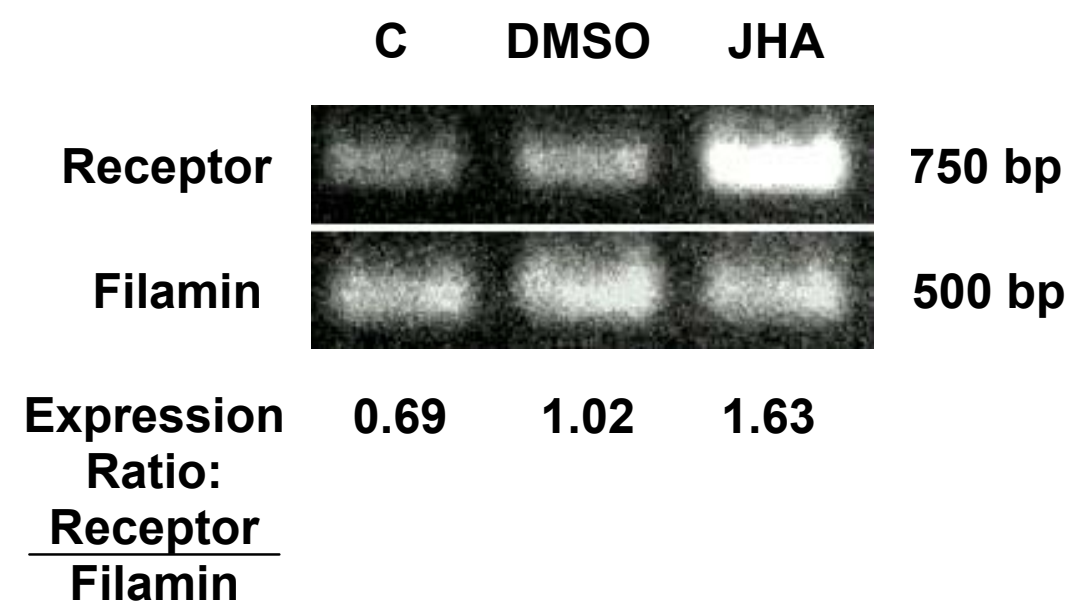

B

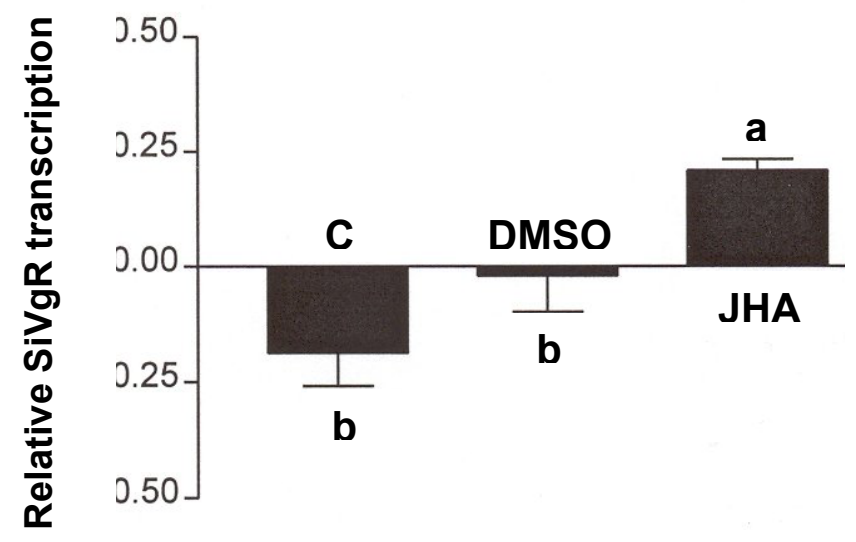

Fig. 5-4. Effect of the juvenile hormone analog, methoprene, on $S i \mathrm{VgR}$ transcription by in vitro ovaries from day-0 alate female $S$. invicta C $=$ control, DMSO = dimethyl sulfoxide, JHA = juvenile hormone analog, methoprene. (A) Semiquantitative RTPCR shows the relative amounts of amplified receptor transcript compared to amplified filamin transcripts for several treatments. (B) The relative $\mathrm{SiVgR}$ transcription level of JHA-treated ovaries is significantly higher than control and DMSO-treated ovaries (Tukey multiple comparison test, $\mathrm{P}<0.05$ ). (C) Qualitative identification of amplified receptor transcripts. Panel 1: Agarose electrophoresis of PCR amplified receptor products for Southern blot. Panel 2: Autoradiograph of the Southern blot of DNA in panel 1. (-) = negative control containing DNA unrelated to the receptor. 
C

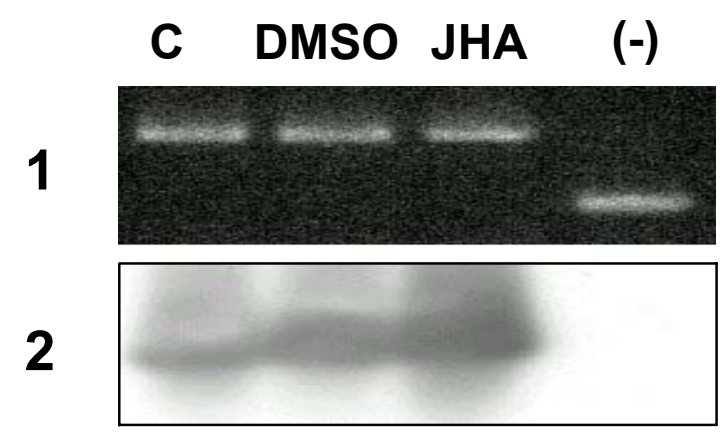

Fig. 5-4. Continued. 
transcript levels by 1.4-fold compared with untreated control ovaries or 0.6-fold compared with DMSO-treated solvent control ovaries $(\mathrm{P}<0.05$; Fig. 5-4B). The in vitro experiments suggested that JH may stimulate $\mathrm{Si} \mathrm{VgR}$ gene expression.

We also investigated whether 20-OHE influenced SiVgR gene expression using the same in vitro system, but with ethanol as the hormone carrier. There was no significant difference between the 20-OHE-treated and control ovaries as measured by the log of the receptor/filamin transcription ratio (Fig. 5-5).

The regulatory role of $20-\mathrm{OHE}$ in $\mathrm{SiVgR}$ transcription has still to be demonstrated by applying inhibitors of 20-OHE and examining the amount of $\mathrm{SiVgR}$ transcripts produced. For example several classes of compounds including cucurbitacins, withanolides, limonoids and stilbenoids antagonize the action of 20-OHE (reviewed in Dinan et al., 2001).

Several in vivo studies indicate that dealation and ovary development in fire ants are controlled by JH (Kearney et al., 1977; Barker 1978, 1979; Fletcher and Blum, 1983; Vargo, 1992; Vargo and Laurel, 1994; Burns et al., 2002), but in vitro experiments have not been performed. It is speculated that the likely mechanism that normally prevents alate females from dealating and initiating reproductive maturation in fire ants involves a primer pheromone produced by the queens (Fletcher and Blum, 1981; Vargo and Laurel, 1994) that may depress virgin alates JH titers (Vargo and Laurel, 1994). Earlier work (Vargo and Laurel, 1994; Lewis et al., 2001, 2003) demonstrated that vitellogenin was present in the hemolymph of alate female $S$. invicta, but without concomitant oocyte maturation. Topical treatment with methoprene induced alate females to develop their ovaries, even in the presence of a functional (pheromone-producing) queen (Vargo 
A

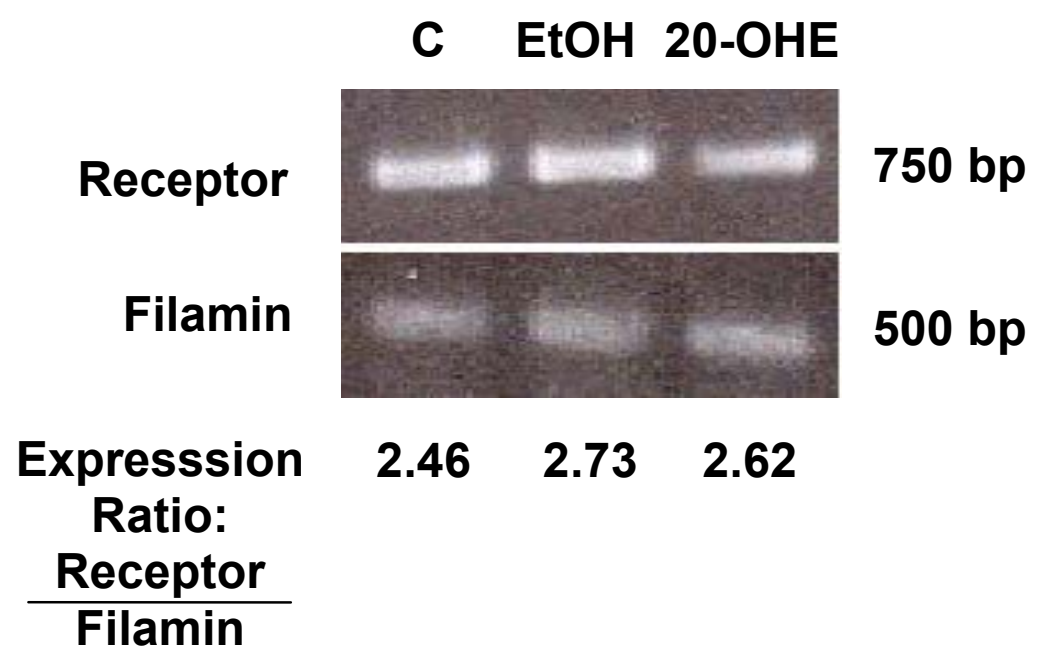

B

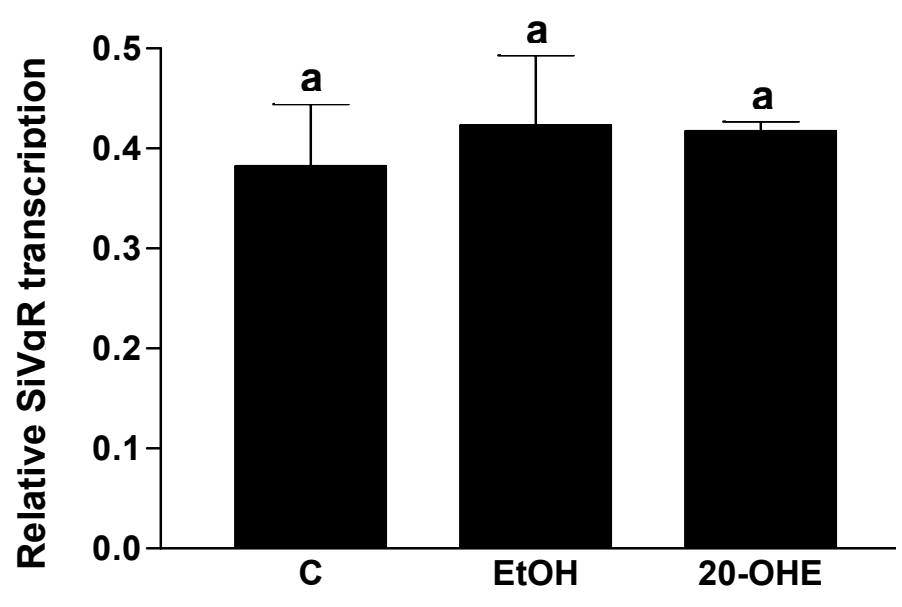

Fig. 5-5. Effect of the 20-hydroxyecdysone on $\mathrm{SiVgR}$ transcription by in vitro ovaries from day-0 alate female $S$. invicta. $\mathrm{C}=$ control, EtOH = ethanol, 20-OHE $=20$ hydroxyecdysone. (A) Semiquantitative RT-PCR shows the relative amounts of amplified receptor transcript compared to amplified filamin transcripts for several treatments. (B) There are no significant differences among the relative $S i \mathrm{VgR}$ transcription levels for the various ovaries (Tukey multiple comparison test, $\mathrm{P}>$ $0.05)$. 
and Laurel, 1994). The results of the present study together with our early work (Lewis et al., 2001; 2003) suggest that by depressing JH titers the queen pheromone prevents ovary development by blocking Vg uptake rather than preventing Vg synthesis.

Fletcher and Blum (1983) and Vargo (1992) hypothesized that fire ant queen primer pheromones prevent ovary development in alate virgin females and reproductively active queens by inhibiting JH synthesis. Further, Vargo and Laurel (1994) proposed a model for the mode of action of the fire ant queen pheromone that inhibits dealation and ovary development. In the model, the pheromone triggers antennal receptors which send inhibitory signals to the median neurosecretory cells in the brain. The suppressed median neurosecretory cells only weakly stimulate the corpora allata to synthesize $\mathrm{JH}$ and maintain low titers of the hormone. At low levels, JH stimulates vitellogenin synthesis in the fat body. In the absence of the pheromone, the fully activeneurosecretory cells send a stronger chemical (and/or neural) signal that triggers the corpora allata to produce larger quantities of JH. At higher titers, JH stimulates dealation and vitellogenin uptake by the ovaries (Vargo and Laurel, 1994).

In Dr. Keeley's laboratory earlier studies on Vg gene, methoprene treatment did not stimulate $\mathrm{Vg}$ transcription in both alate virgin females and mated queens (unpublished data). In the present studies, the $\mathrm{JH}$ analog stimulated the $\mathrm{SiVgR}$ transcription, even in alate females when SiVgR transcript was abundant (Fig. 5-4B). These two experimental results are compatible with the proposed model from Vargo and Laurel.

In order to prove the regulatory role of $\mathrm{JH}$ in $\mathrm{SiVgR}$ transcription, anti-JH agents could be applied to probe the relationship between $\mathrm{JH}$ and the $S i \mathrm{VgR}$ transcription and may suggest ways to suppress $\mathrm{Vg}$ uptake for $S$. invicta control. Precocenes, 
fluoromevalonate, allylic alcohol derivates are all anti-JH agents. Precocene is a compound that destroys the source of $\mathrm{JH}$, the corpora allata. Burns et al. (2002) demonstrated that the size of corpora allata was reduced in alate females of $S$. invicta from monogyne colonies after treatments with precocene II. Therefore, precocene might be applied to functional queens to lower their JH titers below the threshold needed for vitellogenesis. Precocene might also be applied to alate females to decrease the JH titer and prevent alate females from dealating and synthesizing $\mathrm{Vg}$. 


\section{CHAPTER VI}

\section{CONCLUSION}

Since its introduction in 1918, the red imported fire ant, Solenopsis invicta, has spread rapidly across the southeastern USA and has become a serious pest. Its high reproductive rate has equipped the fire ant with the ability to become a successful invader (Vinson, 1997). S. invicta forms monogyne and polygyne colonies with a single queen or with multiple functional (egg-laying) queens, respectively. Although individually the queens of polygyne colonies consistently lay fewer eggs than the queens of monogyne colonies, they collectively produce more eggs per colony (Fletcher, et al., 1980; Vargo and Ross, 1989). Queens of one polygyne colony can produce an average of 355 eggs within five hours (Fletcher, et al., 1980). This high reproductive capacity is the one of main reasons why fire ants are so difficult to control; thus, inhibiting egg maturation is a promising strategy for fire ant control.

In insects, during egg maturation, the major yolk protein precursor, vitellogenin $(\mathrm{Vg})$, is synthesized by the fat body and secreted into the hemolymph. The internalization of $\mathrm{Vg}$ into the growing oocytes is achieved through receptor-mediated endocytosis. In insects, various hormones and environmental cues regulate egg formation. However, species differ greatly in which hormones they use for regulation of egg formation. In many species, the synthesis or uptake of $\mathrm{Vg}$ is stimulated by juvenile hormone $(\mathrm{JH})$. A notable exception is the Diptera, in which Vg synthesis is stimulated by ecdysteroids. 
However, the presence of $\mathrm{Vg}$ does not necessarily equate with reproductive competency. In Apis mellifera, $\mathrm{Vg}$ is produced by worker bees during the nurse stage and occurs in haploid drones as a minor fraction (Trenczek and Engels, 1986; Trenczek et al., 1989). In S. invicta, Vg is present in the hemolymph of all female caste members, including workers, alate virgin females and mated queens (Lewis et al., 2001). Alate virgin females attain $\mathrm{Vg}$ titers comparable to functional queens, but without exhibiting ovarian maturation, suggesting that reproduction may be controlled by $\mathrm{Vg}$ uptake and not by Vg synthesis (Vargo and Laurel, 1994).

This dissertation reports the cloning of the first hymenopteran vitellogenin receptor (VgR) cDNA from the imported fire ant, S. invicta. The complete 5764 bp cDNA encodes a 1782-residue protein with a predicted molecular mass of $201.3 \mathrm{kDa}$ (= $\mathrm{SiVgR}$ ). Northern blot analysis demonstrated that the 7.4-kb SiVgR transcript was present only in ovaries of reproductive females (both alate virgin females and mated queens). The temporal profile of transcriptional expression showed that $\mathrm{SiVgR}$ mRNA increased with age in alate virgin females and could be up-regulated by methoprene, a juvenile hormone $(\mathrm{JH})$ analog in vitro. This suggests that the SiVgR gene may be JH regulated.

Only the $\mathrm{SiVgR}$ cDNA sequence is reported here. It is important for future work to obtain the promoter region of the $S i \mathrm{VgR}$ gene to investigate the relationship between JH and possible transcription factors, and analyze potential regulatory elements. This provides clues to how JH affects $\mathrm{SiVgR}$ expression.

This research is the first to show induction of gene transcription in vitro by juvenile hormone in hymenopteran insects. This in vitro system is a powerful system to define 
the regulatory role of $\mathrm{JH}$ in genes involved in oocyte maturation. It can avoid the influence of endogenous $\mathrm{JH}$ sources and potential inhibitors of JH. This system can be applied to test the regulation of other genes by $\mathrm{JH}$.

Vargo and Laurel (1994) proposed that queen pheromone depresses JH production so that $\mathrm{JH}$ titers are below the threshold needed to stimulate $\mathrm{Vg}$ uptake, but above the level required to induce $\mathrm{Vg}$ synthesis. The present data show that even though the $\mathrm{SiVgR}$ transcript was abundant in alate virgin females, methoprene treatment still had the capacity to increase $\mathrm{SiVgR}$ transcripts (Fig. 4-1A and 5-3A). These results are compatible with the proposed hypothesis (Vargo and Laurel, 1994).

In most insects, the onset of vitellogenesis is characterized by the opening-up of the spaces between follicle cells, a phenomenon called patency, and JH stimulates the formation of spaces between follicle cells (Davey, 1981). In alate virgin female $S$. invicta, the $\mathrm{JH}$ titer is high enough to stimulate $\mathrm{Vg}$ synthesis, but not enough to stimulate $\mathrm{Vg}$ uptake. In addition to the regulation of $\mathrm{SiVgR}$, is the JH titer above the threshold also needed to stimulate patency? Transmission electron microscopy can be performed to observe ovary structure to compare the size of spaces between the follicle cells of alate females and queens.

$\mathrm{Vg}$ receptors have to be incorporated into the plasma membrane of the oocyte to function properly. In D. melanogaster, the yolk protein receptor is expressed in oocytes during the previtellogenic period. These receptors are distributed throughout the cytoplasm of the oocyte. During vitellogenesis when $\mathrm{Vg}$ is being accumulated, the receptors are enriched and localized at the plasma membrane of the oocyte (Schonbaum et al., 2000). This same pattern of expression and localization of $\mathrm{VgR}$ is present in 
chicken (Bujo et al., 1994). Therefore, the question is whether the fire ant $\mathrm{Vg}$ receptor is being expressed in alate virgin females. If so, where is the receptor localized within the non-vitellogenic oocytes?

In order to answer these questions, it is essential to produce a specific anti-Si VgR antibody. Expression and localization of $\mathrm{SiVgR}$ protein in mated queens and alate virgin females could be determined by western blot analysis and immunocytochemistry, respectively, using the anti-SiVgR antibody.

There are four repeats in the first ligand-binding domain of $\mathrm{Si} \mathrm{VgR}$ and it is different from five in the first ligand-binding domain of the mosquito and fruit fly (Fig. 3-2). It would be interesting to test the affinity of the fire ant, mosquito and fruit fly VgR first ligand-binding domain for $\mathrm{Vg}$ binding, because they are unique among the know LDLR superfamily members. The NPXY sequence is necessary for coated pit-mediated internalization. It may be possible to mutate the NPXY sequence to disrupt the internalization process (Lehrman et al., 1985; Chen et al., 1990) to disrupt Vg accumulation in the fire ant oocyte.

Now that we know SiVgR is a member of the LDLR superfamily it will be of great interest to determine if $\mathrm{Si} \mathrm{VgR}$ recognizes more than one ligand, like other LDLR members. Especially, studies from our laboratory (Lewis et al., 2003) and another laboratory (Dr. Craig Coates, Department of Entomology, Texas A\&M University, College Station, TX) indicate that there are probably three Vg genes. Does the cloned $\mathrm{Si} \mathrm{VgR}$ bind and internalize all three Vgs? Or there are three different Vg receptors for different Vgs? Does the oocyte express Vg by itself? These are all interesting topics for future research. 
Based on the results of the present study and the primer pheromone hypothesis (Vargo and Laurel, 1994), a general hypothetical model for $\mathrm{JH}$ regulation of egg maturation of fire ants is illustrated in Fig. 6-1. Mated queens produce the primer pheromone to regulate the $\mathrm{JH}$ titers in alate virgin females. The $\mathrm{JH}$ titer is enough for Vg synthesis and SiVgR transcription in alate females. The possible linkage between the JH titer and Vg uptake could be: 1) the expression and secretory pathway of SiVgR to the plasma membrane of oocytes; 2) the machinery of the endocytotic pathway; 3 ) the regulation of patency.

The JH titer is supposedly higher in mated queens than in alate females. However, the northern blot analysis (Fig. 4-1) showed that level of SiVgR transcripts is lower in mated queen than in alate females. I would hypothesize that in mated queens the effect of JH regulation switches from transcription to the $\mathrm{Si} \mathrm{VgR}$ protein biology (synthesis, post-translational modifications, membrane targeting, and so on) or the regulation of patency. JH may bind to the $\mathrm{JH}$ receptors on the plasma membrane of follicle cells to stimulate the patency in mated queens (Davey, 1981; Ilenchuk and Davey, 1985) and a question derived from this is whether the membrane $\mathrm{JH}$ receptor appears in alate females. JH may also regulate the expression and localization of $\mathrm{Si} \mathrm{VgR}$ protein in the oocyte plasma membrane. 


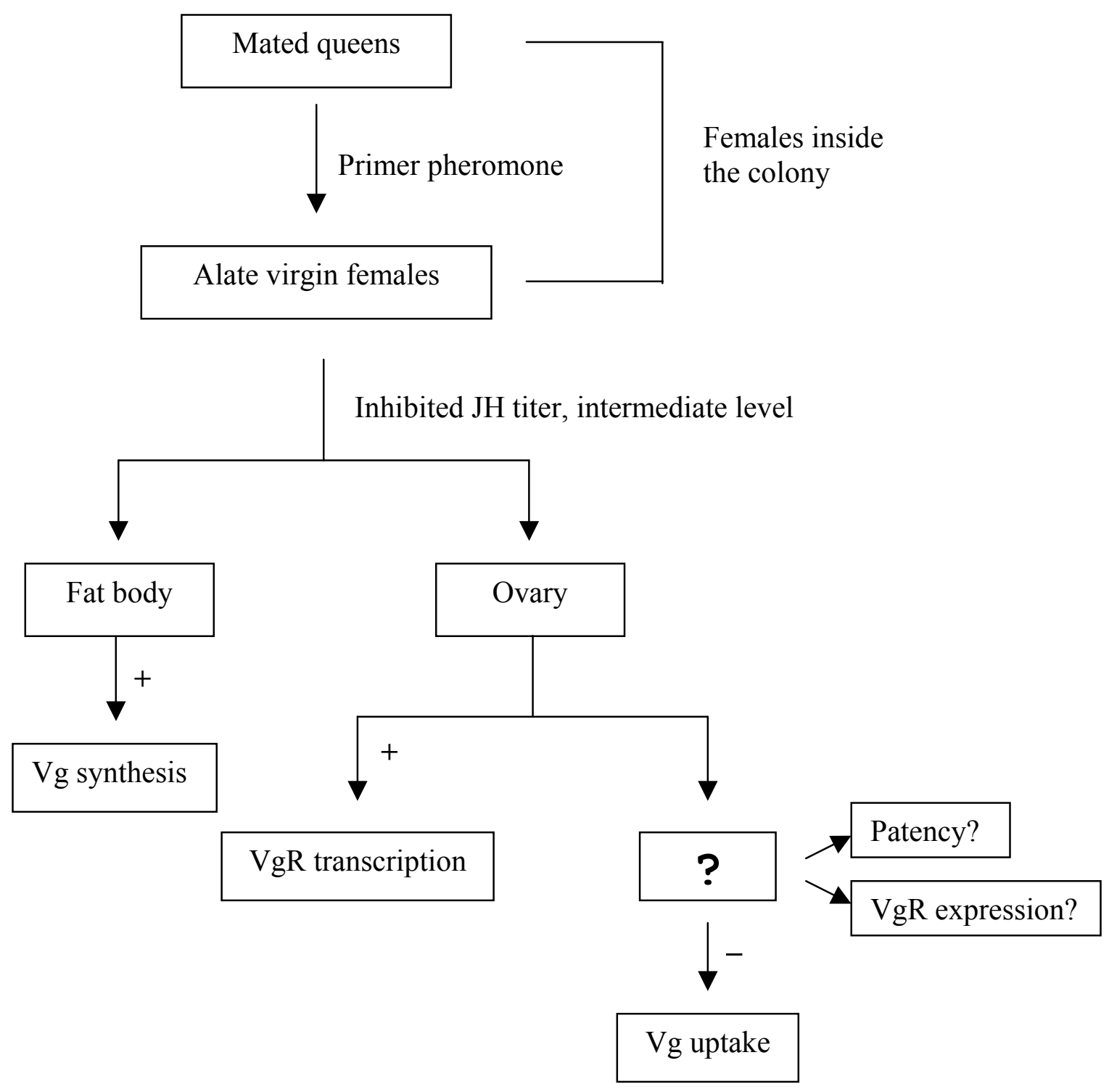

Fig. 6-1. A general hypothetical model of juvenile hormone $(\mathrm{JH})$ regulation of the egg formation in alate virgin female $S$. invicta. Mated queens produced the primer pheromone to decrease the JH titer in alate females that are inside the same colony. The inhibited JH titer is enough for $\mathrm{Vg}$ synthesis by fat body and $\mathrm{SiVgR}$ transcription in the ovary. The possible answer of the question box, that is what determines the beginning of $\mathrm{Vg}$ uptake, could be the presence of patency or the expression and localization of $\mathrm{Si} \mathrm{VgR}$ 


\section{REFERENCES}

Altschul, S.F., Gish, W., Miller, W., Myers, E.W., Lipman, D.J., 1990. Basic local alignment search tool. J. Mol. Biol. 215, 403-410.

Amdam, G.V., Norberg, K., Hagen, A. Omholt, S.W., 2003. Social exploitation of vitellogenin. Proc. Natl. Acad. Sci. USA 100, 1799-1802.

Baker, M.E., 1988. Is vitellogenin an ancestor of apolipoprotein B-100 of human lowdensity lipoprotein and human lipoprotein lipase? Biochem. J. 255, 1057-1060.

Barber, DL, Sander, E.J., Aebersold, R., Schneider, W.J., 1991. The receptor for yolk lipoprotein deposition in the chicken oocyte. J. Biol. Chem. 266, 18761-18770.

Barker, J.F., 1978. Neuroendocrine regulation of oocyte maturation in the imported fire ant Solenopsis invicta. Gen. Comp. Endocrinol. 35, 234-237.

Barker, J.F., 1979. Endocrine basis of wing casting and flight muscle histolysis in the fire ant Solenopsis invicta. Experientia 35, 552-554.

Beisiegel, U., Weber, W., Ihrke, G., Herz, J., Stanley, K.K., 1989. The LDL-receptorrelated protein, LRP, is an apolipoprotein E-binding protein. Nature 341, 162-164.

Bell, W.J., Barth, R.H., 1971. Evidence for juvenile hormone initiated yolk deposition in a cockroach. Nature: New Biol. 230, 220-221.

Bieri, S., Djordjevic, J.T., Daly, N.L., Smith, R., Kroon, P.A., 1995. Disulfide bridges of a cysteine-rich repeat of the LDL receptor lignad-binding domain. Biochemistry 34, 13059-13065.

Blacklock, B. J., Ryan, R.O., 1994. Hemolymph lipid transport. Insect Biochem. Mol. Biol. 24, 855-873. 
Bohm, M.K., 1972. Effects of environment and juvenile hormone on varies of the wasp, Polistes metricus. J. Insect Physiol. 18, 1875-1883.

Bownes, M., Ronaldson, E., Mauchline, D., Martinez, A., 1993. Regulation of vitellogenesis in Drosophila. Int. J. Insect Morphol. .Embryol. 22, 349-367.

Bownes, M., Scott, A., Blair, A., 1987. Hormonal and genetic factors regulating the expression of the genes encoding the Drosophila yolk proteins. Development 101, 931-941.

Brandes, C., Novak, S., Stockinger, W., Herz, J., Schneider, W.J., Nimpf, J., 1997. Avian and murine LR8B and human apolipoprotein E receptor 2: differentially spliced products from corresponding genes. Genomics 42, 185-191.

Briggs, M.R., Yodoyama, C., Wang, X., Brown, M.S., Goldstein, J.L., 1993. Nuclear protein that binds sterol regulatory element of low density lipoprotein receptor promoter. J. Biol. Chem. 268, 14490-14496.

Brown, M.S., Herz, J., Goldstein, J.L., 1997. Calcium cages, acid baths and recycling receptors. Nature 388, 629-630.

Bujo, H., Hermann, M. Kaderli, M.O., Jacobsen, L., Sugawara, S., Nimpf, J., Yamamoto, T., Schneider, W.J., 1994. Chicken oocyte growth is mediated by an eight ligand binding repeat member of the LDL receptor family. EMBO J. 13, $5165-5175$.

Bujo, H., Lindstedt, K.A., Hermann, M., Dalmau, L.M., Nimpf, J., Schneider, W.J., 1995a. Chicken oocytes and somatic cells express different splice variants of a multifunctional receptor. J. Biol. Chem. 270, 23546-23551. 
Bujo, H., Yamamoto, T., Hayash, K., Hermann, M., Nimpf, J., Schneider, W.J., 1995 b. Mutant oocytic low density lipoprotein receptor gene family member causes atherosclerosis and female sterility. Proc. Natl. Acad. Sci. USA 92, 9905-9909.

Burns, S.N., Teal, P.E.A., Vander Meer, R.K., nation, J.L., Vogt, J.T., 2002. Identification and action of juvenile hormone III from sexually mature alate females of the red imported fire ant, Solenopsis invicta. J. Insect Physiol. 48, 357365.

Campbell, I.D., Bork, P., 1993. Epidermal growth factor-like modules. Curr. Opin. Struct. Biol. 3, 385-392.

Chen, W.J., Goldstein, J.L., Brown, M.S., 1990. NPXY, a sequence often found in cytoplasmic tails, is required for coated pit-mediated internalization of the low density lipoprotein receptor. J. Biol. Chem. 265, 3116-3123.

Cheon, H.-M., Seo, S.-J., Sun, J. Sappington, T.W., Raikhel. A.S., 2001. Molecular characterization of the VLDL receptor homolog mediating binding of lipophorin in oocyte of the mosquito Aedes aegypti. Insect Biochem. Mol. Biol. 31, 753-760.

Cho, K.-H., Raikhel, A.S., 2001. Organization and developmental expression of the mosquito vitellogenin receptor gene. Insect Mol. Biol. 10, 465-474.

Chomczynski, P., Sacchi, N., 1987. Single-step method of RNA isolation by acid guanidinium thiocyanate-phenol-chloroform extraction. Anal. Biochem. 162, 156159.

Christensen E.I., Birn, H., Verroust, P., Moestrup, S.K., 1998. Membrane receptors for endocytosis in the renal proximal tubule. Int. Rev. Cytol. 180, 237-284. 
Cônsoli, F.L., Vinson, S.B., 2002. Hemolymph of reproductives of Solenopsis invicta (Hymenoptera: Formicidae)-amino acids, proteins and sugars. Comp. Biochem. Physiol. B 132, 711-719.

Daly, N.L., Scanlon, M.J., Djordjevic, J.T., Droon, P. A., Smith, R., 1995. Threedimensional structure of a cysteine-rich repeat from the low-density lipoprotein receptor. Proc. Natl. Acad. Sci. USA 92, 6334-6338.

Daniel, T.O., Schneider, W.J., Goldstein, J.L., Brown, M.S., 1983. Visualization of lipoprotein receptors by ligand blotting. J. Biol. Chem. 258, 46-6-4611.

Dantuma, N.P., Pijnenburg, M.A.P., Diederen, J.H.B., Van der Horst, D.J., 1997. Developmental down-regulation of receptor-mediated endocytosis of an insect lipoprotein. J. Lipid Res. 38, 254-265.

Dantuma, N.P., Potters, M., De Winther, M.P.J., Tensen, C.P., Kooiman, F.P., Bogerd, J., Van der Horst, D.J., 1999. An insect homolog of the vertebrate very low density lipoprotein receptor mediates endocytosis of lipophorins. J. Lipid Res. 40, 973-978.

Dantuma, N.P., Van Marrewijk, W.J.A., Wynne, H.J., Van der Horst, D.J., 1996. Interaction of an insect lipoprotein with its binding site at the fat body. J. Lipid Res. 37, 1345-1355.

Davail, B., pakdel, F., Bujo, H., Perazzolo, L.M., Waclawek, M., Schneider, W.J., Le Menn F., 1998. Evolution of oogenesis: the receptor for vitellogenin from the rainbow trout. J. Lipid Res. 39, 1929-1937.

Davey, K.G., 1981. Hormonal control of vitellogenin uptake in Rhodnius prolixus Stal. Am. Zool. 21, 701-705. 
Davey, K.G., 1996. Hormonal control of the follicular epithelium during vitellogenin uptake. Invert. Reprod. Devel. 30, 249-254.

Davey, K. G., Sevala, V. L., Gordon, D. R. B., 1993. The action of juvenile hormone and antigonadortropin on the follicle cells of Locusta migratoria. Invert. Reprod. Devel. 24, 473-478.

Davis, C.G., Elhammer, A., Russell, D.W., Schneider, W.J., Kornfeld, S., Brown, M.S., 1986. Deletion of clustered O-linked carbohydrates does not impair function of low density lipoprotein receptor in transfected fibroblasts. J. Biol. Chem. 261, 2828-2838.

Davis, C.G., Goldstein, J.L., Sudhof, T.C., Anderson, R.G., Russell, D.W., Brown, M.S., 1987. Acid-dependent ligand dissociation and recycling of LDL receptor mediated by growth factor homology region. Nature 326, 760-765.

Dawson, P.A., Hofmann, S.L., van der Westhuyzen, D.R., Sudhof, T.C., Brown, M.S., Goldstein, J.L., 1988. Sterol-dependent repression of low density lipoprotein receptor promoter mediated by 16-base pair sequence adjacent to binding site for transcription factor Sp1. J. Biol. Chem. 263, 3372-3379.

Dhadialla, T.S., Hays, A.R., Raikher, A.S., 1992. Characterization of the solubilized mosquito vitellogenin receptor. Insect Biochem. Mol. Biol. 22, 803-816.

Dhadialla, R.S., Raikhel, A.S., 1991. Binding of vitellogenin to membranes isolated from mosquito ovaries. Arch. Insect Biochem. Physiol. 18, 55-70.

Dinan, L., Bourne, P.C., Meng, Y., Sarker, S.D., Tolentino, R.B., Whiting, P., 2001. Assessment of natural products in the Drosophila melanogaster $\mathrm{B}_{\mathrm{II}}$ cell bioassay for ecdysteroid agonist and antagonist activities. Cell. Mol. Life Sci. 58, 321-342. 
Dittrich, E., Rose-John, S., Gerhartz, C., Mullberg, J., Stoyan, T., Yasukawa, K., Heinrich, P.C., Graeve, L., 1994. Identification of a region within the cytoplasmic domain of the interleukin-6 (IL-6) signal transducer gp130 important for ligandinduced endocytosis of the IL-6 receptor. J. Biol. Chem. 269, 19014-19020.

Dozois, C.M., Oswald, E., Gautier, N., Serthelon, J.-P., Fairbrother, J.M., Oswarl, I.P. , 1997. A reverse transcription-polymerase chain reaction method to analyze porcine cytokine gene expression. Vet. Immunol. Immunopathol. 58, 287-300.

Dumont, J.N., 1972. Oogenesis in Xenopus laevis (Daudin) I. Stages of oocyte development in laboratory maintained animals. J. Morphol. 136, 153-179.

Engelmann, F., 1983. Vitellogenesis controlled by juvenile hormone. In:Downer, R.G.H., Laufer, H., (Eds.), Endocrinology of Insects. Alan Liss, New York, pp. 259-270.

Fass, D., Blacklow, S., Kim, P.S., Berger, J.M., 1997. Molecular basis of familial hypercholesterolemia from structure of LDL receptor module. Nature 388, 691693.

Ferenz, H. J., Lubzens, E., 1981. Vitellin and vitellogenin incorporation by isolated oocytes of Locusta migratoria migratorioides (R. F.). J. Insect Physiol. 27: 869875.

Flanagan, T.R., Hagedorn, H.H., 1977. Vitellogenin synthesis in the mosquito: the role of juvenile hormone in the development of responsiveness to ecdysone. Physiol. Entomol. 2, 173-178.

Fletcher, D.J.C., Blum, M.S., 1981. Pheromonal control of dealation and oogenesis in virgin queen fire ants. Science 212, 73-75. 
Fletcher, D.J.C., Blum, M.S., 1983. The inhibitory pheromone of queen fire ants: effects of disinhibition on dealation and oviposition by virgin queens. J. Comp. Physiol. $153,467-475$.

Fletcher, D. J.C., Blum, M.S., Whitt, T.V., Temple, N., 1980. Monogyny and polygyny in the fire ant, Solenopsis invicta. Ann. Entomol. Soc. Amer. 73: 658-661.

Frykman, P.L., Brown, M.S., Yamamoto, T., Goldstein, J.L., Herz, J., 1995. Normal plasma lipoproteins and fertility in gene-targeted mice homozygous for a disruption in the gene encoding very low density lipoprotein receptor. Proc. Natl. Acad. Sci. USA. 92, 8453-8457.

Glenner, G.G., Wong, C.W., 1984. Alzheimer's disease: initial report of the purification and characterization of a novel cerebrovascular amyloid protein. Biochem. Biophys. Res. Commun. 120, 885-890.

Goldstein, J.L., Brown, M.S., 1974. Binding and degradation of low density lipoproteins by cultured human fibroblasts. J. Biol. Chem. 249, 5153-5162.

Goldstein, J.L., Brown, M.S., Anderson, R.G.W., Russell, D.W., Schneider W.J., 1985. Receptor-mediated endocytosis: concepts emerging from the LDL receptor system. Ann. Rev. Cell Biol. 1, 1-39.

Goldstein, J.L., Hobbs, H.H., Brown, M.S., 1995. Familial hypercholesterolemia. In: Scriver, C.R., et al., (Eds.), The metabolic and molecular basis of inherited disorders. McGraw-Hill, New York, pp. 1981-2030.

Grant, B., Hirsh, D., 1999. Receptor-mediated endocytosis in the Caenorhabditis elegans oocyte. Mol. Biol. Cell 10, 4311-4326. 
Greenberg, L., Fletcher, D.J.C., Vinson, S.B., 1985. Differences in worker size and mound distribution in monogynous and polygynous colonies of the fire ant Solenopsis invicta Buren. J. Kansas Entomol. Soc. 58, 9-18.

Grove, R.I., Mazzucco, C.E., Radka, S.F., Shoyab, M., Kiener, P.A., 1991. Oncostatin M up-regulates low density lipoprotein receptors in HepG2 cells by a novel mechanism. J. Biol. Chem. 266, 18194-18199.

Hagedorn, H. H., Kunkel, J.G., 1979. Vitellogenin and vitellin in insects. Ann. Rev. Entomol. 24, 475-505.

Hartfelder, K., Engels, W., 1998. Social insect polymorphism: hormonal regulation of plasticity in development and reproduction in the honeybee. Curr. Top. Dev. Biol. $40,45-77$.

Herz, J., Kowal, R.C., Goldstein, J.L., Brown, M.S., 1990. Proteolytic processing of the $600 \mathrm{kd}$ low density lipoprotein receptor-related protein (LRP) occurs in a transGolgi compartment. EMBO. J. 9, 1769-76.

Hiesberger, T., Hermann, M., Jacobsen, L., Novak, S., Hodits, R.A., Bujo, H., Meilinger, M., Huttinger, M., Schneider, W.J., Nimpf, J., 1995. The chicken oocyte receptor for yolk precursors as a model for studying the action of receptorassociated protein and lactoferrin. J. Bio. Chem. 270, 18219-18226.

Holmes, S.P., He, H., Chen, A.C., Ivie, G.W., Pietrantonio, P.V., 2000. Cloning and transcriptional expression of a leucokinin-like peptide receptor from the Southern cattle tick, Boophilus microplus (Acari: Ixodidae). Insect Mol. Biol. 9, 457-465.

Hussain, M.M., Strickland, D.K., Bakillah, A., 1999. The mammalian low-density lipoprotein receptor family. Annu. Rev. Nutr. 19, 141-172. 
Ilenchuk, T. T., Davey, K. G., 1985. The binding of juvenile hormone to membranes of follicle cells in the insect Rhodnius prolixus. Can. J. Biochem. Cell Biol. 63, 102106.

Indrasith, L.S., Kindle, H., Lanzrein, B., 1990. Solubilization, identification and localization of vitellogenin-binding sites in follicles of the cockroach Nauphoeta cinerea. Arch. Insect Biochem. Physiol. 15, 213-228.

Jordan, J., Galindo, M.F., Miller R.J., Reardon, C.A., Getz, G.S., LaDu, M.J., 1998. Isoform-specific effect of apolipoprotein E on cell survival and beta-amyloidinduced toxicity in rat hippocampal pyramidal neuronal cultures. J. Neurosci. 18, 195-204.

Jowett, T., Postlethwait, J.H., 1980. The regulation of yolk polypeptide synthesis in Drosophila ovaries and fat body by 20-hydroxyecdysone and a juvenile hormone analog. Dev. Biol. 80, 225-234.

Kang, D.E., Pietrzik, C.U., Baum, L., Chevallier, N., Merriam, D.E., Kounnas, M. Z., Wagner, S.L., Troncoso, J.C., Kawas, C.H., katzman, R. Koo, E., 2000. Modulation of amyloid beta-protein clearance and Alzheimer's disease susceptibility by the LDL receptor-related protein pathway. J. Clin. Invest. 106, 1159-1166.

Kearney, G.P., Toom, P.M., Blomquist, G.L., 1977. Induction of de-alation in virgin female Solenopsis invicta with juvenile hormones. Ann. Entomol. Soc. Am. 70, 699-701. 
Keeley, L.L., Sowa, S.M., Hesson, A.S., 1995. In vitro bioassay for hypertrehalosemic hormone-dependent trehalose biosynthesis by fat body from adult Blaberus discoidalis cockroaches. Arch. Insect Biochem. Physiol. 28, 313-324.

Kim, D.-H., Iijima, H., Goto, K., Sakai, J., Ishii, H., Kim, H.-J., Suzuki, H., Kondo, H., Saeki, S., Yamatoto, T., 1996. Human apolipoprotein E receptor 2. J. Biol. Chem. 271, 8373-8380.

Kindle, H., Konig, R., Lanzrein, B., 1988. In vitro uptake of vitellogenin by follicles of the cockroach Nauphoeta cinerea: comparison of artificial media with haemolymph media and role of vitellogenin concentration and of juvenile hormone. J. Insect Physiol. 34, 541-548.

Koeppe, J.K., Fuchs, M., Chen T.T., Hunt, L.-M., Kovalick, G.E., Briers, T., 1985. The role of juvenile hormone in reproduction. In: Kerkut, G.A., Hilbert, L.I. (Eds), Comprehensive insect physiology, biochemistry and pharmacology, vol. 8 . Pergamon, New York, pp. 165-203.

Koller, C. N., Dhadialla, T.S., Raikhel, A.S., 1989. Selective endocytosis of vitellogenin by oocytes of the mosquito, Aedes aegypti: an in vitro study. Insect Biochem. 19: 693-702.

Konig, R., Lanzrein, B., 1985. Binding of vitellogenin to specific receptors in oocyte membrane preparations of the ovoviviparous cockroach Nauphoeta cinerea. Insect Biochem. 15, 735-747.

Konig, R., Nordin, J.H., Gochoco, C.H., Kunkel, J.G., 1988. Studies on ligand recognition by vitellogenin receptors in follicle membrane preparations of the German cockroach, Blattella germanica. Insect Biochem. 18, 395-404. 
Kozak M., 1984. Compilation and analysis of sequences upstream from the translational start site in eukaryotic mRNAs. Nucl. Acids Res. 12, 857-872.

Krieger, M, Herz, J., 1994. Structures and functions of multiligand lipoprotein receptors: macrophage scavenger receptors and LDL receptor-related protein (LRP). Annu. Rev. Biochem. 63, 601-637.

Kulakosky, P. C., Telfer, W.H., 1987. Selective endocytosis, in vitro, by ovarian follicles from Hyalophora cecropia. Insect Biochem. 17: 845-858.

Kuriachan, I., Vinson, S.B., 2000. A queen's worker attractiveness influences her movement in polygynous colonies of the red imported fire ant (Hymenoptera: Formicidae) in response to adverse temperatures. Environ. Entomol. 29, 943-949.

Lancaster, P.M., Tyler, C.R., 1994. Developmental expression and modulation of the vitellogenin receptor in ovarian follicles of the rainbow trout, Oncorhychus mykiss. J. Exp. Zool. 269, 458-466.

Lehrman, M.A., Goldstein, J.L., Brown, M.S., Russell D.W., Schneider, W.J., 1985. Internalization-defective LDL receptors produced by genes with nonsense and frameshift mutations that truncate the cytoplasmic domain. Cell 41, 735-743.

Letourneur, F., Klausner, R.D., 1992. A novel di-leucine motif and a tyrosine-based motif independently mediate lysosomal targeting and endocytosis of CD3 chains. Cell 69, 1143-1157.

Letunic, I., Goodstadt, L., Kickens, N.J., Koerks, T., Schultz, J., Mott, R., Ciccarelli, F., Copley, R.R., Ponting, C.P., Bork, P., 2002. Recent improvements to the SMART domain-based sequence annotation resource. Nucl. Acids Res. 30, 242-244. 
Lewis, D.K., Campbell, J.Q., Sowa, S.M., Chen, M.E., Vinson, S.B. and Keeley, L.L., 2001. Characterization of vitellogenin in the red imported fire ant, Solenopsis invicta (Hymenoptera : Apocrita : Formicidae). J. Insect Physiol. 47, 543-551.

Lewis, D.K., Chen, M.E., Vinson, S.B., Keeley, L.L., 2003. Cloning and characterization of the vitellogenin cDNA from the imported fire ant Solenopsis invicta (Formicidae: Apocrita). (submitted to Insect Biochem. Mol. Biol.)

Li, A., Sadasivam, M., Ding, J.L., 2003. Receptor-ligand interaction between vitellogenin receptor (VtgR) and vitellogenin (Vtg), implications on low density lipoprotein receptor and apolipoprotein $\mathrm{B} / \mathrm{E}$. The first three ligand-binding repeats of VtgR interact with the amino-terminal region of Vtg. J. Biol. Chem. 278, 27992806.

Li, C., Kraemer, F.B., Ahlborn, T.E., Liu, J., 1999a. Induction of low density lipoprotein receptor (LDLR) transcription by oncostatin $\mathrm{M}$ is mediated by the extracellular signal-regulated kinase signaling pathway and the repeat 3 element of the LDLR promoter. J. Biol. Chem. 274, 6747-6753.

Li, M.-G., Serr, M., Edwards, K., Ludmann, S., Yamamoto, D., Tilney, L.G., Field, C.M., Hays, T.S., 1999b. Filamin is required for ring canal assembly and actin organization during Drosophila oogenesis. J Cell Biol. 146, 1061-1073.

Liu, J., Ahlhorn, T.E., Briggs, M.R., Kraemer, F.B., 2000. Identification of a novel sterol-independent regulatory element in the human low density lipoprotein receptor promoter. J. Biol. Chem. 275, 5214-5221. 
Liu, J., Streiff, R., Zhang, Y.L., Vestal, R.E., Spence, M.J., Briggs, M.R., 1997. Novel mechanism of transcriptional activation of hepatic LDL receptor by oncostatin M. J. Lipid Res. 38, 2035-2048.

Martinez, A., Bownes, M., 1994. The sequence and expression pattern of the Calliphora erythrocephala yolk protein A and B genes. J. Mol. Evol. 38, 336-351.

Mehta, K.D., Chen, W.-J., Goldstein, J.L., Brown, M.S., 1991. The low density lipoprotein receptor in Xenopus laevis. J. Biol. Chem. 266, 10406-10414.

Montgomery, D.C., 1997. The analysis of covariance. In: Robey, C. (Ed.), Design and analysis of experiments. Fourth Edition. J. Wiley \& Sons, New York, pp. 149-166.

Mozas, P., Galetto, R., Albajar, M., Ros, E., Pocovi, M., Rodriguez-Rey, C., 2002. A mutation $(-49 \mathrm{C}>\mathrm{T})$ in the promoter of the low density lipoprotein receptor gene associated with familial hypercholesterolemia. J. Lipid Res. 43, 13-18.

Narita, M., Holtzman, D.M., Schwartz, A.L., Bu, G., 1997. Alpha2-macroglobulin complexes with and mediates the endocytosis of beta-amyloid peptide via cell surface low-density lipoprotein receptor-related protein. J. Neurochem. 69, 19041911.

Novak, S., Hiesberger, T., Schneider, W.J., Nimpf, J., 1996. A new low density lipoprotein receptor homologue with 8 ligand binding repeats in brain of chicken and mouse. J. Biol. Chem. 271, 11732-11736.

Nunez Rodriguez, J., Bon, E., Le Menn, F., 1996. Vitellogenin receptors during vitellogenesis in the rainbow trout Oncorhynchus mykiss. J. Exp. Zool. 274, 163170. 
Nykjaer A., Willnow, T.E., 2002. The low-density lipoprotein receptor gene family: a cellular Swiss army knife? Trends Cell Biol. 12, 273-280.

Okabayashi, K., Shoji, H., Nakamura, T., Hashimoto, O., Asashima, M., Sugino, H., 1996. cDNA cloning and expression of the Xenopus laevis vitellogenin receptor. Biochem. Biophys. Res. Com. 224, 406-413.

Oliveira, P. L., Gondim, K.C., Guedes, D.M., 1986. Uptake of yolk proteins in Rhodnius prolixus. J. Insect Physiol. 32: 859-866.

Osir, E.O. and Law, J.H., 1986. Studies on binding and uptake of vitellogenin by follicles of the tobacco hornworm, Manduca sexta. Arch. Insect Biochem. Physiol. $3,513-528$.

Peeters, A.V., Kotze, M.J., Scholtz, C.L., De Waal, L.F., Rubinsztein, D.C., Coetzee, G.A., Zuliani, G., Streiff, R., Liu, J., van der Westhuyzen, D.R., 1998. A 3basepair deletion in repeat 1 of the LDL receptor promoter reduces transcriptional activity in a South African Pedi. J. Lipid Res. 38, 1021-1024.

Perazzolo, L.M., coward, K., Davail, B., Normand, E., Tyler, C.R., Pakdel, F., Schneider, W.J., Le Menn, F., 1999. Expression and localization of messenger ribonucleic acid for the vitellogenin receptor in ovarian follicles throughout oogenesis in the rainbow trout, Oncorhynchus mykiss. Biol. Reprod. 60, 10571068.

Perrimon, N., Mohler, D., Engstrom, L., Mahowald, A.P., 1986. X-linked female-sterile loci in Drosophila melanogaster. Genetics 113, 695-712. 
Perry, M.M., Gilbert, A.B., 1979. Yolk transport in the ovarian follicle of the hen (Gallus domesticus): lipoprotein-like particles at the periphery of the oocyte in the rapid growth phase. J. Cell Sci. 39, 257-279.

Pietrantonio, P.V., Holmes, S.P., Jagge, C., Frazier, S.K., 2002. Cloning of troponin C and other gene fragments from the red imported fire ant Solenopsis invicta Buren (Hymenoptera, Formacidae). Southwest. Entomol. Suppl. 25, 89-96.

Pinson, K.I., Brennan, J., Monkley, S., Avery, B.J., Skarnes, W.C. 2000. An LDLreceptor-related protein mediates Wnt signaling in mice. Nature 407, 535-538.

Postlethwait, J.H., Weiser, K., 1973. Vitellogenesis induced by juvenile hormone in the female sterile mutant apterous ${ }^{4}$ in Drosophila melanogaster. Nature: New Biol. $244,284-285$.

Prat, F., Coward, K., Sumpter, J.P., Tyler, C.R., 1998. Molecular characterization and expression of two ovarian lipoprotein receptors in the rainbow trout, Oncorhynchus mykiss. Biol. Reprod. 58, 1146-1153.

Price, D.L., Sisodia, S.S., Borchelt, D.R., 1998. Alzheimer disease-when and why? Nat. Genet. 19, 314-316.

Puissant, C., Houdebine, L.-M., 1990. An improvement of the single-step method of RNA isolation by acid guanidinium thiocyanate-phenol-chloroform extraction. BioTech. 8, 148-149.

Raikhel, A.S., Dhadialla, T.S., 1992. Accumulation of yolk proteins in insect oocytes. Annu. Rev. Entomol. 37, 217-251.

Richard, D.S., Jones, J.M., Barbarito, M.R., Cerula, S. Detweiler, J.P., Fisher, S.J., Brannigan, D.M., Scheswohl, D.M., 2001. Vitellogenesis in diapausing and 
mutant Drosophila melanogaster: further evidence for the relative roles of ecdysteroids and juvenile hormones. J Insect Physiol. 47, 905-913.

Richard, D.S., Watkins, N.L., Serafin, R.B., Gilbert, L.I., 1998. Ecdysteroids regulate yolk protein uptake by Drosophila melanogaster oocytes. J Insect Physiol. 44, 637-644.

Rina, M., Savakis, C., 1991. A cluster of vitellogenin genes in the mediterranean fruit fly Ceratitis capitata: sequence and structural conservation in dipteran yolk proteins and their genes. Genetics 127, 769-780.

Robinson, G.E., Vargo, E.L., 1997. Juvenile hormone in adult eusocial Hymenoptera: gonadotropin and behavioral pacemaker. Arch. Insect Biochem. Physiol. 35, 559583.

Rohrkasten, A., Ferenz, H.-J., 1985. In vitro study of selective endocytosis of vitellogenin by locust oocytes. Roux's Archs. Dev. Biol. 194, 411-416.

Rohrkasten, A., Ferenz, H.J., 1986a. Properties of the vitellogenin receptor of isolated locust oocyte membranes. Int. J. Invertebr. Reprod. Dev. 10, 133-142.

Rohrkasten, A., Ferenz, H.J., 1986b. Solubilization of the locust vitellogenin receptor. Biochim. Biophys. Acta. 860, 577-582.

Röseler, P.-F., 1977. Juvenile hormone control of oogenesis in bumble bee workers, Bombus terrestris. J Insect Physiol. 23, 985-992.

Röseler, P.-F., Röseler, I., Strambi, S., 1980. The activities of corpora allata in dominant and subordinated females of the wasp Polistes gallicus. Insectes Soc. 27, 97-107.

Roth, T. F., Porter, K.R., 1964. Yolk protein uptake in the oocyte of the mosquito Aedes aegypti L. J. Cell Biol. 20: 313-332. 
Ryan, R.O., 1990. Dynamics of insect lipophorin metabolism. J. Lipid. Res. 31, 17251739.

Ryan, R.O. 1994. The structures of insect lipoproteins. Curr. Opin. Struct. Biol. 4, 499506.

Sakai, J., Hoshino, A., Miura, Y., Ishii, H., Suzuki, H., Kawarabayasi, Y., Yamamoto, R., 1994. Structure, chromosome location, and expression of the human very low density lipoprotein receptor gene. J. Biol. Chem. 269, 2173-2182.

Sanchez, H.B., Yieh, L., Osborne, T.F., 1995. Cooperation by sterol regulatory elementbinding protein and $\mathrm{Sp} 1$ in sterol regulation of low density lipoprotein receptor gene. J. Biol. Chem. 270, 1161-1169.

Sappington, T.W., Hays, A.R., Raikhel, A.S., 1995. Mosquito vitellogenin receptor: purification, developmental and biochemical characterization. Insect Biochem. Mol. Biol. 25, 807-817.

Sappington, T.W., Kokoza, V.A., Cho, W.-L. and Raikhel, A.S., 1996. Molecular characterization of the mosquito vitellogenin receptor reveals unexpected high homology to the Drosophila yolk protein receptor. Proc. Natl. Acad. Sci. USA 93, 8934-8939.

Sappington, T.W., Raikhel, A.S., 1998. Molecular characteristics of insect vitellogenins and vitellogenin receptors. Insect Biochem. Mol. Biol. 28, 277-300.

Schneider, W.J., 1996. Vitellogenin receptors: oocyte-specific members of the lowdensity lipoprotein receptor supergene family. Intl. Rev. Cytol. 166, 103-137. 
Schneider, W.J., Nimpf, J., Brandes, C., Drexler, M., 1999. The low-density lipoprotein receptor family: genetics, function, and evolution. Current Atherosclerosis Reports $1,115-122$.

Scholtz, C.L., Peeters, A.V., Hoogendijk, C. F., Thiart, R., de Villiers, J.N.P., Hillermann, R., Liu, J., Marais, A.D., Kotze, M.J., 1999. Mutation $-59 c \rightarrow t$ in repeat 2 of the LDL receptor promoter: reduction in transcriptional activity and possible allelic interaction in a South African family with familial hypercholesterolaemia. Hum. Mol. Genet. 8, 2025-2030.

Schonbaum, C.P., Lee, S. and Mahowald, A.P., 1995. The Drosophila yolkless gene encodes a vitellogenin receptor belonging to the low density lipoprotein receptor superfamily. Proc. Natl. Acad. Sci. USA 92, 1485-1489.

Schonbaum, C.P., Perrino, J.J., Mahowald, A.P., 2000. Regulation of the vitellogenin receptor during Drosophila melanogaster oogenesis. Mol. Biol. Cell 11, 511-521.

Schultz, J., Milpetz, F., Bork, P., Ponting, C.P., 1998. SMART, a simple modular architecture research tool: identification of signaling domains. Proc. Natl. Acad. Sci. USA 95, 5857-5864.

Shapiro, J.P., Hagedorn, H.H., 1982. Juvenile hormone and the development of ovarian responsiveness to a brain hormone in the mosquito Aedes aegypti. Gen. Comp. Endocrinol. 46, 176-183.

Snigirevskaya, E.S., Sappington, T.W. and Raikhel, A.S., 1997. Internalization and recycling of vitellogenin receptor in the mosquito oocyte. Cell Tissue Res. 290, 175-183. 
Soller, M., Bownes, M., Kubli, E., 1999. Control of oocyte maturation in sexually mature Drosophila females. Dev. Biol. 208, 337-351.

Steyrer, E., Barber, D.L., Schneider, W.J., 1990. Evolution of lipoprotein receptors. J. Biol. Chem. 265, 19575-19581.

Stifani, S., Barber, D.L., Aebersold, R., steyrer, E., Shen, X., Nimph, J., Schneider, W.J., 1991. The laying hen expresses two different low density lipoprotein receptor-related proteins. J. Biol. Chem. 266, 19079-19087.

Stifani, S., Le Menn, F., Nunez Rodriguez, J., Schneider, W.J., 1990. Regulation of oogenesis: the piscine receptor for vitellogenin. Biochim. Biophys. Acta. 1045, 271-279.

Strickland, D.K., Gonias, S.L., Argraves, W.S., 2002. Diverse roles for the LDL receptor family. Trends Endocrinol. Metabol. 13, 66-74.

Sudhof, R.C., Goldstein, J.L., Brown, M.S., Russel, D.W., 1985. The LDL receptor gene: a mosaic of exons shared with different proteins. Science 228, 815-822.

Sudhof, T.C., Russell, D.W., Brown, M.S., Goldstein, J.L., 1987a. 42 bp element from LDL receptor gene confers end-product repression by sterols when inserted into viral TK promoter. Cell 48, 1061-1069.

Sudhof, T.C., van der Westhuyzen, D.R., Goldstein, J.L., Brown, M.S., Russell, D. W., 1987b. Three direct repeats and a TATA-like sequence are required for regulated expression of the human low density lipoprotein receptor gene. J. Biol. Chem. 262, 10773-10779. 
Sun, J., Hiraoka, T., Dittmer, N.T., Cho, K.-H., Raikher, A.s., 2000. Lipophorin as a yolk protein precursor in the mosquito, Aedes aegypti. Insect Biochem. Mol. Biol. $30,1161-1171$.

Tacken, P.J., Teusink, B., Jong, M.C., Harats, D., Havekes, L. M., Willems van Dijk, K., Hofker, M.H., 2000. LDL receptor deficiency unmasks altered VLDL triglyceride metabolism in VLDL receptor transgenic and knockout mice. J. Lipid Res. 41, 2055-2062.

Takahashi, S., Kawarabayasi, Y., Nakai, T., Sakai, J., Yamamoto, T., 1992. Rabbit very low density lipoprotein receptor: a low density lipoprotein receptor-like protein with distinct ligand specificity. Proc. Natl., Acad. Sci. USA 89, 9252-9256.

Tamai, K., Semenov, M., Kato, Y., Spokony, R., Liu, C., Katsuyama, Y., et al. 2000. LDL-receptor-related proteins in Wnt signal transduction. Nature 407, 530-535.

Telfer, W. H., Pan, M.L., Law, J.H., 1991. Lipophorin in developing adults of Hyalophora cecropia: support of yolk formation and preparation for flight. Insect Biochem. 21, 653-663.

Terpstra, P., Ab, G., 1988. Homology of Drosophila yolk proteins and the triacylglycerol lipase family. J. Mol. Biol. 202, 663-665.

Texas A\&M University, 2001. The statewide economic impact of the red imported fire ant in Texas. Texas A\&M University, College Station, pp. 1-9.

Thompson, J.D., Higgins, D.G., Gibson, T.J., 1994. Clustal W: improving the sensitivity of progressive multiple sequence alignment through sequence weighting, position-specific gap penalties and weight matrix. Nucl. Acids Res. 22, 4673-4680. 
Tiebel, O., Lka, K., Robinson, K., Sullivan, M., Martinez, J., Nakamuta, M., Oka, K.I., Chan, L., 1999. Mouse very low-density lipoprotein receptor (VLDLR): gene structure, tissue-specific expression and dietary and developmental regulation. Atherosclerosis 145, 239-251.

Trenczek, T., Engels, W., 1986. Occurrence of vitellogenin in drone honey bees (Apis mellitica). Int. J. Invert. Reprod. and Dev.. 10, 307-311.

Trenczek, T., Zillikens, A., Engels, W., 1989. Developmental patterns of vitellogenin haemolymph titre and rate of synthesis in adult drone honey bees (Apis mellifera). J. Insect Physiol. 35, 475-481,

Tyler, C.R., Lubberink, K., 1996. Identification of four ovarian receptor proteins that bind vitellogenin but not other homologous plasma lipoproteins in the rainbow trout, Oncorhynchus mykiss. J. Comp. Physiol. 166, 11-20.

Tyler, C.R., Sumpter, J.P., 1996. Oocyte growth and development in teleosts. Rev. Fish Biol. Fish 6, 287-318.

Van Antwerpen, R., Wynne, H.J.A., Van der Horst, D.J., Beenakkers, A.M.T., 1989. Binding of lipophorin to the fat body of the migratory locust. Insect Biochem. 19, 809-814.

Van der Horst, D.J., 1990. Lipid transport function in lipoproteins in flying insects. Biochim. Biophys. Acta. 1047, 195-211.

Vargo, E. L., 1992. Mutual pheromonal inhibition among queens in polygyne colonies of the fire ant Solenopsis invicta. Behav. Ecol. Sociobiol. 31, 205-210. 
Vargo, E.L., 1998. Primer pheromones in ants. In: Vander Meer, R.K., Breed, M.D., Winston, M.L., Espelie, K.E., (Eds), Pheromone communication in social insects: ants, wasps, bees, and termites. Westview Press, Boulder, Colorado, pp. 293-313.

Vargo, E.L., 1999. Reproductive development and ontogeny of queen pheromone production in the fire ant Solenopsis invicta. Physiol. Entomol. 24, 370-376.

Vargo, E.L., Fletcher, D.J.C., 1989. On the relationship between queen number and fecundity in polygyne colonies of the fire ant Solenopsis invicta. Physiol. Entomol. 14, 223-232.

Vargo, E.L., Laurel, M., 1994. Studies on the mode of action of a queen primer pheromone of the fire ant Solenopsis invicta. J Insect Physiol. 40, 601-610.

Vargo, E.L., Ross, K.G., 1989. Differential viability of eggs laid by queens in polygyne colonies of the fire ant, Solenopsis invicta. J. Insect Physiol. 35, 587-593.

Vinson, S.B., 1997. Invasion of the red imported fire ant (Hymenoptera: Formicidae). Spread, biology, and impact. American Entomologist (Spring) 23-39.

Wallace, R.A., Misulovin, Z., 1978. Long-term growth and differentiation of Xenopus oocytes in a defined medium. Proc. Natl. Acad. Sci. USA 75, 5534-5538.

Wallace, R.A., Nickol, J.M., Ho, T., Jared, D.W., 1972. Studies on amphibian yolk. X. The relative roles of autosynthetic and heterosynthetic processes during yolk protein assembly by isolated oocytes. Dev. Biol. 29, 255-272.

Wang, Z., Davey, K.G., 1992. Characterization of yolk protein and its receptor on the oocyte membrane in Rhodnius prolixus. Insect Biochem. Molec. Biol. 22, 757767. 
Waring, G.L., DiOrio, J.P., Hennen, S., 1983. Isolation of germ line-dependent femalesterile mutation that affects yolk specific sequestration and chorion formation in Drosophila. Dev. Biol. 100, 452-463.

Webb, J.C., Patel, D.D., Jones, M.D., Knight, B.L., Soutar, A.K., 1994. Characterization and tissue-specific expression of the human 'very low density lipoprotein (VLDL) receptor' mRNA. Hum. Mol. Genet. 3, 531-537.

Wehrli, M., Dougan, S.T., Calswell, K., O’Keefe, L., Schwartz, S., Vaizel-Ohayon, D., Schejter, E., Tomlinson, A., DiNardo, S., 2000. arrow encodes an LDL-receptorrelated protein essential for Wingless signaling. Nature 407, 527-530.

Wiley, H.S., Dumont, J.N., 1978. Stimulation of vitellogenin uptake in stage IV Xenopus oocytes by treatment with chorionic gonadotropin in vitro. Biol. Reprod. $18,762-771$.

Willnow, T.E., 1999. The low-density lipoprotein receptor gene family: multiple roles in lipid metabolism. J. Mol. Med. 77, 306-315.

Willnow, T.E., Goldstein, J.L., Orth, K., Brown, M.S., Herz, J., 1992. Low density lipoprotein receptor-related protein (LRP) and gp330 bind similar ligands, including plasminogen activator/inhibitor complexes and lactoferrin, an inhibitor of chylomicron remnant clearance. J. Biol. Chem. 267, 26172-26180.

Willnow, T.E., Hilpert, J., Armstrong, S.A., Rohlmann, A., Hammer, R.E., Burns, D.K., Herz, J., 1996. Defective forebrain development in mice lacking gp330/megalin. Proc. Natl., Acad. Sci. USA 93, 8460-8464. 
Wilson, T.G., 1982. A correlation between juvenile hormone deficiency and vitellogenic oocyte degeneration in Drosophila melanogaster. Roux's Arch. Dev. Biol. 191, 257-263.

Wodarz, A., Nusse, R., 1998. Mechanisms of Wnt signaling in development. Annu. Rev. Cell Dev. Biol. 14, 59-88.

Yamamoto, T., Davis, C.G., Brown, M.S., Schneider, W.J., Casey, M.L., 1984. The human LDL receptor: a cysteine-rich protein with multiple Alu sequences in its mRNA. Cell 39, 27-38.

Yochem, J., Greenwald, I., 1993. A gene for a low density lipoprotein receptor-related protein in the nematode Caenorhabditis elegans. Proc. Natl., Acad. Sci. USA 90, $4572-4576$.

Yochem, J., Tuck, S., Greenwald, I., Han, M., 1999. A gp330/megalin-related protein is required in the major epidermis of Caenorhabditis elegans for completion of molting. Development 126, 597-606. 


\section{VITA}

NAME: $\quad$ Mei-Er Chen

ADDRESS: $\quad$ Permanent

51 Chung-Hsing Rd.

Ma-Gung, Peng-Hu Hsing

Taiwan

EDUCATIONAL BACKGROUND:

1993-1995 M.S. in Entomology, National Chung-Hsing University, Taiwan

1989-1993 B.S. in Entomology, National Chung-Hsing University, Taiwan

PROFESSIONAL EXPERIENCE

1995-1998 Research Assistant. Institute of Zoology, Academia Sinica, Taipei, Taiwan.

1998-present Graduate Research Assistant. Dept. of Entomology, Texas A\&M University, College Station, TX.

2001-2002 Served as graduate student representative on the Area of Excellence International Programs Committee, EGSO, Texas A\&M University, College Station, TX.

2002, 2003 Graduate Teaching Assistant. Dept. of Entomology, Texas A\&M University, College Station, TX.

8/2002, 2003 First place in the Fifth Annual Graduate Student Forum, 8/2002. Dept. of Entomology, Texas A\&M University, College Station

3/2003 Participation in Student Research Week, Texas A\&M University, College Station, TX.

5/2003 Awarded \$300 Sigma Xi Grants-in-Aid of Research.

9/2003 Lillian and Alex Feir graduate student travel award in insect physiology, biochemistry, or molecular biology. 